UNIVERSIDADE DA BEIRA INTERIOR

Engenharia

\title{
Mass Prediction Models for Air Cargo Challenge Aircraft
}

(versão corrigida após defesa)

Gustavo Lima Garcia

Dissertação para obtenção do Grau de Mestre em
Engenharia Aeronáutica
(Ciclo de estudos integrado)

Orientador: Prof. Doutor Pedro Vieira Gamboa

Covilhã, julho de 2018 


\section{Abstract}

The development of mass prediction models, specific for the Air Cargo Challenge competition, is presented on this dissertation. This Design/Build/Fly competition has a major interest to the University of Beira Interior, particularly to the Aerospace Sciences Department. These models are divided in two development methods: statistical and structure equations based type.

The statistical mass models are developed based on data collected from past editions and are divided in general and component based mass models. The accuracy of this type of models is, mainly, dependent on the amount of data available. On both of them three models are presented, one containing all available aircraft and two more created from the division in two groups of the original one.

Using the structure equations method, where the amount of material is determined, required to withstand the stresses that the airplane is subjected, a model is developed for each one of the three wing configurations considered, mainly CFRP, D-box CFRP and CFRP tube spar. The tail boom component equation is created independently and the remaining components masses are determined from coefficients based on geometric characteristics and the wing mass calculated. The associated average error to these models is inferior to $1 \%$.

The results obtained from the application in the considered study cases are also presented and the respective validity, accuracy and application, in terms of design phase, for each method, are discussed.

\section{Keywords}

Mass prediction models; Air Cargo Challenge; Aircraft; UAV; Airfoil; Data fitting; Wing configuration; CFRP 


\section{Resumo}

O desenvolvimento de modelos de previsão de massa para aeronaves da competição Air Cargo Challenge é apresentado nesta dissertação. Esta competição, do tipo Design/Build/Fly, tem um grande interesse para a Universidade da Beira Interior, em particular para o Departamento de Ciências Aeroespaciais. Estes modelos estão divididos em dois métodos de desenvolvimento: baseados em métodos estatísticos e em equações da estrutura

Os modelos estatísticos desenvolvidos são baseados em dados recolhidos de edições passadas e divididos em gerais e divididos por componentes. A precisão destes modelos está, essencialmente, dependente da quantidade de dados disponíveis. Em ambos, são apresentados três modelos, um contendo todas as aeronaves disponíveis e outros dois criados a partir da divisão em dois grupos do original.

Utilizando o método das equações da estrutura, é determinada onde a quantidade de material necessária, para resistir às forças a que a aeronave está sujeita, é desenvolvido um modelo para cada uma das três configurações de asa consideradas, maioritariamente em compósito de fibra de carbono, D-box em compósito de fibra de carbono e longarina em tubo de compósito de fibra de carbono. 0 cone da cauda é desenvolvido independentemente e a massa dos restantes componentes é determinada a partir de coeficientes baseados em características geométricas e na massa da asa calculada. 0 erro médio associado a estes modelos é inferior a $1 \%$.

Apresentam-se também os resultados obtidos para a aplicação nos casos de estudo considerados e são discutidas as respetivas validade, precisão e aplicação, em termos de fase de projeto, para cada método.

\section{Palavras-chave}

Modelos de previsão de massa; Air Cargo Challenge; Aeronave; Veículo aéreo não-tripulado; Perfil alar; Ajuste de dados; Configuração de asa; Polímero de fibra de carbono reforçado 


\section{Contents}

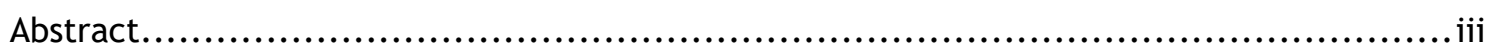

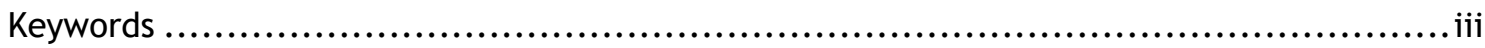

Resumo ................................................................................

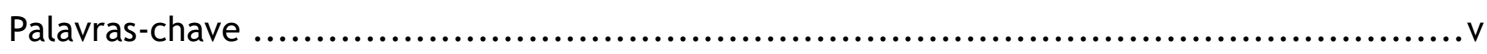

Contents ........................................................................ vii

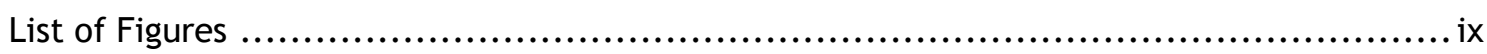

List of Tables .....................................................................

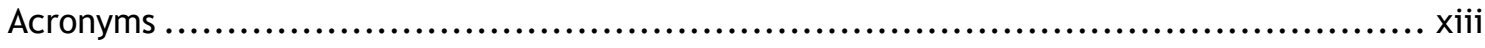

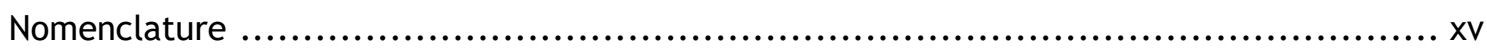

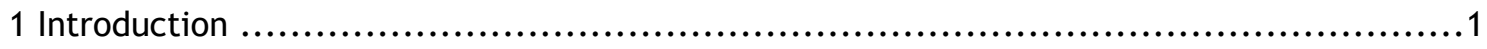

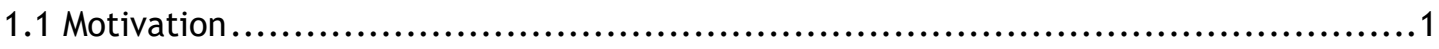

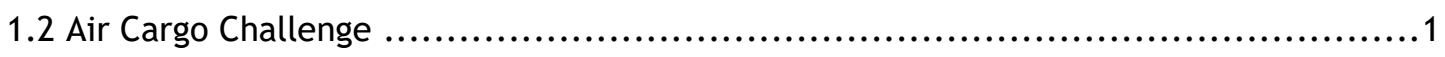

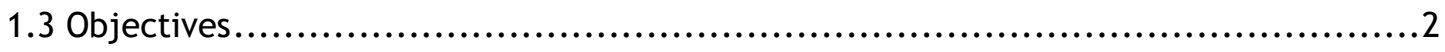

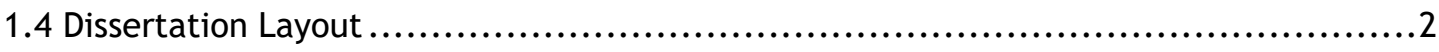

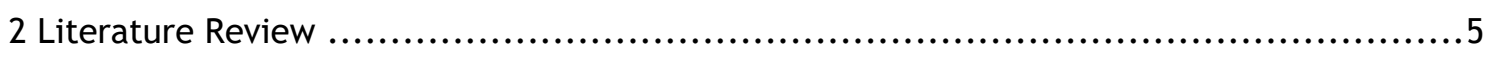

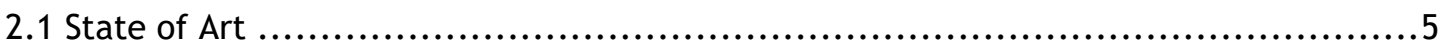

2.1.1 Air Cargo Challenge Aircraft ................................................ 5

2.1.2 Mass Prediction Models ..................................................... 10

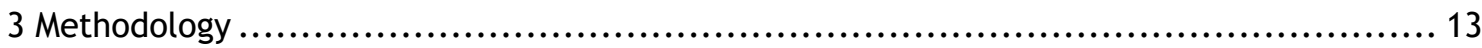

3.1 Statistical Models ............................................................... 13

3.1.1 General Mass Model............................................................ 14

3.1.2 Component Based Mass Model ........................................... 14

3.2 Structure Type Based Mass Models ............................................... 15

3.2.1 Load Conditions ........................................................ 15

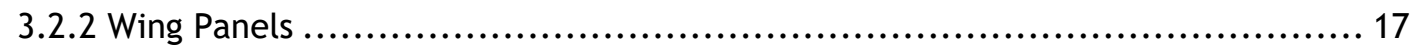

3.2.3 Load Bearing Skin Wing Configuration ............................................. 19

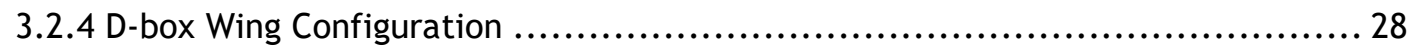

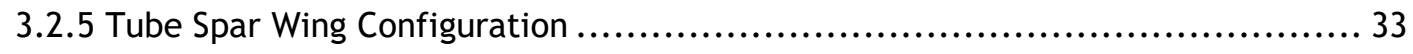

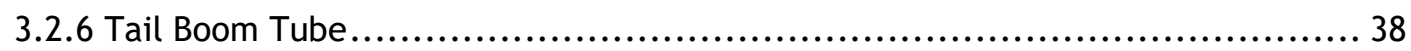

3.2.7 Remaining Components ................................................... 40

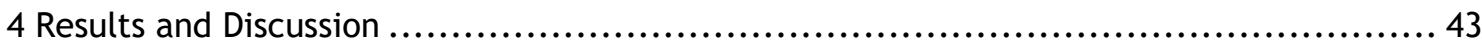

4.1 Statistical Models ................................................................ 43

4.1.1 General Mass Models ......................................................... 43

4.1.2 Component Based Mass Models ............................................. 49

4.1.3 Comparison between General and Component Based Mass Models .................. 55

4.2 Structure Type Based Mass Models ........................................... 56

4.2.1 Carbon Fiber Skin Wing Configuration......................................... 57 


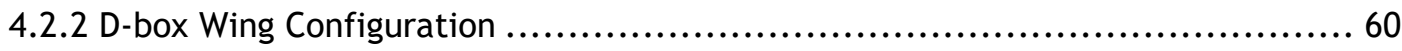

4.2.3 Tube Spar Wing Configuration ............................................... 61

4.2.4 Comparison between Results for the Different Configurations .................... 64

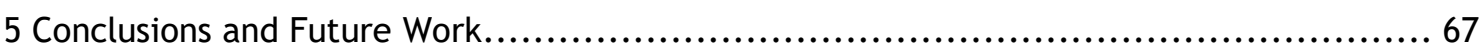

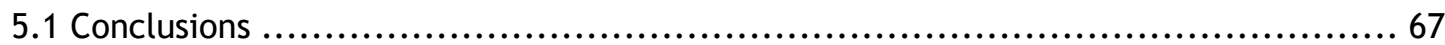

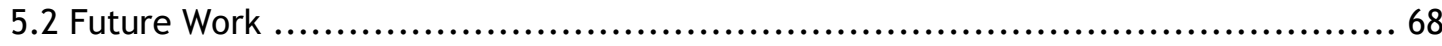

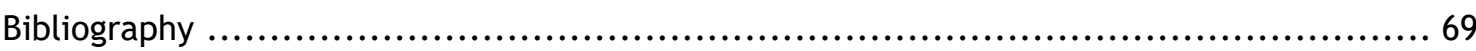




\section{List of Figures}

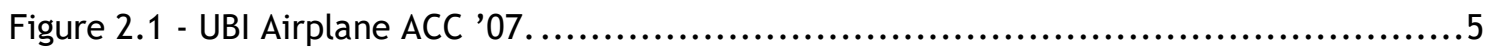

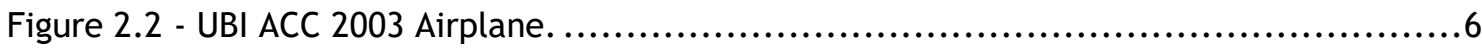

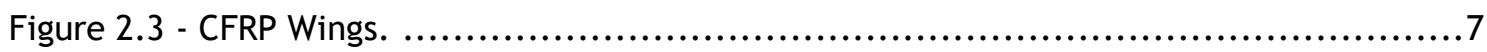

Figure 2.4 - UBI Airplane ACC 2015 (LE and TE detail)....................................

Figure 2.5 - AKAModell Stuttgart Airplane ACC '09 [4] ....................................

Figure 2.6 - UBI Airplane ACC '07 (Cargo Bay detail) [5]. .................................

Figure 2.7 - UBI PVG ACC' 17 (Landing Gear detail)......................................

Figure 2.8 - University of Patras ACC '15 (Tail detail). ......................................

Figure 3.1 - Spanwise Lift Distribution. .................................................. 16

Figure 3.2 - Structural Validation Test................................................. 16

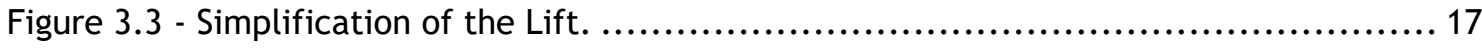

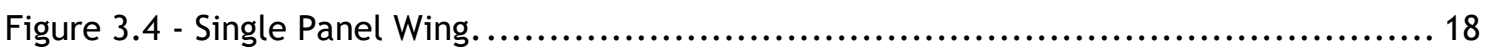

Figure 3.5 - Multiple Panels Wing. ......................................................... 19

Figure 3.6 - Carbon Fiber Configuration. ................................................. 20

Figure 3.7 - Airfoil Divided in Two Cells. ............................................... 21

Figure 3.8 - D-box Configuration. ........................................................... 28

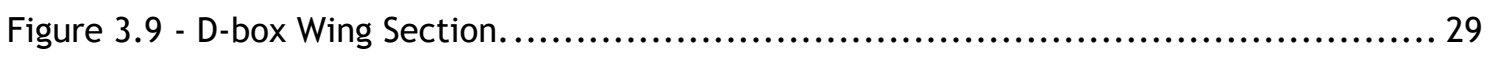

Figure 3.10 - Real and Approximate Airfoil Lift Distribution [1]. ........................... 31

Figure 3.11 - Tube Spar Configuration. .................................................. 33

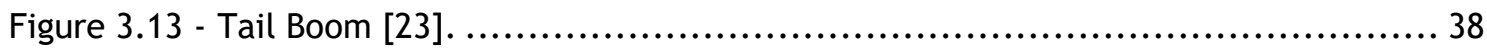

Figure 4.1 - General Mass Model. ........................................................... 45

Figure 4.2 - General Mass Model - Fixed Payloads. ....................................... 45

Figure 4.3 - General Mass Model - Fixed Chords........................................... 46

Figure 4.4 - General Mass Model - Fixed Spans. ........................................... 46

Figure 4.5 - General Mass Model - Group I. ............................................ 47

Figure 4.6 - General Model - Group II. ................................................. 47

Figure 4.7 - General Mass Model - Fixed Payloads (Group I). ............................. 48

Figure 4.8 - General Mass Model - Fixed Payloads (Group II). ............................. 49

Figure 4.9 - Component Based Mass Model (Empty Mass)................................... 51

Figure 4.10 - Component Based Mass Model (Total Mass). .................................. 51

Figure 4.11 - Component Based Mass Model - Group I (Empty Mass). ......................... 53

Figure 4.12 - Component Based Mass Model - Group I (Total Mass)............................ 53

Figure 4.13 - Component Based Mass Model - Group II (Empty Mass)........................... 54

Figure 4.14 - Component Based Mass Model - Group II (Total Mass).......................... 54

Figure 4.15 - Structure Based Mass Model - Empty Mass..................................... 64

Figure 4.16 - Structure Based Mass Model - Total Mass. ..................................... 65 


\section{List of Tables}

Table 4.1 - Teams with Reports Considered. ............................................ 43

Table 4.2 - Data Collected from the Reports. ........................................... 44

Table 4.3 - General Mass Models Equations. ........................................... 49

Table 4.4 - Considered Reports (Component Based Mass Models). ............................ 50

Table 4.5 - Component Based Mass Model Equations.................................... 51

Table 4.6 - Component Based Mass Model Equations (Group I)............................ 52

Table 4.7 - Component Based Mass Model Equations (Group II). ............................ 53

Table 4.8 - Error Comparison. ...................................................... 55

Table 4.9 - Error Comparison for Groups Division.......................................... 55

Table 4.10 - Coefficient of Determination Comparison. .................................. 56

Table 4.11 - Generic Inputs. ........................................................ 57

Table 4.12 - Specific Inputs for Carbon Fiber Configuration. ............................... 58

Table 4.13 - Material Properties for Carbon Fiber Configuration. ........................... 58

Table 4.14 - AERO@UBI_MARS Calculated and Real Masses. .................................... 59

Table 4.15 - AKAModell13 Calculated and Real Masses. ................................... 59

Table 4.16 - Specific Inputs for D-box Configuration. ........................................6 60

Table 4.17 - Material Properties for D-box Configuration. .................................61

Table 4.18 - AERO@UBI_PVG Calculated and Real Masses.....................................61

Table 4.19 - Specific Inputs for Tube Configuration..................................... 62

Table 4.20 - Material Properties for Tube Configuration. .................................62

Table 4.21 - AERO@UBI_Team Calculated and Real Masses. ......................................62

Table 4.22 - Portugal Team Calculated and Real Masses. ................................63 63

Table 4.23 - GRAVITY Calculated and Real Masses. ........................................64 


\section{Acronyms}

$\begin{array}{ll}\text { ACC } & \text { Air Cargo Challenge } \\ \text { ACSYNT } & \text { AirCraft SYNThesis } \\ \text { AIAA } & \text { American Institute of Aeronautics and Astronautics } \\ \text { APAE } & \text { Portuguese Association of Aeronautics and Space } \\ \text { CAD } & \text { Computer Aided Design } \\ \text { CFRP } & \text { Carbon Fiber Reinforced Polymer } \\ \text { DCA } & \text { Aerospace Sciences Department } \\ \text { FAME-W } & \text { Fast and Advanced Mass Estimation Wing } \\ \text { FEM } & \text { Finite Element Method } \\ \text { GFRP } & \text { Glass Fiber Reinforced Polymer } \\ \text { GRG } & \text { Generalized Reduced Gradient } \\ \text { HT } & \text { Horizontal Tail } \\ \text { LE } & \text { Leading edge } \\ \text { MDO } & \text { Multidisciplinary Design Optimization } \\ \text { NASA } & \text { National Aeronautics and Space Administration } \\ \text { PDCYL } & \text { Point Design of Cylindrical-bodied Aircraft } \\ \text { SF } & \text { Safety Factor } \\ \text { TE } & \text { Trailing edge } \\ \text { UBI } & \text { University of Beira Interior } \\ \text { USA } & \text { United States of America } \\ \text { VT } & \text { Vertical Tail } \\ \text { WAATS } & \text { Weights Analysis for Advanced Transportation Systems }\end{array}$




\section{Nomenclature}

\begin{tabular}{lll}
$A$ & Area & {$\left[\mathrm{m}^{2}\right]$} \\
$a_{i}$ & Variables & {$[-]$} \\
$A R$ & Aspect ratio & {$[-]$} \\
$b$ & Span & {$[\mathrm{m}]$} \\
$c$ & Chord & {$[\mathrm{m}]$} \\
$c f_{i}$ & Correction factors & {$[-]$} \\
$C_{d}$ & Drag coefficient & {$[-]$} \\
$C_{i}$ & Constants & {$[-]$} \\
$C_{l}$ & Lift coefficient & {$[-]$} \\
$C_{m}$ & Moment coefficient & {$[-]$} \\
$d s$ & Infinitesimal distance & {$[\mathrm{m}]$} \\
$d \theta$ & Twist rate & {$[-]$} \\
\hline$d y$ & Young's modulus & {$\left[\mathrm{N} / \mathrm{m}^{2}\right]$} \\
$E$ & Gravity acceleration & {$\left[\mathrm{m} / \mathrm{s}^{2}\right]$} \\
$g$ & Shear modulus & {$\left[\mathrm{N} / \mathrm{m}^{2}\right]$} \\
$G$ & Second moment of area in x axis & {$\left[\mathrm{m}^{4}\right]$} \\
$I_{x x}$ & Second moment of area in y axis & {$\left[\mathrm{m}^{4}\right]$} \\
$I_{y y}$ & Polar inertia moment & {$\left[\mathrm{m}^{4}\right]$} \\
$J$ & Constants & {$[-]$} \\
$k$ & Constants & {$[-]$} \\
$K_{i}$ & Mass & {$[\mathrm{kg}]$} \\
$m$ & Moment & {$[\mathrm{Nm}]$} \\
$M$ & Soad factor & {$[-]$} \\
$n$ & Number of ribs & {$[\mathrm{H}$} \\
$n_{r i b}$ & Perimeter & {$[\mathrm{m} / \mathrm{s}]$} \\
$p$ & Concentrated load & {$[\mathrm{N}]$} \\
$P$ & Shear flow & {$[\mathrm{N} / \mathrm{m}]$} \\
$q$ & Wing Area & {$\left[\mathrm{m}^{2}\right]$} \\
$S$ & Shear strength & {$[\mathrm{N}]$} \\
$S$ & Wetted Surface Area & {$\left[\mathrm{m}^{2}\right]$} \\
$S$ & Thickness & {$[\mathrm{m}]$} \\
$S_{w e t}$ & Torfoil thickness-to-chord ratio & {$[-]$} \\
$t$ & Selocity & {$[\mathrm{m}]$} \\
& &
\end{tabular}

\section{Greek Symbols}

$\beta \quad$ Bending slope

[degree]

$\delta \quad$ Deflection

[m] 


$\begin{array}{lll}\theta & \text { Rotation angle } & {[\text { degree }]} \\ \theta & \text { Twist angle } & {[\text { degree }]} \\ \lambda & \text { Tapper } & {[-]} \\ \rho & \text { Density } & {\left[\mathrm{kg} / \mathrm{m}^{3}\right]} \\ \sigma & \text { Normal stress } & {\left[\mathrm{N} / \mathrm{m}^{2}\right]} \\ \tau & \text { Shear stress } & {\left[\mathrm{N} / \mathrm{m}^{2}\right]} \\ \omega & \text { Distributed load value } & {[\mathrm{N} / \mathrm{m}]}\end{array}$

\section{Subscripts}

$\begin{array}{ll}\text { A } & \text { Area } \\ \text { box } & \text { D-box } \\ \text { CB } & \text { Cargo Bay } \\ \text { core } & \text { Core related } \\ \text { empty } & \text { Empty } \\ \text { est } & \text { Estimated } \\ \text { face } & \text { Web Face related } \\ \text { fus } & \text { Fuselage } \\ \text { h, HT } & \text { Horizontal Tail } \\ \text { i,j } & \text { Counters } \\ \text { LG } & \text { Landing Gear } \\ \text { material } & \text { Material } \\ \text { max } & \text { Maximum value } \\ \text { P } & \text { Perimeter } \\ \text { pay } & \text { Payload } \\ \text { R } & \text { Cell Number } \\ \text { real } & \text { Real } \\ \text { rib } & \text { Rib related } \\ \text { skin } & \text { Skin related } \\ \text { spar } & \text { Spar Cap related } \\ \text { syst } & \text { Systems } \\ \text { tb } & \text { Tail Boom } \\ \text { tip } & \text { Wing Tip } \\ \text { tube } & \text { Tube } \\ \text { VT } & \text { Vertical Tail } \\ \text { wall } & \text { Cell Wall } \\ \text { wing, w } & \text { Wing related } \\ \text { x, y, z } & \text { Cartesian system coordinates } \\ & \end{array}$




\section{Introduction}

\subsection{Motivation}

The need to have a precise estimate of an airplane mass, at the early stages of aircraft design, has been proven to be crucial to maintain the capability to perform the sizing mission without increasing the take-off mass [1]. In any type of aircraft, the preliminary value obtained is essential to define and calculate the succeeding design parameters.

The Aerospace Sciences Department (DCA) of the University of Beira Interior (UBI) has a major interest in the Air Cargo Challenge (ACC) competition. Having participated in all editions until today, with three wins (two since the competition became international in 2007), it has become a very important event to improve knowledge and apply new techniques, required to develop such project.

In this competition, the experience has demonstrated the major significance of a correct estimation of the aircraft final mass. To further optimize the aircraft design, more accurate models must be developed. That leads to the possibility to dedicate more time to other tasks, increasing the manufacture quality and leading to a better final product.

\subsection{Air Cargo Challenge}

The ACC is a biannual competition between universities, whose main objective is the design and construction of an aircraft [2], similar to the Design/Build/Fly sponsored by the American institute of Aeronautics and Astronautics (AIAA) [3], carried out in the United States of America (USA). In addition, the development of theoretical knowledge and skills, related to design and manufacturing, and the contact between students, mainly in the aeronautics and aerospace field, is stimulated, allowing the share of knowledge and experience.

The competition was created in 2003, organized under the auspices of the APAE (Portuguese Association of Aeronautics and Space), only for Portuguese universities, and took place in Lisbon, Portugal.

In 2007, the event was internationalized, maintaining the primary objectives, allowing a greater vitalization and development of it. A new reality was introduced in this edition to encourage a major participation. In addition to the prize money awarded to the winner, the possibility to organize the next edition was offered.

Regarding the competition itself, the development and construction of a radio controlled aircraft, capable of carrying the maximum payload possible, is required. There is also a need to perform the take-off from a distance equal to or less than 60 meters, to make, at least, 
one turn around the airfield and to land safely, so that the flight can be considered valid. Adding to these objectives, from the 2015 edition on, it was added the need to execute a greater number of legs (defined point passages) in a determined time gap, allying the need to carry payload with the highest velocity possible. As a result of this regulation modification, there were changes in the aircraft development.

Some parameters, such as wingspan, wing area, motor type or empty take-off mass, were imposed by the regulation. This has been modified over the years to promote the increase of the number of participants, since it is necessary to carry out a new project for each edition, approximating the results of new entries and more experienced participants. However, it should be noted that, from the observation of the results, teams with more participations, are, most likely, closer to the top of the classification. Nevertheless, positive results were obtained by most recent participations of extra-European universities, from countries like China and Brazil.

\subsection{Objectives}

The main scope of this dissertation is the development of mass prediction models that can be used in the design of aircraft for the ACC competition.

The integration of a more precise model in the design of the aircraft, to be used in coming competitions, might lead to better results and be adopted by other universities, increasing the contribution to the state of art of mass prediction models.

It is also intended to present alternative methods to the development of these types of models, with the objective of obtaining accurate results without the complexity of other procedures.

\subsection{Dissertation Layout}

The dissertation begins with an introductory chapter in which the objectives and the motivation for the accomplishment of this work are exposed. There is also an explanation regarding the ACC competition, as well as its purposes, the importance to the aerospace students and, in particular, to the university.

In the second chapter, it is presented a state of art containing the evolution of the ACC aircraft and the different types of mass prediction models, regarding its development and application.

In the third chapter, the mass models are introduced, containing the explanation concerning the implemented methods, including the equations derivation. 
Then, in the fourth chapter, the results obtained for each method are presented, accompanied by an analysis, focused on the errors associated to each one and their accuracy and validity.

Finally, the conclusions, an overview of the developed work and possible recommendations for future work are presented in the fifth chapter. 


\section{Literature Review}

\subsection{State of Art}

\subsubsection{Air Cargo Challenge Aircraft}

These aircraft are built with the main purpose of carrying the maximum payload.

Over the years, regulations have imposed limitations, mostly associated with geometry, and, in recent years, there has been a need to cover as much distance as possible within a given period of time. The existence of a more complex project was then imposed due to the need to ally the payload transport to the performance of the airplane, in order to obtain a higher score possible.

Taking that into account, there was a need to evolve from a structural point of view, combining technological advances with the ease of access to certain materials and construction techniques, thus making changes in the configuration of these aircraft.

In the first editions of the competition, the airplanes had structures made, essentially, of balsa wood and covering film, like it is possible to verify in the wing configuration in Figure 2.1 , with the aim of imparting mechanical resistance and shape, respectively. There were also others made of fiber-glass and foam (see Figure 2.2). The introduction of a more extensive use of composite structures occurred in the 2007 edition, in which it was possible to observe the existence of composite carbon fiber tubes used for the tail boom (see Figure 2.1).

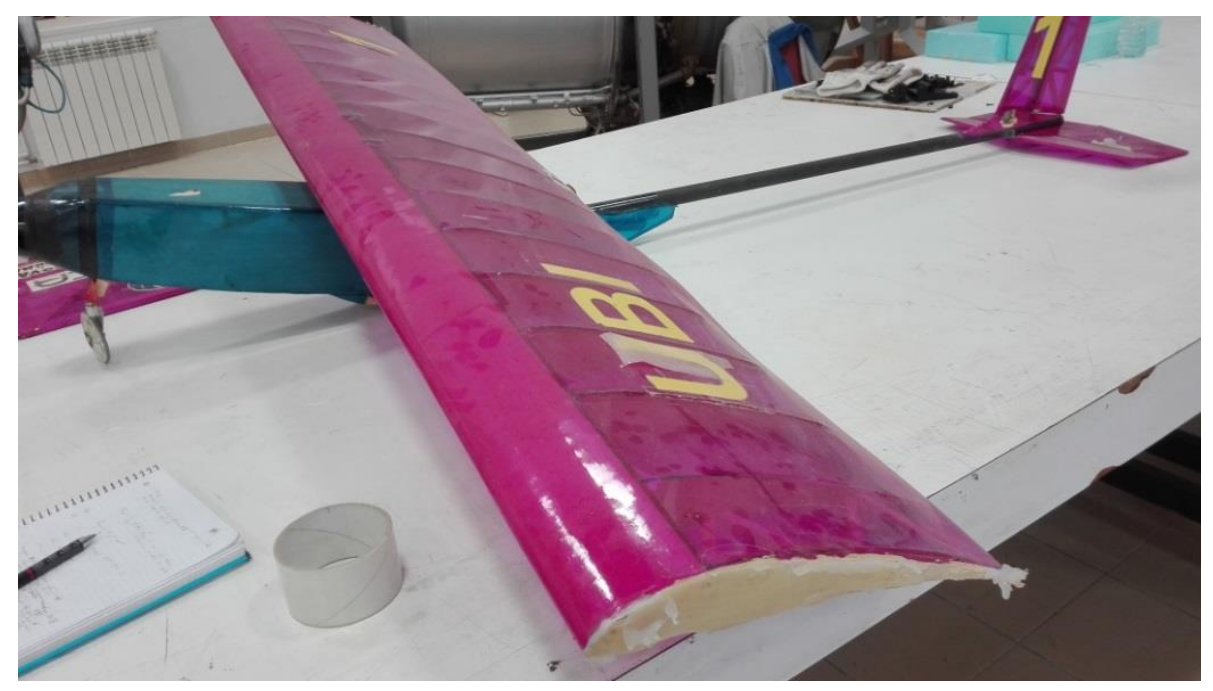

Figure 2.1 - UBI Airplane ACC '07. 


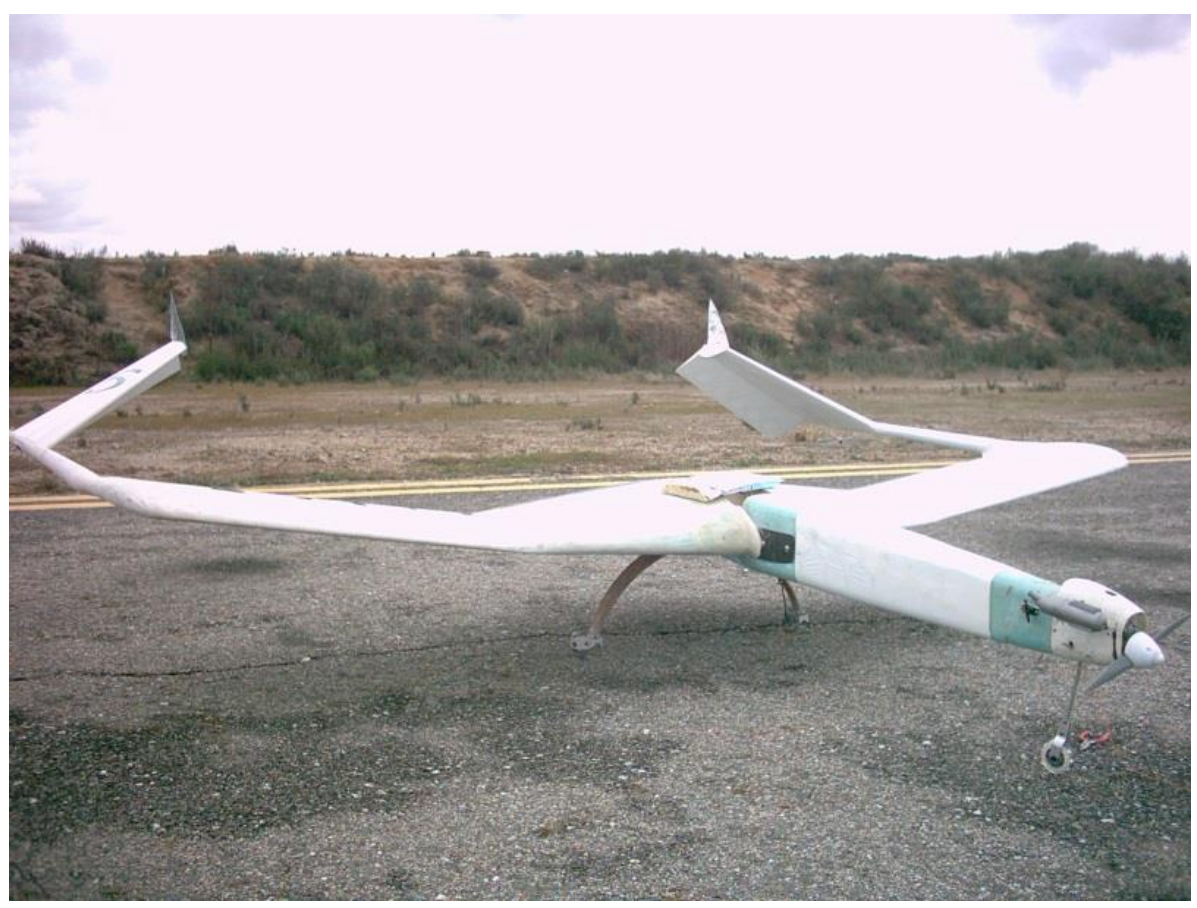

Figure 2.2 - UBI ACC 2003 Airplane.

Of course, due to the mechanical properties of this type of structure being more adequate to the necessities in question and to the fact that the competition has evolved, thus increasing the financial capacity of the participants, the use of composites was extended to other components of the aircraft. The main change was in the wing structure, namely the wing spar, which has become, fundamentally, a CFRP tube (see Figure 2.3 (a)), thus resisting bending and twisting strength with an obvious decrease in weight.

Another aspect to consider is the fact that some competitors have adopted more complex flaps, to which greater aerodynamic loads are associated in the wing, being necessary to increase the resistance to these forces and moments. This implied extending the use of carbon fiber composites to a greater percentage of the wing, becoming spars (see Figure 2.3 (b) (c)) and skin made of this material (see Figure 2.3 (c) (d)). 


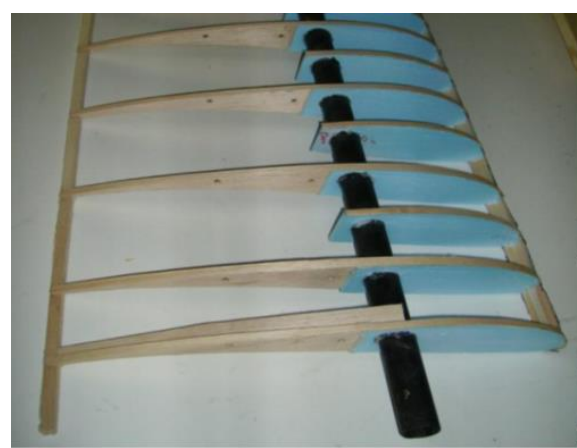

(a) CFRP Tube Spar

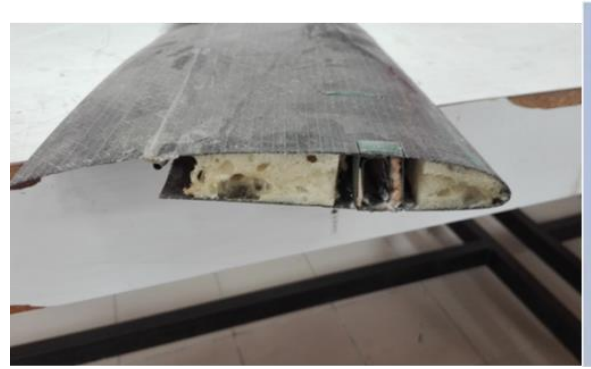

(c) CFRP Spar and Skin

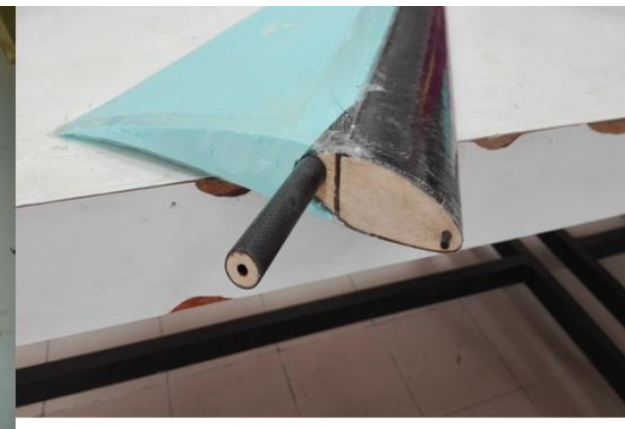

(b) CFRP D-box

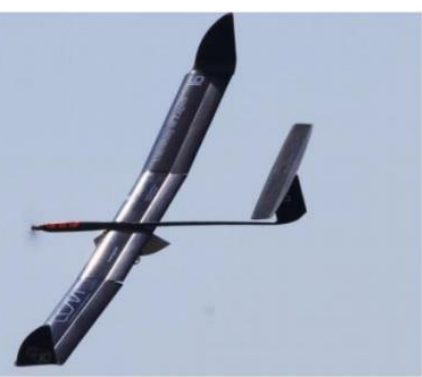

(d) Zagreb Airplane ACC '15 (CFRP made)

Figure 2.3 - CFRP Wings.

It is also worth noting reinforcements in the leading and trailing edges in balsa (see Figure 2.4), being used glass fiber or carbon composite in more recent aircraft.

Regarding the configuration of the fuselage, it is possible to divide it into two cases: full length tube, where the cargo bay is attached (see Figure 2.5) and traditional fuselage, where the payload is placed in the cargo bay and a tail boom is used for the remaining length (see Figure 2.1).

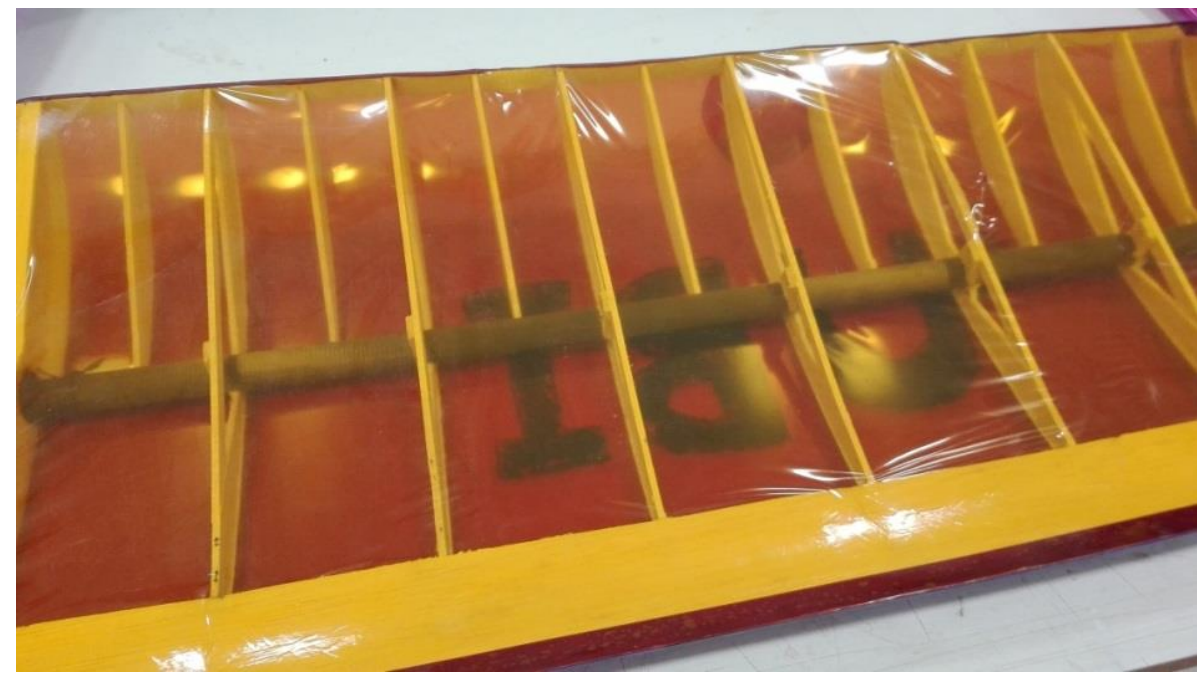

Figure 2.4 - UBI Airplane ACC 2015 (LE and TE detail). 


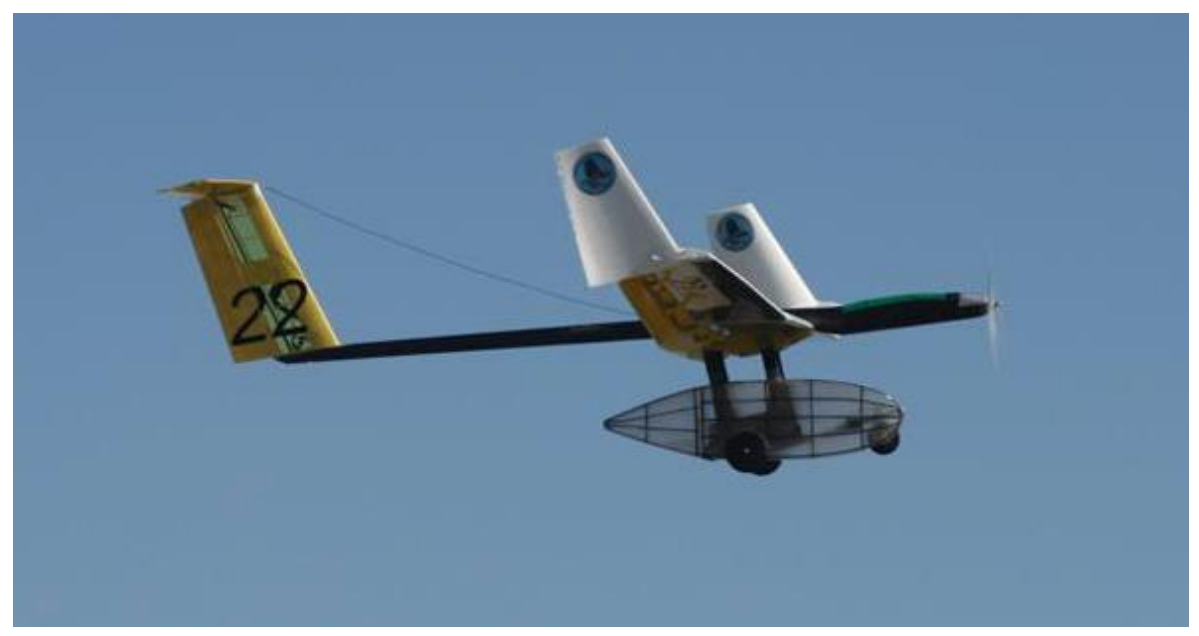

Figure 2.5 - AKAModell Stuttgart Airplane ACC '09 [4].

The cargo bay is essentially made of balsa wood and covering film (see Figure 2.6) or, in some cases, composites. In the case of the landing gear, in the situations in which it is adopted, there are several philosophies applied in its construction, being possible to divide it in a two wheels configuration, connected by a tube (see Figure 2.7), often in CFRP, and main and secondary landing gear (see Figure 2.5). Note also the differences in the complexity of the landing gear component, with the existence of simple structures, there being cases in which this part of the aircraft is discarded, and others developed with special attention to the preservation of the integrity of the aircraft, since there is a need to avoid compromise it, that could prevent future attempts or even disqualification of the flight.

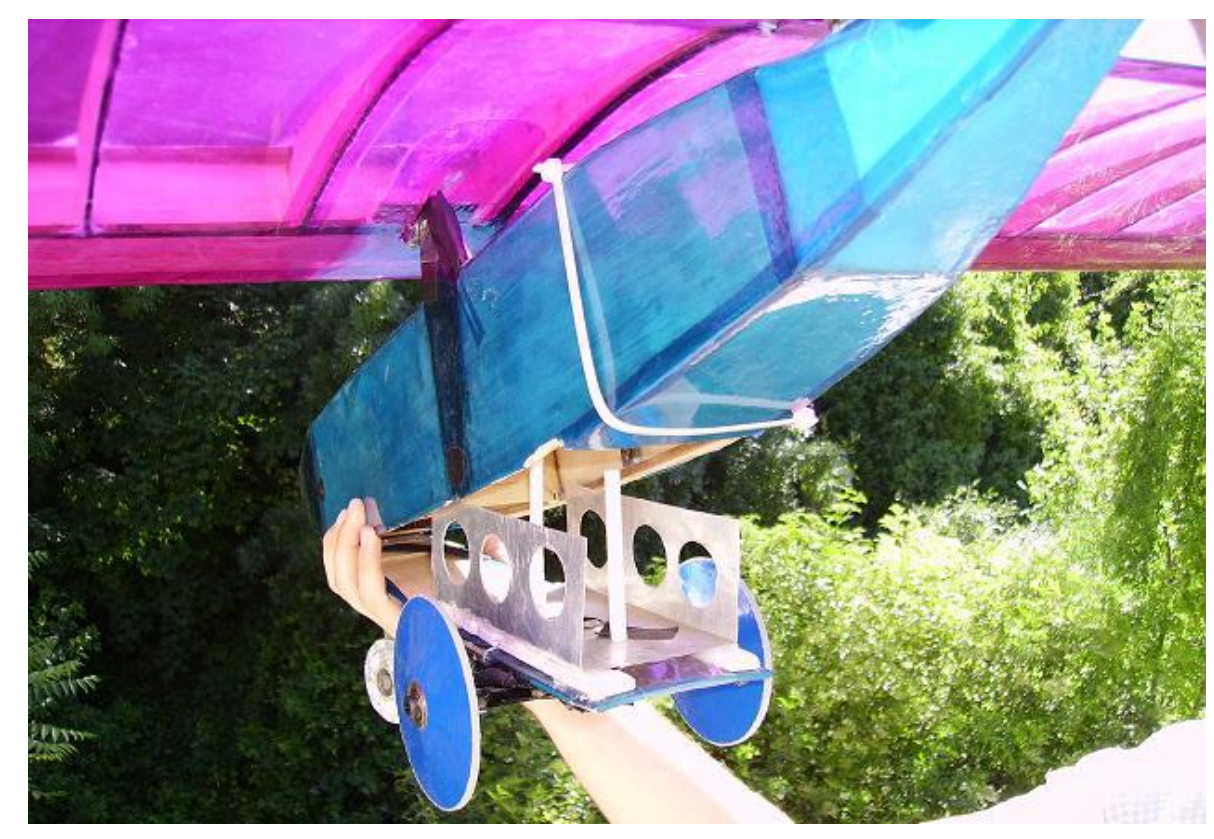

Figure 2.6 - UBI Airplane ACC '07 (Cargo Bay detail) [5]. 


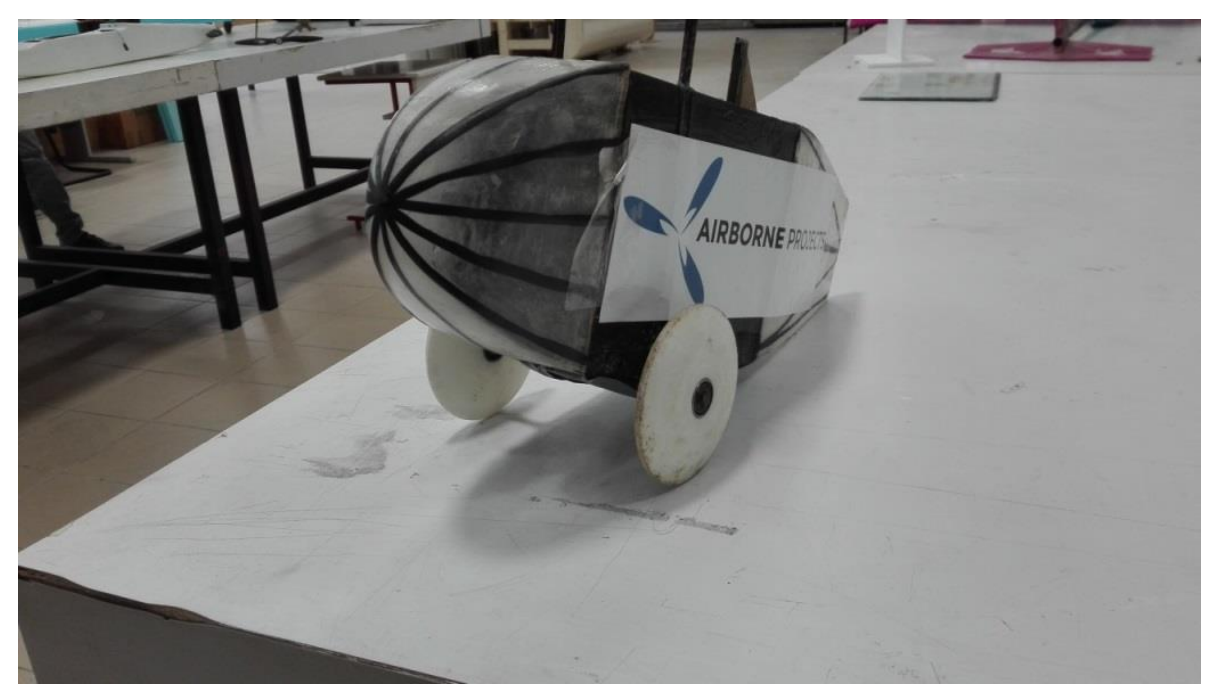

Figure 2.7 - UBI PVG ACC' 17 (Landing Gear detail).

As for the planes' tail surfaces, it is possible to verify that, despite the increase of composite structures, the magnitude of the forces is much lower, comparing with the wing, resulting in structures similar to those used in the beginnings of the competition, i.e., balsa wood and covering film, resulting in very reduced masses (see Figure 2.8).

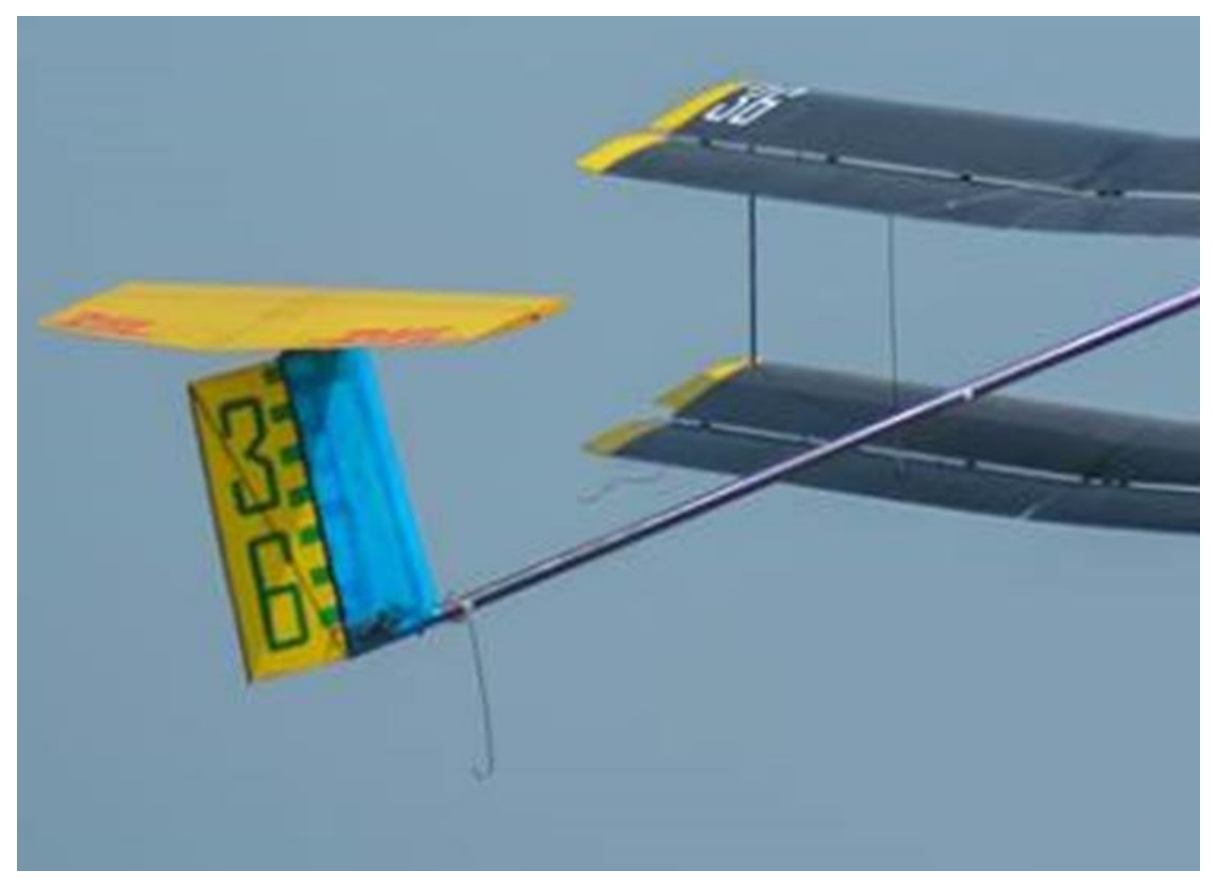

Figure 2.8 - University of Patras ACC '15 (Tail detail). 


\subsubsection{Mass Prediction Models}

For the design of an aircraft it has been proved that an adequate weight estimate is essential, that is, that it provides values of the final mass of the aircraft that are close to reality [1]. Given this, there are many models proposed over time, usually developed for a specific type of aircraft. Dababneha and Kipouros [6] present a review of the existing methods and a division in classes. This division, based on their complexity, elaborated by Elham et al. [7], is presented next:

- Class I: In this class, the equations representing the mass are essentially developed from statistical data as functions of parameters such as empty mass, payload and fuel mass. In this situation, the initial data are scarce and, usually, only the required range and velocity are available, resulting in simple equations with a high associated error when compared to other more effective methods. Methods of this class are presented by Roskam [8], Jenkinson [9], Raymer [1] and Torenbeek [10], and Weights Analysis for Advanced Transportation Systems (WAATS), the program developed by National Aeronautics and Space Administration (NASA) [11].

- Class II: As in class I methods, these are based on statistical data. However, in this case, the designer has access to information regarding the influence that his choices, related to geometry and other aspects of the components, have on the final mass of the aircraft. Semi-empirical relationships based on essentially geometric characteristics are used, and may or may not be divided into components (fuselage, wing, tail, landing gear). Examples of these methods are presented by Torenbeek [10], Raymer [1], Niu [12], Jenkinson [9] and Howe [13].

- Class III: In this situation, physics based on structural analysis is used rather than statistical data. Usually FEM (finite element method) is used. The various components are sized based on the structural requirements and the weight is calculated based on volumes and densities of the materials to be used. Examples are the works elaborated by Bindolino [14] and Ardema et al. [15] who developed the Point Design of Cylindrical-bodied Aircraft (PDCYL) program, integrated in the AirCraft SYNThesis (ACSYNT) program developed by NASA.

- Class IV methods are also presented and described as being developed for use outside the conceptual design zone and preliminary design. They are more detailed methods, based on FEM, than the class III ones, adding to the mass calculation CAD models and components from catalogues and suppliers.

It is also presented a class II \& $1 / 2$, described as semi-empirical methods that use elemental analysis, based on the stiffness and mechanical resistance of the materials, combined with statistical data. The amount of material required is calculated to withstand stress using simple structure equations. Examples are the work of Burt [16], Torenbeek [17], Elham et al. 
[7], FAME-W (Fast and Advanced Mass Estimation Wing) software developed by Airbus Germany [18] and Dijk [19], who created a program for Airbus Industry in Toulouse.

From the presented examples, it is possible to notice that the evolution of the computational capacity associated with the refinement of existing methods resulted in greater accuracy. Also note the existence of methods developed by authors that appear associated with design books, as well as models developed and applied by companies that use their aircraft data and then, in exchange with competitors, have access to more data, allowing more accurate results. It is also possible to perceive the difference between types of methods, both in terms of their complexity and in the way they are presented, that is, there are models from which an estimate is obtained for the total weight of the aircraft, others where it is possible to know the estimate for each constituent group and also estimate by component or set of components. There are also some examples of methods developed specifically for wing mass prediction, a critical component in any type of aircraft [15].

In the examples presented by the books focused on aircraft design, it is possible to observe the division of the models associated with each type of airplane by its application [1], [10]. It should also be noted that, for most models, the range of its applicability is specified, that is, the size limitation in terms of geometry or mass for which they have been developed and consequently for which they are valid. 


\section{Methodology}

In this chapter, the mass models are introduced. The equations, along with the mathematical methods used, the derivations, the simplifications and the necessary considerations are presented.

\subsection{Statistical Models}

To determine the required equations for each model presented hereafter it is necessary to define the method adopted, based on the conducted research.

Due to the fact that the variables are independent, the equation considered adequate to represent the mass, $m$, has the following form:

$$
m=k \prod_{i=1}^{n} a_{i}^{c_{i}}
$$

where $k$ is a constant, $c_{i}$ are coefficients and $a_{i}$ are variables.

The least square fitting method minimizes the sum of square errors and the following objective function is used in order to determine the unknown coefficients:

$$
\text { Objective Function }=\sum_{j=1}^{k} \frac{\left(m_{\text {est }_{j}}-m_{\text {real }_{j}}\right)^{2}}{m_{\text {real }_{j}}^{2}}
$$

where $m_{e s t}$ is the estimated mass and $m_{\text {real }}$ is the real mass.

The iterative process minimizes the difference between the real value for the mass and the one calculated using the defined equation, varying the coefficients in order to approximate these values. To do so, the Excel Solver is used and a nonlinear Generalized Reduced Gradient (GRG) method is applied. These methods are algorithms used to determine the solution of non-linear problems, with the main application being optimization [20].

The coefficient of determination, $R^{2}$, is the proportion of the variance in the dependent variable that is predictable from the independent variable. A closer value to one means an adequate fit of the data. If the parameter takes a value near zero, the fitting does not represent the data properly [21]. The expression used to calculate the coefficient of determination is:

$$
R^{2}=1-\frac{\sum_{j=1}^{k}\left(m_{\text {est }_{j}}-m_{\text {real }_{j}}\right)^{2}}{\sum_{j=1}^{k}\left(m_{\text {real }_{j}}-\overline{m_{\text {real }}}\right)^{2}}
$$

where $\overline{m_{\text {real }}}$ is the mean value of real masses. 


\subsubsection{General Mass Model}

This is a class I model, whose developed equation has the following form, where the unknown values are determined implementing the previously described process:

$$
m=k a_{1}^{c_{1}} a_{2}^{c_{2}} a_{3}^{c_{3}}
$$

where the variables $a_{1}, a_{2}$ e $a_{3}$ represent the wingspan, wing chord and payload (or wing area, aspect ratio and payload), respectively [22].

\subsubsection{Component Based Mass Model}

This class II model is developed considering the different constituent parts of the aircraft, namely, wing, horizontal and vertical tails, systems, landing gear, fuselage and payload. Again, the previously described method was implemented with the following equations and parameters of interest for each component.

The mass of the wing is given by:

$$
m_{\text {wing }}=k_{\text {wing }} b^{c_{1 \text { wing }}} c^{c_{2 \text { wing }}} \lambda^{c_{3 \text { wing }}}\left(\frac{t}{c}\right)^{c_{4 \text { wing }}}
$$

where the variables $b, c, \lambda$ and $\left(\frac{t}{c}\right)$ represent span, chord, taper ratio and airfoil thickness-tochord ratio, respectively, and the constant and the coefficients are associated to the wing mass function.

The mass of the horizontal and vertical tails is given by:

$$
m_{H T / V T}=k_{H T / V T} b_{H T / V T}^{c_{1 H T / V T}} c_{H T / V T}^{c_{2} H T V T}
$$

where the variables, the constant and the coefficients represent the same parameters, but associated to the horizontal and vertical tails.

The systems, $m_{\text {syst }}$, landing gear, $m_{L G}$, and fuselage, $m_{f u s}$, masses are considered constant, result of the verification that these values have small variations. The empty mass, $m_{\text {empty }}$, is given by:

$$
m_{\text {empty }}=m_{\text {wing }}+m_{H T}+m_{V T}+m_{f u s}+m_{\text {syst }}+m_{L G}
$$

The payload mass, $m_{\text {pay }}$, is specified by the user. The sum of all previous parameters results in the following expression for the final mass of the aircraft:

$$
m=m_{\text {pay }}+m_{\text {empty }}
$$




\subsection{Structure Type Based Mass Models}

These class II \& $1 / 2$ models are based on the equations that relate the geometric and mechanical characteristics of the components of an aircraft with the forces and moments to which it is subjected. The expressions obtained allow the determination the quantity of material, for certain expected operating conditions, necessary for the fulfilment of the imposed mission. It is then possible to get the resulting mass of each component by summing the fractions obtained to resist each force or moment, as it is explained later.

It is also important to take into account the fact that deformations, resulting from stresses, may have implications in performance and structural integrity, due to aeroelastic instability. Given that, it is considered appropriate to limit some of these structural displacements. To determine the appropriate value to use in each element, a critical analysis must be conducted.

In order to establish the allowable stress, for the material's mechanical properties a safety factor, $S F$, is defined.

$$
S F=\frac{\text { ultimate stress }}{\text { allowable stress }}
$$

Due to the fact that the calculated material mass is fully necessary to withstand the loads, some mass penalty factors related to the interfaces, required to join different parts, and to extra material, needed to bond different elements, are defined, so that the final mass obtained for the wing is adjusted to be closer to the reality.

In the wing panels with taper, the root chord is considered, resulting in oversizing. However, it has been verified that the influence in the final result is not significant. For this reason, the difference is ignored, simplifying the model.

Based on the observation of the different wing structures used in the ACC aircraft, three wing structure types were considered in this study, namely, load bearing skin structure (section 3.2.3), D-box (section 3.2.4) and tube main spar (section 3.2.5).

\subsubsection{Load Conditions}

To size the structure it is necessary to consider the loads it is subjected to. In this study, two situations are considered: flight (see Figure 3.1) and ground test (see Figure 3.2). 


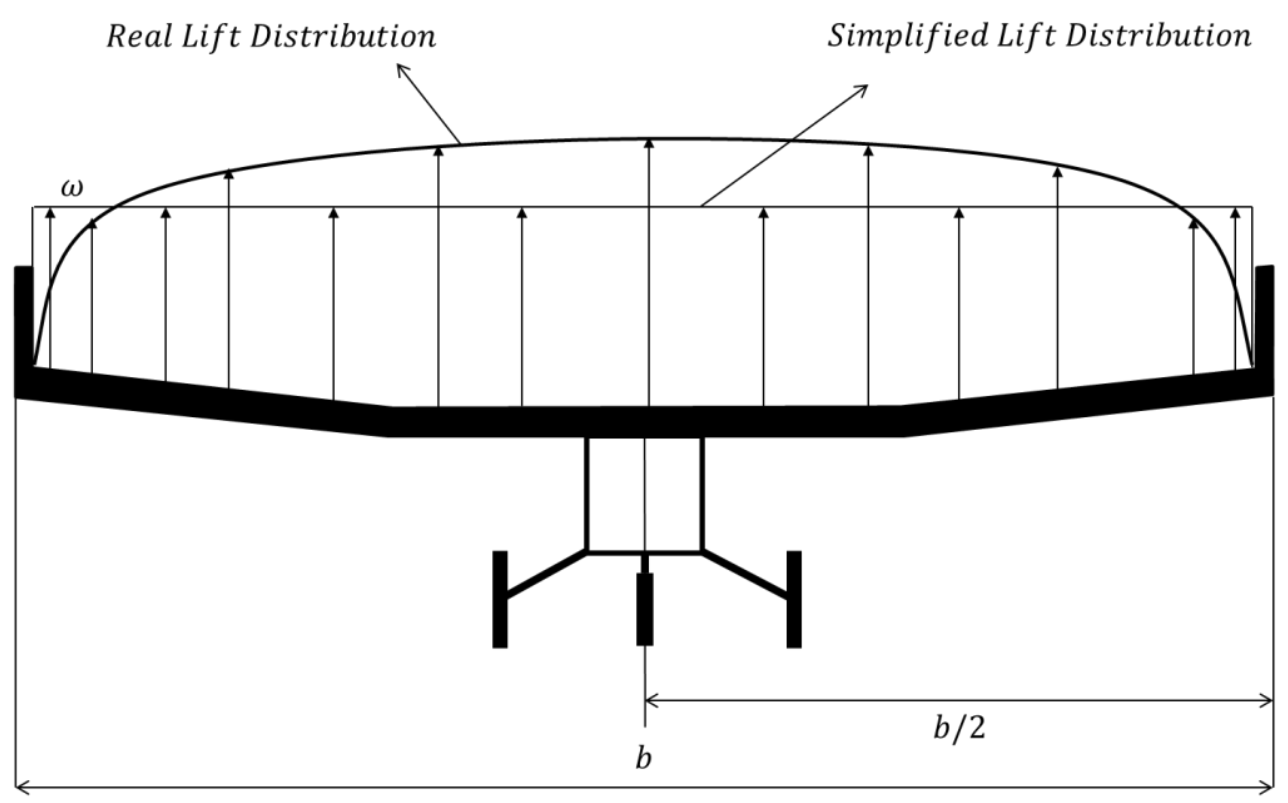

Figure 3.1 - Spanwise Lift Distribution.

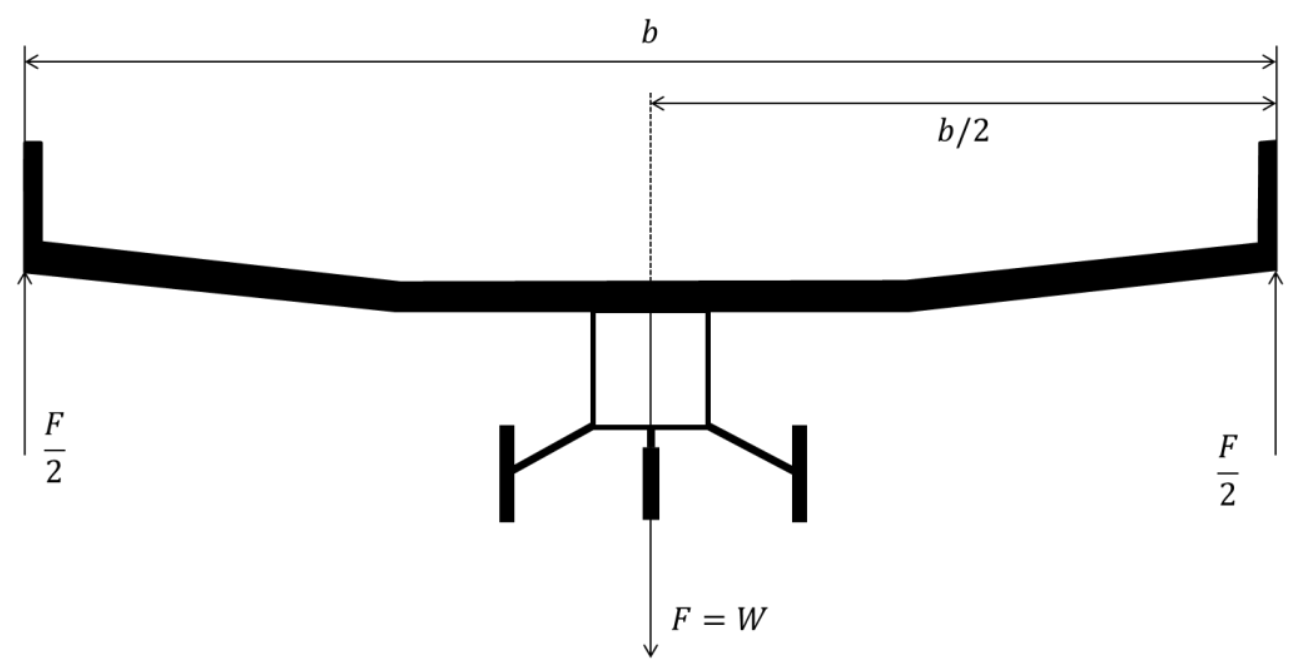

Figure 3.2 - Structural Validation Test.

For the first case, the lift distribution is simplified as a uniformly distributed load. For the calculations, in some situations, the lift in the half span is assumed to be a concentrated load applied in its centre, in order to simplify the model (see Figure 3.3). Both the bending moment and shear force have their maximum values at the wing root decreasing to zero at the tip. 


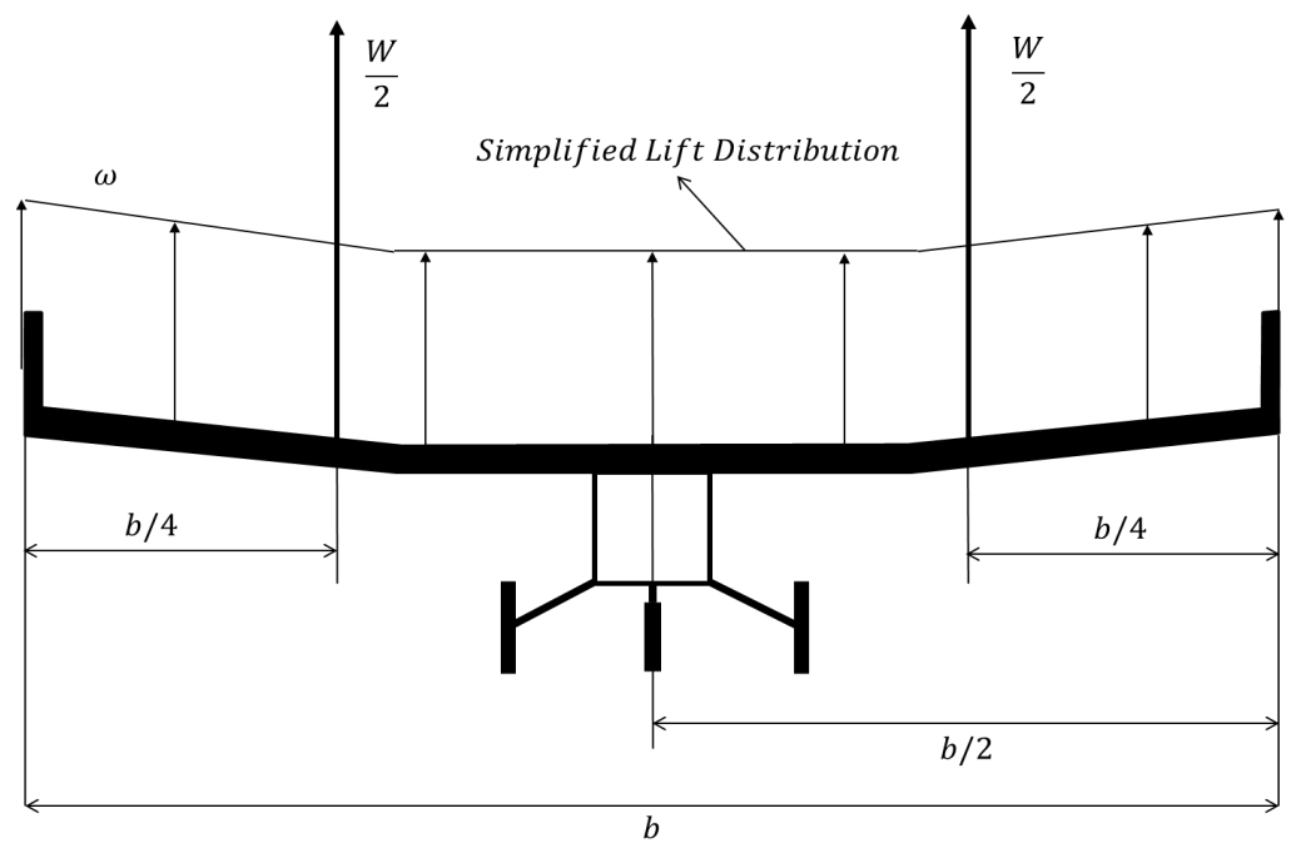

Figure 3.3 - Simplification of the Lift.

The structural validation test, required by the competition's regulation, consists in supporting the aircraft at the wing tips and loading it. In this case, the bending moment is also maximum at the root and zero at the wing tip. However, the shear force is constant throughout the wing.

The distributed load value, $\omega$, is defined as:

$$
\omega=\frac{n W}{b}
$$

where $n$ is the load factor and $W$ is the airplane weight.

Both these cases are considered in the sizing of the structure and the critical situation is selected.

\subsubsection{Wing Panels}

Due to the possible existence of tapper, the wing might be divided in panels. If the chord of the wing is constant along the span, this component can be composed by a single panel such as in Figure 3.4. In this case, the characteristics of the transversal section are defined at the root of the wing's half-span and are constant throughout it. 


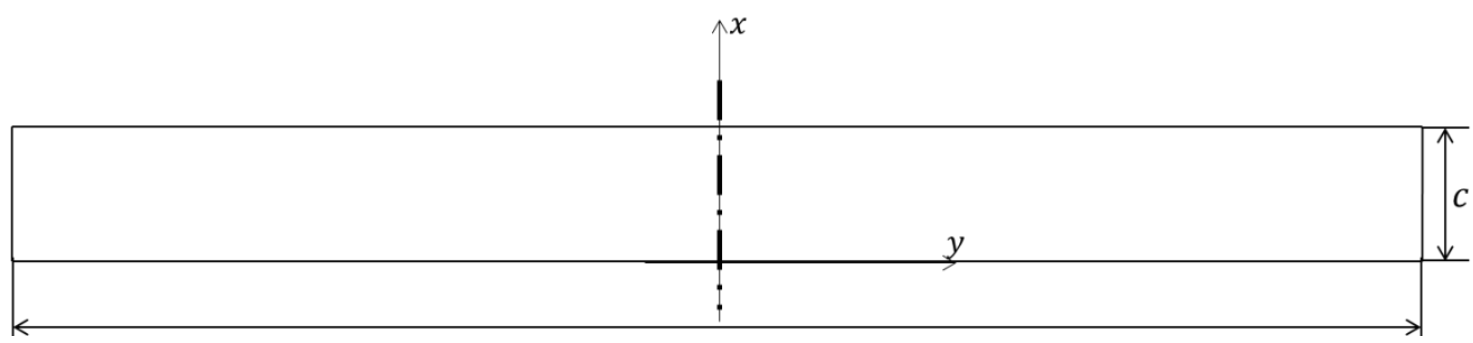

(a) Top View

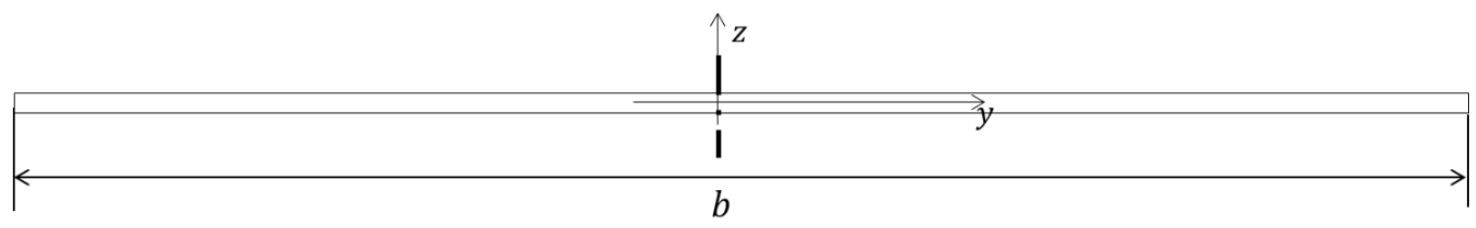

(b) Front View

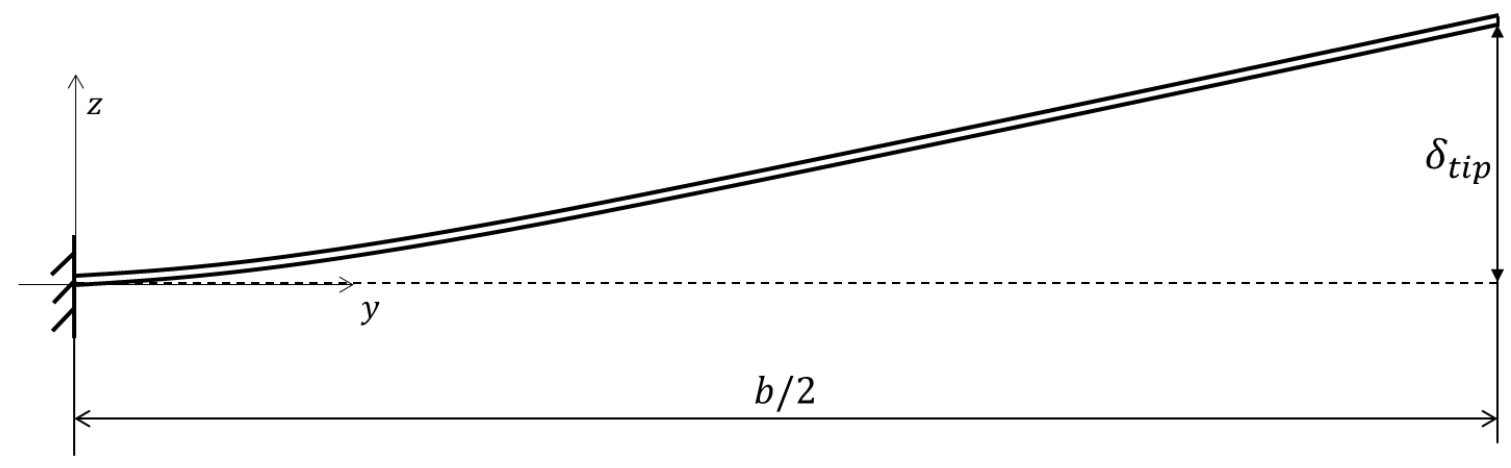

(c) Half Span Deflection

Figure 3.4 - Single Panel Wing.

However, in almost all aircraft in the ACC competition, wings have tapper. This chord variation might be constant throughout the wing span or the tapper might vary. In both cases the wing is composed by panels (see Figure 3.5). The sizing is done for the first panel, with the remaining sections characteristics being determined based on the obtained for the first and some considerations regarding the impact of the respective stresses along the wing span.

The sizing is done at panel's root, so the characteristics are constant throughout the panel. It also considered the chord variation, so, to determine the required material, sections are defined at the panels' edges. 


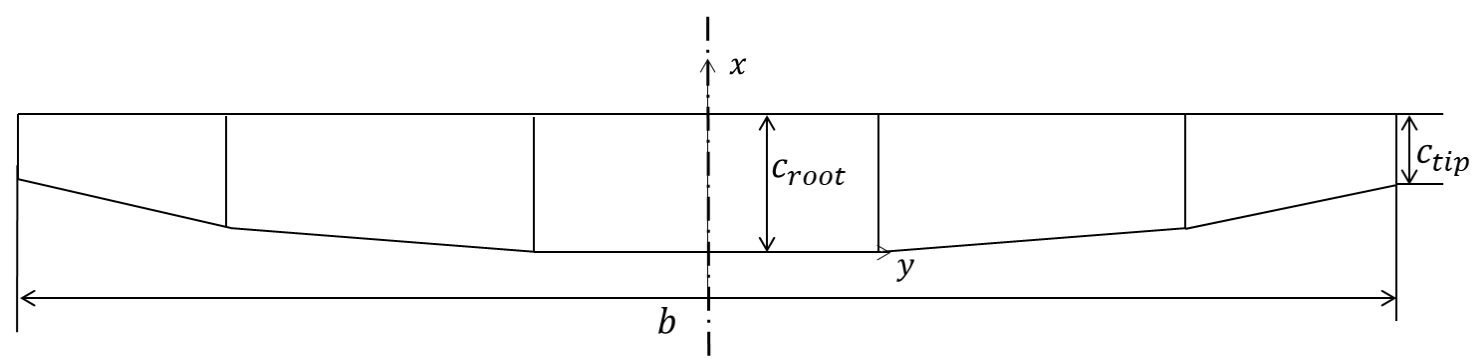

(a) Top View.

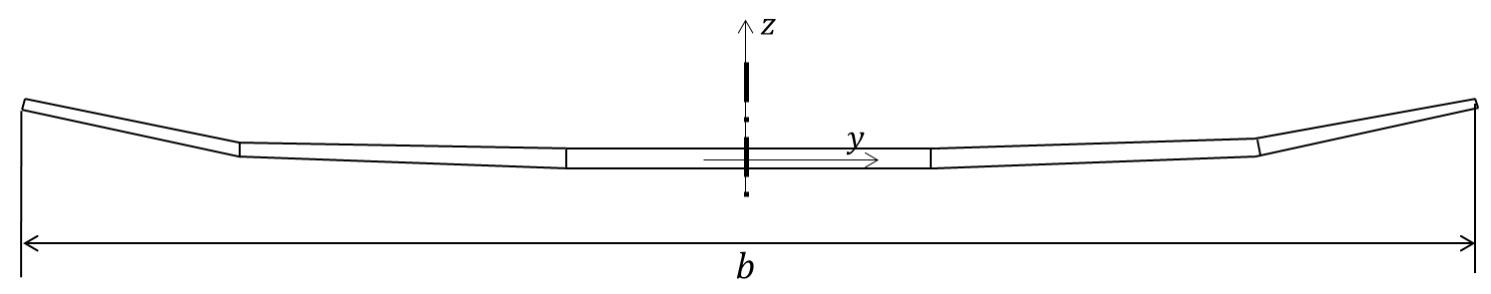

(b) Front View.

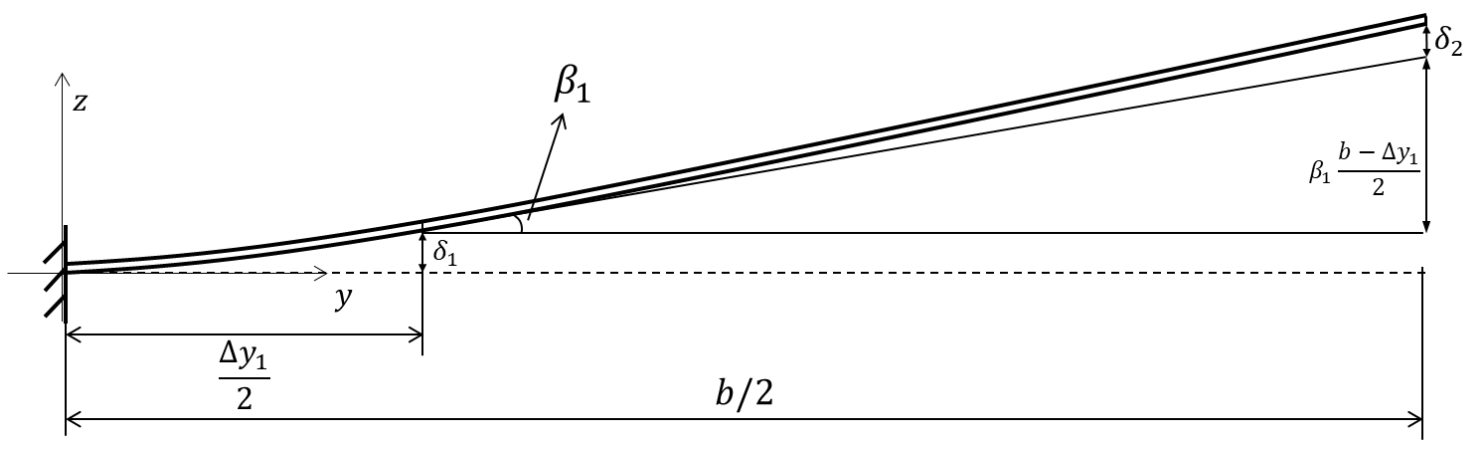

(c) Half Span Deflection.

Figure 3.5 - Multiple Panels Wing.

\subsubsection{Load Bearing Skin Wing Configuration}

For this first case, the structure thereof can be described as being predominantly manufactured in carbon fiber composite with a foam core, resulting in a sandwich configuration exemplified in Figure 3.6.

Some simplifications are assumed in the calculation of the required material to withstand each stress. It was considered that only the spar cap would resist bending loads (both for flight and ground test). The allowable stress and tip deflection are taken as limiting factors.

The thickness of the spar web results from the sum of the amount of material required to withstand the shear and the torsion stresses. 


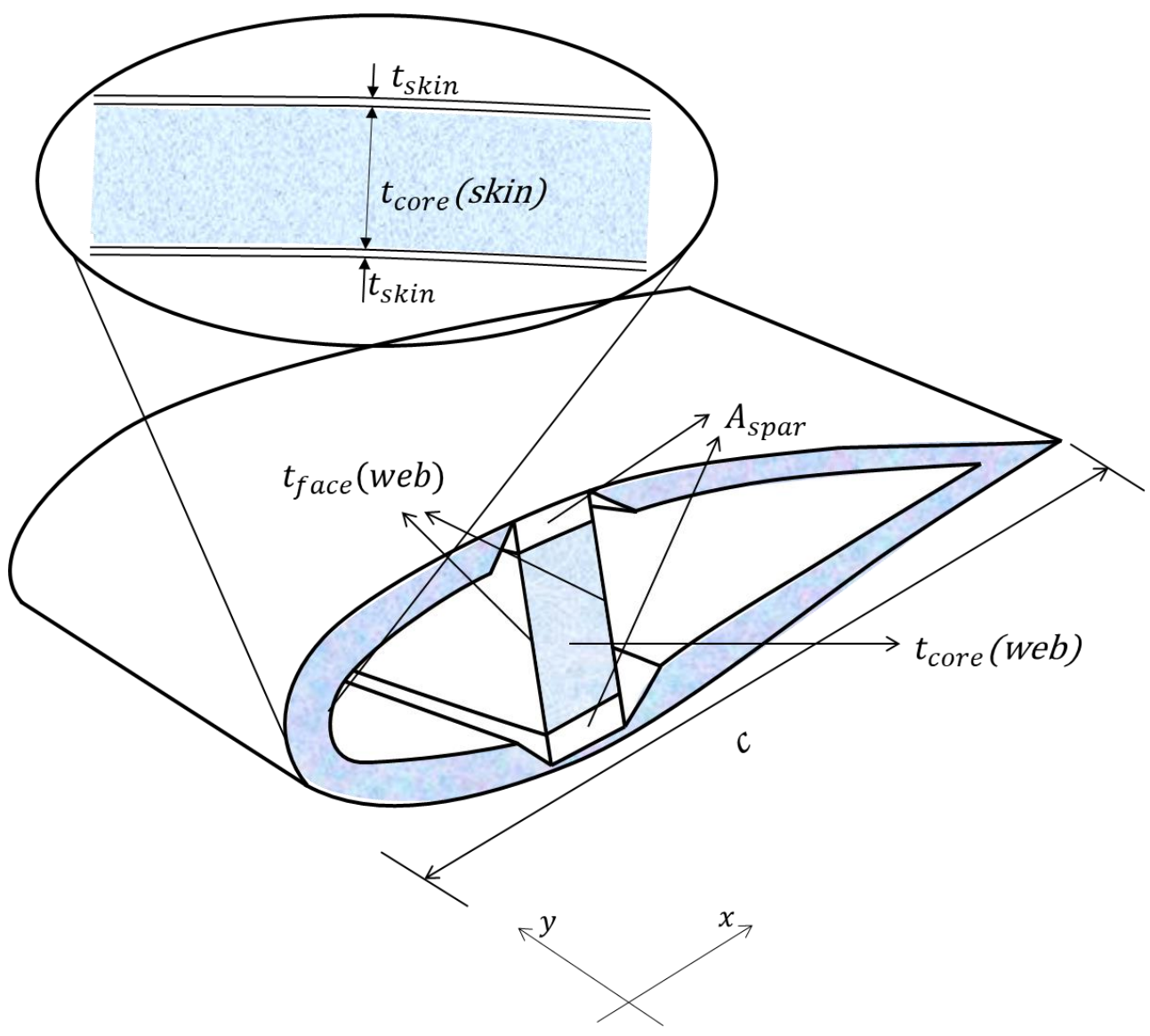

Figure 3.6 - Load Bearing Skin Wing Configuration.

In the torsion case, being the section airfoil made of composite, it is divided into two cells having the web as a common element (see Figure 3.7). The perimeter of cell I and cell II are represented in red and green, respectively. The quantity of material required is obtained to withstand the resulting shear flow in each cell. For the sake of simplicity, the thickness of the shell is constant in both cells, thus obtaining an oversizing in the cell where the shear flow is smaller, proving that this was not problematic for the final result. Associated with the need to resist the torque, it was still considered relevant to limit the wing tip twist. The thickness considered for mass calculation is selected for the different loading cases, from the comparison of the results obtained, to the critical situation. 


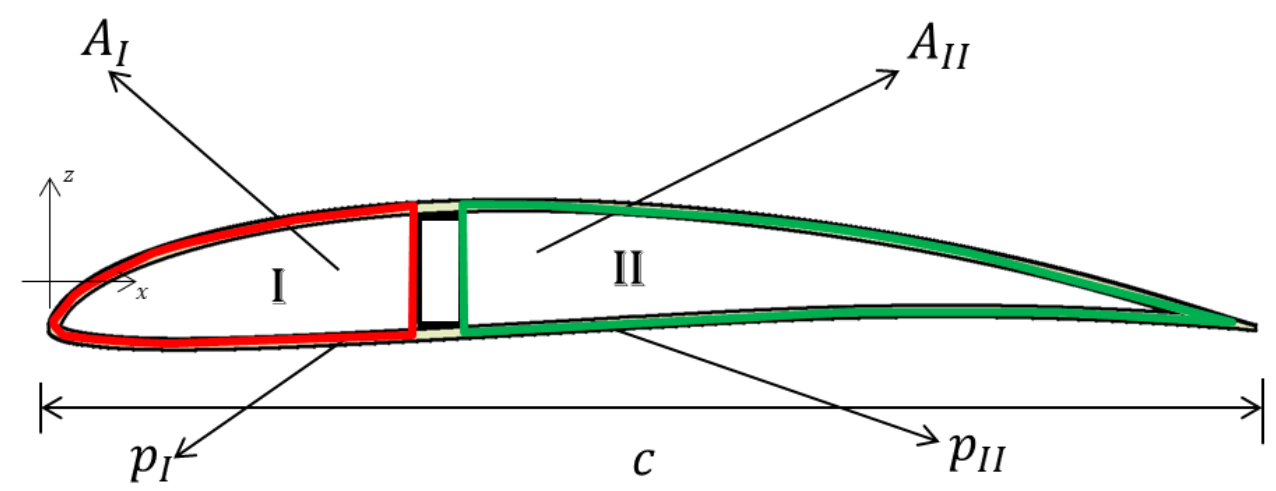

Figure 3.7 - Airfoil Divided in Two Cells.

The following equations are presented as the basis for the calculation and are accompanied by the deduction and some considerations to be taken into account.

The constants associated with the area are inversely proportional to the chord squared and airfoil thickness-to-chord ratio.

$$
\begin{aligned}
K_{A_{I}} & =\frac{\left(\frac{A_{I}}{A_{\text {airfoil }}}\right) A_{\text {airfoil }}}{c^{2}\left(\frac{t}{c}\right)} \\
K_{A_{I I}} & =\frac{\left(\frac{A_{I I}}{A_{\text {airfoil }}}\right) A_{\text {airfoil }}}{c^{2}\left(\frac{t}{c}\right)}
\end{aligned}
$$

where $A_{I}, A_{I I}$ and $A_{\text {airfoil }}$ are the cell I, cell II and airfoil cross-section areas, respectively.

Assuming that the thickness-to-chord ratio varies only a few per cent, then the perimeter's constants are only functions of the chord.

$$
\begin{aligned}
K p_{I} & =\frac{\left(\frac{p_{I}}{p_{\text {airfoil }}}\right) p_{\text {airfoil }}}{c} \\
K p_{I I}= & \frac{\left(\frac{p_{I I}}{p_{\text {airfoil }}}\right) p_{\text {airfoil }}}{c}
\end{aligned}
$$

where $p_{I}, p_{I I}$ and $p_{\text {airfoil }}$ are the cell I, cell II and airfoil perimeters, respectively. 
Regarding the bending strength:

The second moment of area, $I_{x x}$, according to the axes represented in Figure 3.7, is given by:

$$
I_{x x}=\int_{A} z^{2} d A
$$

where $d A$ is the infinitesimal area of the arbitrary shape, and $z$ is the distance from the $x$-axis to $d A$.

Neglecting the geometry of the section and assuming that the entire transversal element area is concentrated in its centroid, the second moment of area is simplified to:

$$
I_{x x}=A d^{2}
$$

where $A$ is the section area and $d$ is the distance from the $x$-axis to the section's centroid.

Taking into account that,

$$
\begin{aligned}
& A=2 A_{\text {spar }} \\
& d=\left(\frac{c\left(\frac{t}{c}\right)}{2}\right)
\end{aligned}
$$

where $A_{\text {spar }}$ is the spar cap area and substituting Eq. (3.17) and Eq. (3.18) into Eq. (3.16), the expression for the second moment of area is:

$$
I_{x x}=\frac{A_{\text {spar }} c^{2}\left(\frac{t}{c}\right)^{2}}{2}
$$

For the calculation of the required spar cap area, the limiting criteria are the bending moment and the tip deflection. For the flight, it is assumed the simplification described in the previous section where the lift in the half-span is replaced by a concentrated load.

Starting with the known equations for normal stress, $\sigma_{y}$, and bending moment, $M_{x}$, from the axes represented Figure 3.6:

$$
\sigma_{y}=\frac{\frac{M_{x} c\left(\frac{t}{c}\right)}{2}}{I_{x x}}
$$




$$
M_{x}=\frac{n W b}{8}
$$

Substituting Eq. (3.19) and Eq. (3.21) into Eq.(3.20), the spar cap area is determined as follows:

$$
A_{\text {spar }}^{M f l}=\frac{1}{8 \sigma_{y_{\max }}} \frac{n W b}{c\left(\frac{t}{c}\right)}
$$

where $\sigma_{y_{\max }}$ is the maximum allowable normal stress.

Due to the simplification considered for the lift distribution, the bending moment varies with the span squared. Once verified that, the spar cap area is also considered to vary with the span squared, for the remaining panels, and it is determined using the following expression:

$$
A_{\text {spar }_{i}}=\left(\frac{b-\Delta y_{i}}{b}\right)^{2} A_{\text {spar }_{1}}
$$

where $\Delta y_{i}$ is the sum of the panels' length until the respective position.

In case of the ground test, the load factor is eliminated from Eq. (3.21) and it is considered that the force is applied at the wing tip, resulting on the following bending moment:

$$
M_{x}=\frac{W b}{4}
$$

and substituting Eq. (3.24) and Eq. (3.19) into Eq. (3.20), the required spar cap area is given by:

$$
A_{\text {spar }}^{M g t}=\frac{1}{4 \sigma_{y_{\max }}} \frac{W b}{c\left(\frac{t}{c}\right)}
$$

In the deflection case, considering that the wing bending curvature occurs mainly close to the root, the expression of the tip deflection, $\delta_{t i p}$, is given as (the parameters are represented in Figure 3.5):

$$
\delta_{\text {tip }}=\delta_{1}+\beta_{1} \frac{b-\Delta y_{1}}{2}+\delta_{2}
$$

where, $\delta_{1}$ is the deflection at the first panel tip, $\beta_{1}$ is the bending slope at the first panel tip and $\delta_{2}$ is the deflection for the remaining wing. 
That said, the expressions for the respective parameters are considered, according to the axes represented in Figure 3.5:

$$
\begin{aligned}
& \beta=\frac{\omega L^{3}}{6 E I_{x x}}+\frac{M_{x} L}{E I_{x x}} \\
& \delta=\frac{\omega L^{4}}{8 E I_{x x}}+\frac{M_{x} L^{2}}{2 E I_{x x}}
\end{aligned}
$$

where $\beta$ is the bending slope, $\delta$ is the deflection, $L$ is the panel length and $E$ is the Young's modulus.

Assuming that the spar cap area decrease is proportional to the span squared, the second moment of area for the remaining wing is assumed to be:

$$
I_{x x_{2}}=\left(\frac{b-\Delta y_{i}}{b}\right)^{2} I_{x x_{1}}
$$

Initially, the panel length and the moment, resulting from the distributed load for the remaining wing, have to be defined:

$$
\begin{gathered}
L=\frac{\Delta y_{1}}{2} \\
M=\frac{n W}{b}\left(\frac{b-\Delta y_{1}}{4}\right)\left(\frac{b-\Delta y_{1}}{2}\right)
\end{gathered}
$$

Knowing the necessary data, substituting Eq. (3.26), Eq. (3.29), Eq. (3.30) and Eq. (3.31) into Eq. (3.28), the expression for the deflection is obtained and, rearranging it, the required spar cap area is determined:

$$
\begin{aligned}
& \delta_{\text {tip }}=\frac{n W}{192 E b A_{\text {spar }} c^{2}\left(\frac{t}{c}\right)^{2}}\left(3 b^{4}-3 b^{2} \Delta y_{1}^{2}+b \Delta y_{1}^{3}+2 \Delta y_{1}^{4}\right) \\
& A_{\text {spar }}^{\delta}=\frac{1}{192 E \delta_{t i p}} \frac{n W}{b c^{2}\left(\frac{t}{c}\right)^{2}}\left(3 b^{4}-3 b^{2} \Delta y_{1}^{2}+b \Delta y_{1}^{3}+2 \Delta y_{1}^{4}\right)
\end{aligned}
$$


The remaining panels' spar cap area is determined using Eq. (3.23).

The final spar cap area is the maximum value between the ones calculated for the bending moment (flight, Eq. (3.22), and ground test, Eq. (3.25)) and for the maximum allowable wing tip deflection, Eq. (3.33), and is given by the following expression:

$$
A_{\text {spar }}=\max \left(A_{\text {spar }}^{\text {Mfl }} ; A_{\text {spar }}^{\text {Mgt }} ; A_{\text {spar }}^{\delta}\right)
$$

In the shear stress case, $\tau$, its maximum value (located in the neutral axis) is calculated using the following expressions:

$$
\begin{gathered}
\tau=\frac{3}{2} \frac{S_{z}}{2 t_{\text {face }} c\left(\frac{t}{c}\right)} \\
S_{z}=\frac{n W}{2} \\
\tau=\frac{3 n W}{8 t_{\text {face }} c\left(\frac{t}{c}\right)}
\end{gathered}
$$

where $S_{z}$ is the maximum shear force and $t_{\text {face }}$ is the web face thickness.

Hereupon, the thickness expression is determined from Eq. (3.37):

$$
t_{\text {face }}^{f l}=\frac{3}{8 \tau_{\max }} \frac{n W}{c\left(\frac{t}{c}\right)}
$$

where $\tau_{\max }$ is the maximum allowable shear stress.

For the ground test, the load factor is not considered in Eq. (3.38), resulting in:

$$
t_{\text {face }}^{g t}=\frac{3}{8 \tau_{\max }} \frac{W}{c\left(\frac{t}{c}\right)}
$$

As already was mentioned, on the ground test, the force is constant throughout the wing and, in flight, its value is maximum at the root and null at the tip. 
In the torsion case, the division of the airfoil into two cells is considered, with the following expressions being implemented for torque, $T$, and twist rate, $\frac{d \theta}{d y}$ :

$$
\begin{gathered}
T=\sum_{R=1}^{n} 2 A_{R} q_{r} \\
\frac{d \theta}{d y}=\frac{1}{2 A_{R} G} \oint q_{R} \frac{d s}{t}
\end{gathered}
$$

where $A_{R}$ and $q_{R}$ are the area and shear flow of the $R^{\text {th }}$ cell, $G$ is the shear modulus, $d s$ is the infinitesimal distance along the cell wall and $t$ is the cell wall thickness.

Based on that, a three equations system is defined:

$$
\left\{\begin{array}{c}
\left(\frac{d \theta}{d y}\right)_{I}=\frac{1}{2 A_{I} G}\left(q_{I} \frac{p_{I}}{t}-q_{I I} \frac{c\left(\frac{t}{c}\right)}{t}\right) \\
\left(\frac{d \theta}{d y}\right)_{I I}=\frac{1}{2 A_{I I} G}\left(-q_{I} \frac{c\left(\frac{t}{c}\right)}{t}+q_{I I} \frac{p_{I I}}{t}\right) \\
T=2 A_{I} q_{I}+2 A_{I I} q_{I I}
\end{array}\right.
$$

where $q_{I}$ and $q_{I I}$ are shear flows in cell I and II, respectively.

The unknowns are the two shear flows in the cells and the thickness required to ensure the determined twist at the wing tip.

In order to solve the system and based on the known values, the following parameters are defined:

$$
\begin{gathered}
t=2 t_{\text {skin }} \\
T=\frac{1}{2} \rho V^{2} \frac{b}{2} c^{2} C_{m} \\
q_{I}=q_{I I} C_{1} \\
C_{1}=\frac{K_{p_{I I}}+\frac{K_{A_{I I}}}{K_{A_{I}}}\left(\frac{t}{c}\right)}{\frac{K_{A_{I I}} K p_{I}}{K_{A_{I}}}+\left(\frac{t}{c}\right)}
\end{gathered}
$$




$$
\begin{gathered}
C_{2}=\frac{\rho V^{2} b C_{m}}{8\left(\frac{t}{c}\right)} \\
q=t \tau
\end{gathered}
$$

where $t_{\text {skin }}$ is the skin face thickness, $\rho$ is the air density, $V$ is the velocity, $C_{m}$ is the coefficient of pitching moment and $C_{1}$ and $C_{2}$ are constants.

Once Eq. (3.45) to Eq. (3.50) are substituted in the three equations system and this one is solved, the expressions for the shear flows are known and thicknesses are also determined to withstand the torque. The thicknesses expressions obtained are (torque, in cell I and II, and twist):

$$
\begin{gathered}
t_{\text {skin }_{I}}=\frac{C_{2}}{\left(K_{A_{I I}}+K_{A_{I}} C_{1}\right) 2 \tau_{\max }} \\
t_{\text {skin }_{I I}}=\frac{C_{1} C_{2}}{\left(K_{A_{I I}}+K_{A_{I}} C_{1}\right) 2 \tau_{\max }} \\
t_{\text {skin }}^{\theta}=\frac{C_{2}\left(C_{1} K_{p_{I}}-\left(\frac{t}{c}\right)\right) b}{\left(8 K_{A_{I}} c\left(\frac{t}{c}\right) G \theta_{\text {max }}\right)\left(K_{A_{I I}}+K_{A_{I}} C_{1}\right)}
\end{gathered}
$$

where $\theta_{\max }$ is the maximum allowable wing tip twist angle.

The final skin thickness is the maximum value between the ones determined to withstand the torque (cell I, Eq. (3.51), and cell II, Eq. (3.52)) and to guarantee the allowable wing tip twist, Eq. (3.53), and is given by the following expression:

$$
t_{\text {skin }}=\max \left(t_{\text {skin }} ; t_{\text {skin II }} ; t_{\text {skin }}^{\theta}\right)
$$

The final web face thickness is the sum of the maximum value, required to withstand the shear stress, between the ones calculated for flight, Eq. (3.38), and ground test, Eq. (3.39), and the thickness required to withstand the torsion, obtained in Eq. (3.54). The web face thickness is given by the following expression:

$$
t_{\text {face }}=\max \left(t_{\text {face }}^{f l} ; t_{\text {face }}^{g t}\right)+t_{\text {skin }}
$$


The wing mass might be determined from user-defined data, allowing realistic values for the construction, rather than the thicknesses obtained from the expressions, which might not be suitable from the practical perspective.

The core foam mass, $m_{\text {core }}$, is determined from a thickness value deemed suitable by the user.

$$
m_{\text {core }}=t_{\text {core }} b\left(p_{\text {airfoil }}+\frac{t}{c} c\right) \rho_{\text {core }}
$$

where $t_{\text {core }}$ is the core thickness and $\rho_{\text {core }}$ is the foam density.

\subsubsection{D-box Wing Configuration}

The second configuration consists of a D-box structure, from the leading edge until the spar. As before, a sandwich structure is used, made of carbon fiber composite shell and foam core, simplified in Figure 3.8.

The rear section of the airfoil has ribs for the purpose of transmitting stresses to the spar and to guarantee the airfoil shape, provided by the covering film, and reinforcement in the trailing edge made of balsa wood.

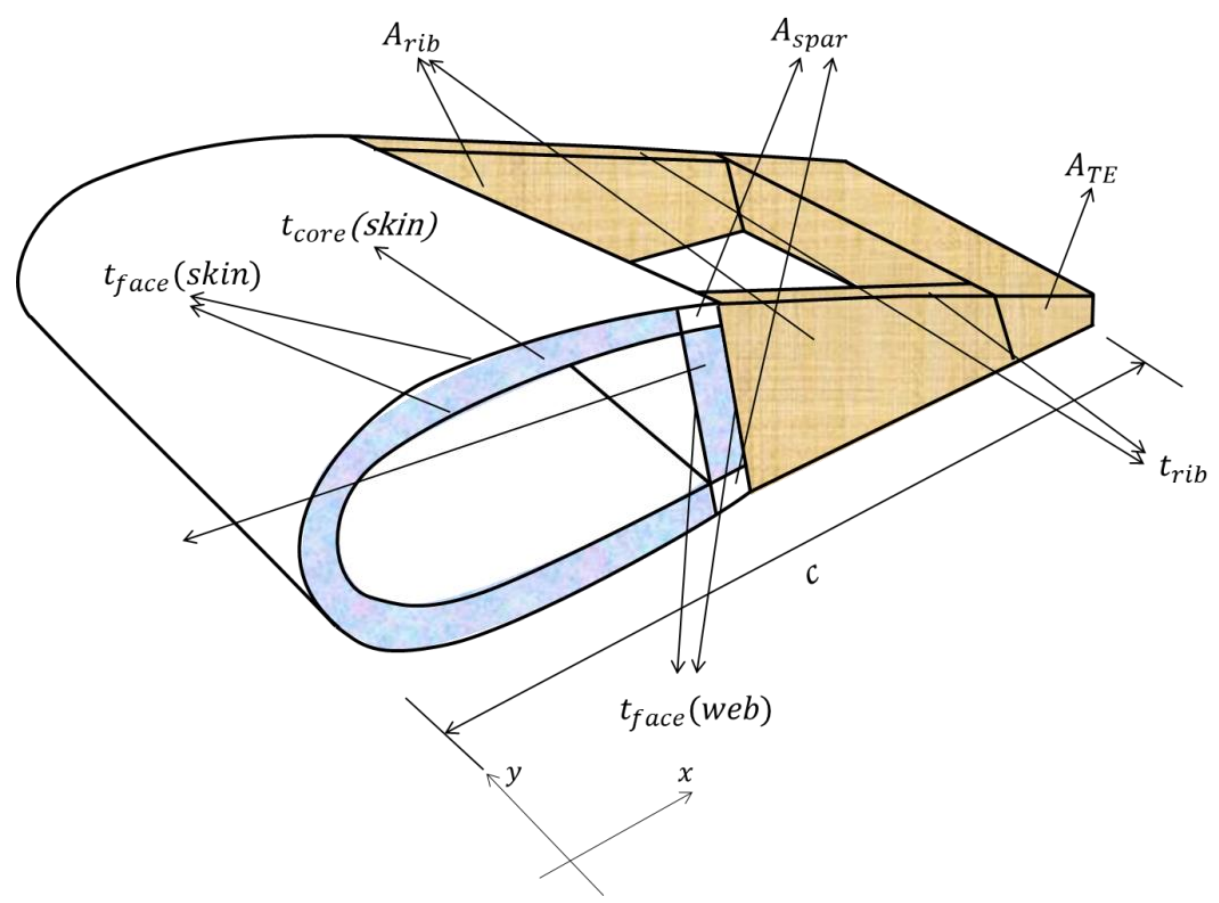

Figure 3.8 - D-box Wing Configuration. 
Similarly to the previous case, it is considered that the bending moment is resisted by the spar caps and the shear stress by the spar web. Thus, the equations presented above are also valid.

In this case, only the D-box resists to torque, being necessary the implementation of new equations. The side view is represented in Figure 3.9, where the D-box perimeter is represented in red.

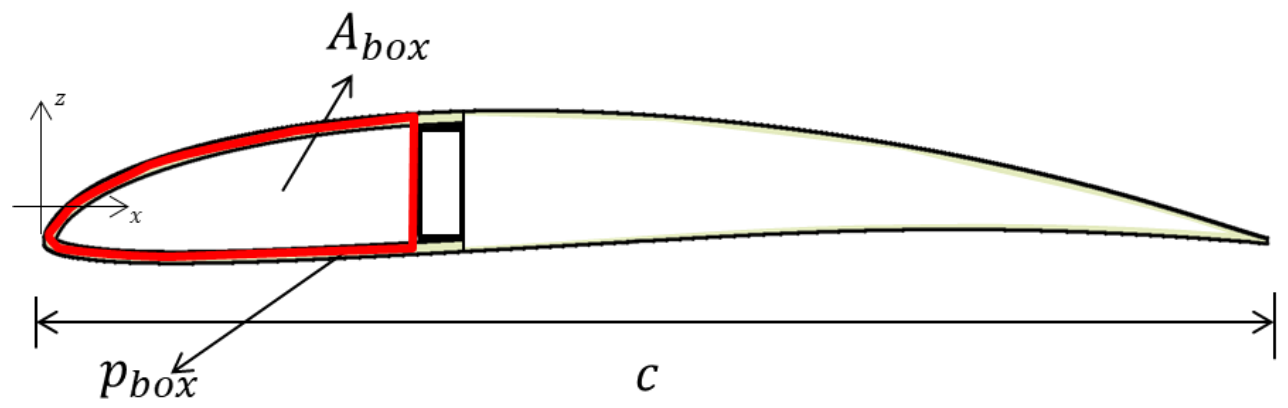

Figure 3.9 - D-box Wing Section.

The constants associated to the perimeter, $K_{b o x}$, and area, $K_{b o x_{2}}$, are:

$$
\begin{aligned}
K_{\text {box }} & =\frac{\left(\frac{p_{\text {box }}}{p_{\text {airfoil }}}\right) p_{\text {airfoil }}}{c} \\
K_{\text {box }_{2}} & =\frac{\left(\frac{A_{\text {box }}}{A_{\text {airfoil }}}\right) A_{\text {airfoil }}}{c^{2}\left(\frac{t}{c}\right)}
\end{aligned}
$$

where $p_{b o x}$ and $A_{b o x}$ are the D-box perimeter and cross-section area, respectively.

Again, there is a need for the structure to withstand the torque and a limitation for the tip wing twist is imposed. Initially, the following expressions are used:

$$
\begin{gathered}
T=2 A q \\
t=2 t_{\text {face }}
\end{gathered}
$$

Therefore, Eq. (3.46) (resulting torque from the aerodynamic load in half span), Eq. (3.50) (resulting shear flow in a section with a given thickness and subjected to shear stress) and Eq. 
(3.60) are substituted into Eq. (3.59) resulting in the following expression for the spar web thickness, required to resist to the torsion:

$$
t_{\text {face }}^{T}=\frac{\rho_{\text {air }} C_{m}}{16 K_{\text {box }} \tau_{\max }} \frac{V^{2} b}{\left(\frac{t}{c}\right)}
$$

For the twist case, according to the axes represented in Figure 3.8, the expressions for torsion in a single cell and Eq. (3.46) (resulting torque from the aerodynamic load in half span) are considered:

$$
\begin{gathered}
\frac{d \theta}{d y}=\frac{T}{G J} \\
G J=\frac{4 A_{b o x}^{2}}{\oint \frac{d s}{G t}} \\
\frac{d \theta}{d y}=\frac{\rho V^{2} b C_{m} K_{b o x}}{32 G K_{b o x_{2}}^{2} c\left(\frac{t}{c}\right)^{2} t_{\text {face }}}
\end{gathered}
$$

The required thickness is obtained from the simplification of Eq. (3.64), resulting in the following expression:

$$
t_{\text {face }}^{\theta}=\frac{\rho C_{m} K_{\text {box }}}{64 G K_{\text {box } 2}^{2} \theta_{\max }} \frac{V^{2} b^{2}}{c\left(\frac{t}{c}\right)^{2}}
$$

The final face thickness is the maximum value between the ones determined to withstand the torque, Eq. (3.61), and to guarantee the allowable wing tip twist, Eq. (3.65), and is given by the following expression:

$$
t_{\text {face }}=\max \left(t_{\text {face }}^{T} ; t_{\text {face }}^{\theta}\right)
$$

It is also needed to ensure that the ribs transmit the stresses and do not fail, being necessary the sizing that allows that this component resists the shear force in the rear region of the wing. The defined constants for the ribs are:

$$
K_{\text {rib }}=\frac{\left(\frac{A_{\text {rib }}}{A_{\text {airfoil }}}\right) A_{\text {airfoil }}}{c^{2}\left(\frac{t}{c}\right)}
$$




$$
K_{r i b_{2}}=\frac{l_{r i b}}{c}
$$

where $A_{\text {rib }}$ is the area and $l_{\text {rib }}$ is the length of the rib.

Initially, the following lift simplified distribution along the chord, represented in Figure 3.10, is considered, from which the respective load is determined:

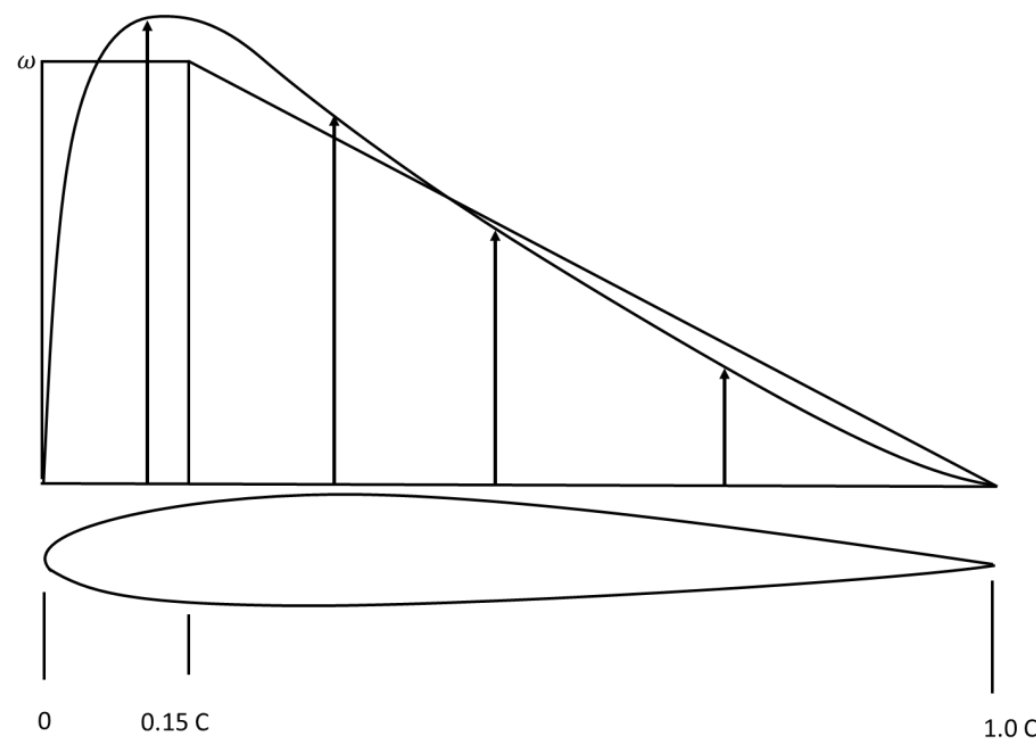

Figure 3.10 - Real and Approximate Airfoil Lift Distribution [1].

Based on to the axes represented in Figure 3.9 and from the integration of the lift along the cord it is possible to determine the load distribution value, $\omega$ :

$$
\begin{gathered}
L=2 \int_{0}^{\frac{b}{2}} \int_{0}^{c} p(x) d x d z \\
n W=2 \frac{b}{2} \int_{0}^{c} p(x) d x \\
\int_{0}^{c} p(x) d x=0,15 c \omega+\frac{0,85 c \omega}{2} \\
\omega=\frac{40}{23} \frac{n W}{b c}
\end{gathered}
$$

Based on that, the maximum shear force, $S_{z}^{\prime}$, located in the spar region is determined by integrating the distributed load from the trailing edge to the spar, resulting in the total force applied in the rib region, resulting in the following equation: 


$$
S_{z}^{\prime}=\frac{l_{\text {rib }} \frac{l_{\text {rib }}}{0,85 c} \omega}{2}
$$

Substituting Eq. (3.68) and Eq. (3.72) into Eq. (3.73), the shear force is simplified.

$$
S_{z}^{\prime}=\frac{400}{391} \frac{K_{r i b_{2}}^{2} n W}{b}
$$

The shear stress expression is:

$$
\tau=\frac{3}{2} \frac{S_{z}^{\prime} / n_{r i b}}{t_{r i b} c\left(\frac{t}{c}\right)}
$$

where $n_{\text {rib }}$ is the number of ribs.

Finally, the product of the ribs thickness by its total number is obtained from the substitution of Eq. (3.74) into Eq. (3.75):

$$
t_{r i b} n_{r i b}=\frac{600}{391} \frac{K_{r i b_{2}}^{2}}{\tau_{\max }} \frac{n W}{c b\left(\frac{t}{c}\right)}
$$

The mass of the trailing edge, $m_{T E}$, is given by:

$$
m_{T E}=K_{T E} c^{2}\left(\frac{t}{c}\right) b \rho_{\text {balsa }}
$$

where $\rho_{\text {balsa }}$ is the balsa density and the trailing edge coefficient, $K_{T E}$, is calculated as follows:

$$
K_{T E}=\frac{\left(\frac{A_{T E}}{A_{\text {airfoil }}}\right) A_{\text {airfoil }}}{c^{2}\left(\frac{t}{c}\right)}
$$

where $A_{T E}$ is the trailing edge side area.

The balsa wood mass is determined by adding the ribs and trailing edge masses. 
The core foam mass is determined from a thickness value deemed suitable by the user.

$$
m_{\text {core }}=t_{\text {core }} b p_{\text {box }} \rho_{\text {core }}
$$

The final mass might be determined using specified values for spar cap and web thicknesses, as previously.

\subsubsection{Tube Spar Wing Configuration}

In this last configuration, illustrated in Figure 3.11., the wing is composed by a circular thinwalled section spar, with ribs to transmit the stresses and support the covering film, to provide the desired airfoil shape, with reinforcements in the leading and trailing edges made of balsa wood.

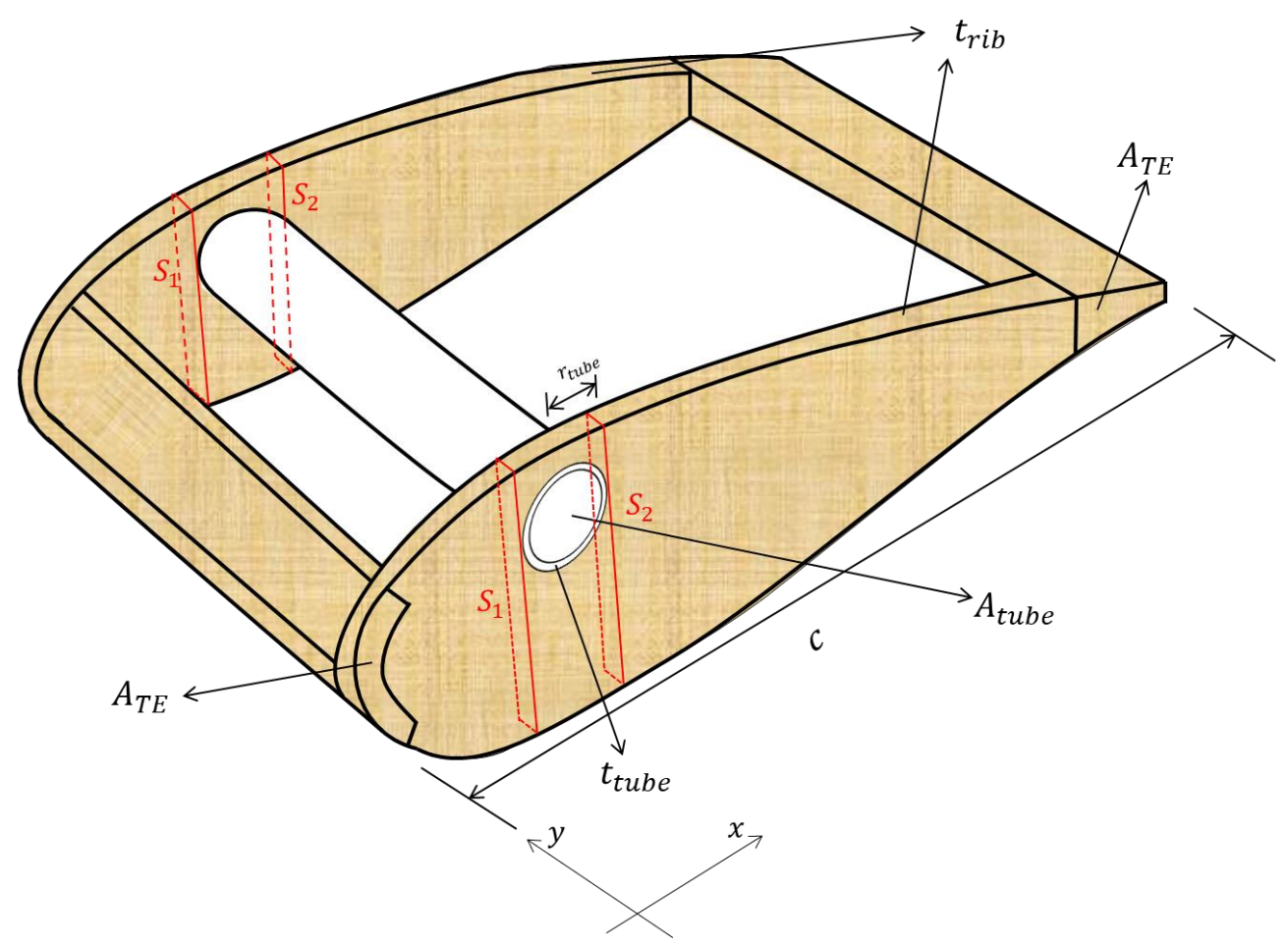

Figure 3.11 - Tube Spar Wing Configuration.

Instead of the presented so far, where the loads were divided by the different wing parts, in this situation, the required tube thickness is calculated to resist bending, shear and torsion, being, the final result, the sum of all individual thicknesses obtained for the above mentioned stresses.

For the necessary calculations, the following constant is determined from known data:

$$
K_{\text {tube }}=\frac{r_{\text {tube }}}{c}
$$


where $r_{\text {tube }}$ is the tube radius.

The second moment of area is given by the following simplified expression for thin tubes:

$$
I_{x x}=\pi r_{\text {tube }}^{3} t_{\text {tube }}
$$

where $t_{\text {tube }}$ is the tube thickness.

As previously, the same simplification on the lift is assumed for the calculation of the bending moment. The required thickness is determined by the critical case when comparing the results for the bending moment (in flight and ground test) and the tip deflection.

Initially, based on the axes represented in Figure 3.11, the following expression is considered to determine the normal stress:

$$
\sigma_{y}=\frac{M_{x} r_{t u b e}}{I_{x x}}
$$

Substituting Eq. (3.21) (bending moment), Eq. (3.81) and Eq. (3.80) into Eq. (3.82), the required tube thickness is given by the following expression:

$$
t_{\text {tube }}^{M f l}=\frac{1}{8 \pi K_{\text {tube }}^{2} \sigma_{y_{\max }}} \frac{n W b}{c^{2}}
$$

For the ground test, the same process is implemented with the difference that Eq. (3.24) (bending moment with concentrated load applied on the wing tip) is considered instead of Eq. (3.21), for the bending moment determination, resulting in:

$$
t_{\text {tube }}^{M g t}=\frac{1}{4 \pi K_{\text {tube }}^{2} \sigma_{y_{\max }}} \frac{W b}{c^{2}\left(\frac{t}{c}\right)^{2}}
$$

The thicknesses for the remaining sections are determined based on the assumption that it varies with the span squared:

$$
t_{\text {tube }_{i}}=\left(\frac{b-\Delta y_{i}}{b}\right)^{2} t_{\text {tube }_{1}}
$$

In the deflection case, assuming that thickness varies with the span squared and considering Eq. (3.27) to Eq. (3.31) (deflection simplifications) and Eq. (3.81) and substituting into Eq. (3.26), the following expression for the tip deflection is obtained: 


$$
\delta_{\text {tip }}=\frac{n W}{192 E b \pi r_{\text {tube }}^{3} t_{\text {tube }}}\left(2 b^{4}+4 b^{3} \Delta y_{1}-15 \Delta y_{1}^{2}+14 b \Delta y_{1}^{3}-3 \Delta y_{1}^{4}\right)
$$

Rearranging Eq. (3.86), the required tube thickness is given by:

$$
t_{\text {tube }}^{\delta}=\frac{1}{192 E \pi \delta_{\text {tip }}} \frac{n W}{b r_{\text {tube }}^{3}}\left(2 b^{4}+4 b^{3} \Delta y_{1}-15 \Delta y_{1}^{2}+14 b \Delta y_{1}^{3}-3 \Delta y_{1}^{4}\right)
$$

As before, the thicknesses for the remaining sections are determined, based on the assumption that it varies with the span squared, from Eq. (3.81).

The expression for the shear stress is similar to the one obtained for the previous configurations, having an obvious change in the form of tube section area, $A_{\text {tube }}$ :

$$
\begin{aligned}
A_{\text {tube }} & =2 \pi r_{\text {tube }} t_{\text {tube }} \\
\tau & =\frac{3}{2} \frac{S_{z}}{A_{\text {tube }}}
\end{aligned}
$$

Substituting the expression for the shear force, Eq. (3.36), into Eq. (3.89), the shear stress results in:

$$
\tau=\frac{3 n W}{8 \pi K_{\text {tube }} c t_{\text {tube }}}
$$

Rearranging Eq. (3.90) the required tube thickness is:

$$
t_{\text {tube }}^{\tau f l}=\frac{3}{8 \pi K_{\text {tube }} \tau_{\max }} \frac{n W}{c}
$$

For the ground test, once again, the load factor is removed from Eq. (3.91):

$$
t_{\text {tube }}^{\tau g t}=\frac{3}{8 \pi K_{\text {tube }} \tau_{\max }} \frac{W}{c}
$$

As before, for flight, the shear stress is maximum at the root and null at the tip. On the ground it is constant along the wingspan. 
Regarding the torsion load bearing structure:

The circle area of the tube is given by the following equation:

$$
A=\pi r_{\text {tube }}^{2}
$$

The expressions used for the torque and shear flow are identical to those of the D-box, Eq. (3.46) (torque resulting from the aerodynamic load in half span), Eq. (3.59) (torque resulting from the shear flow) and Eq. (3.50) (shear flow), with Eq. (3.93) being used for the area, resulting in the required thickness to withstand the torque:

$$
t_{\text {tube }}^{T}=\frac{\rho C_{m}}{8 \pi K_{\text {tube }}^{2} \tau_{\max }} V^{2} b
$$

For the twist case, once again, the difference is the area calculation, determined from Eq. (3.93), being used Eq. (3.62) to determine the twist ratio and Eq. (3.46) to determine the torque, resulting in these expressions:

$$
\begin{aligned}
& G J=2 \pi K_{\text {tube }}^{3} c^{3} G t_{\text {tube }} \\
& \frac{d \theta}{d y}=\frac{\rho V^{2} b C_{m}}{8 \pi G K_{\text {tube }}^{3} c t_{\text {ube }}}
\end{aligned}
$$

From Eq. (3.96), the required tube thickness is obtained:

$$
t_{\text {tube }}^{\theta}=\frac{\rho C_{m}}{8 \pi G K_{\text {tube }}^{3} \theta_{\text {max }}} \frac{V^{2} b^{2}}{c}
$$

The final tube thickness results from the sum of all individual thicknesses, required to withstand the bending moment (Eq. (3.83), Eq. (3.84) and Eq. (3.87)), the shear stress (Eq. (3.91) and Eq. (3.92)) and the torsion (Eq. (3.94) and Eq. (3.97)). For each stress, the maximum value, among the ones calculated for each limiting criteria, is considered. The expression for the tube thickness is:

$$
t_{\text {tube }}=\max \left(t_{\text {tube }}^{M f l} ; t_{\text {tube }}^{M g t} ; t_{\text {tube }}^{\delta}\right)+\max \left(t_{\text {tube }}^{\tau f l} ; t_{\text {tube }}^{\tau g t}\right)+\max \left(t_{\text {tube }}^{T} ; t_{\text {tube }}^{\theta}\right)
$$


This value might be indicated by the user in order to ensure a viable value from which the mass of the component is determined.

Once again, sizing the ribs is required. In this situation, it has been determined that the maximum shear is located in positions $S_{1}$ and $S_{2}$, indicated in Figure 3.11 .

The following calculations demonstrate the shear in those positions, assuming that spar is located at $30 \%$ of the chord.

$$
\begin{gathered}
S_{1}=0,15 c \omega+\frac{\omega+\frac{0,7 c}{0,85 c} \omega}{2} 0,15 c \approx 0,3 \omega c \\
S_{2}=\frac{0,7 c \frac{0,7 c}{0,85 c} \omega}{2} \approx 0,3 \omega c
\end{gathered}
$$

Based on that, it is possible to assume that the shear force value is, approximately, identical in positions $S_{1}$ and $S_{2}$. The shear force is then simplified such as determined in the previous demonstrations:

$$
S_{z}^{\prime}=0,3 \omega c
$$

Using the equation determined in the previous section, for the distributed load, Eq. (3.72) and considering Eq. (3.99) for the shear force, substituting into Eq. (3.75), the shear stress is obtained. Rearranging the resulting equation, the product of the rib thickness by the total number of ribs is determined:

$$
t_{\text {rib }} n_{\text {rib }}=\frac{36}{23 \tau_{x y_{\max }}} \frac{n W}{c\left(\frac{t}{c}\right) b}
$$

The leading and trailing edges masses are determined as follows:

$$
m_{L E / T E}=K_{L E / T E} c^{2}\left(\frac{t}{c}\right) b \rho_{\text {balsa }}
$$

and the respective coefficients are:

$$
K_{T E}=\frac{\left(\frac{A_{T E}}{A_{\text {airfoil }}}\right) A_{\text {airfoil }}}{c^{2}\left(\frac{t}{c}\right)}
$$




$$
K_{L E}=\frac{\left(\frac{A_{L E}}{A_{\text {airfoil }}}\right) A_{\text {airfoil }}}{c^{2}\left(\frac{t}{c}\right)}
$$

where $A_{L E}$ is the leading edge area.

\subsubsection{Tail Boom Tube}

This component is used to connect the tail to the remaining airplane and provide the required length between the wing and the tail and, subsequently, the necessary stability. It is made of CFRP and it is attached to the cargo bay or the rest of the fuselage that supports the wing, as previously described. An example of the first case can be observed in Figure 3.12.

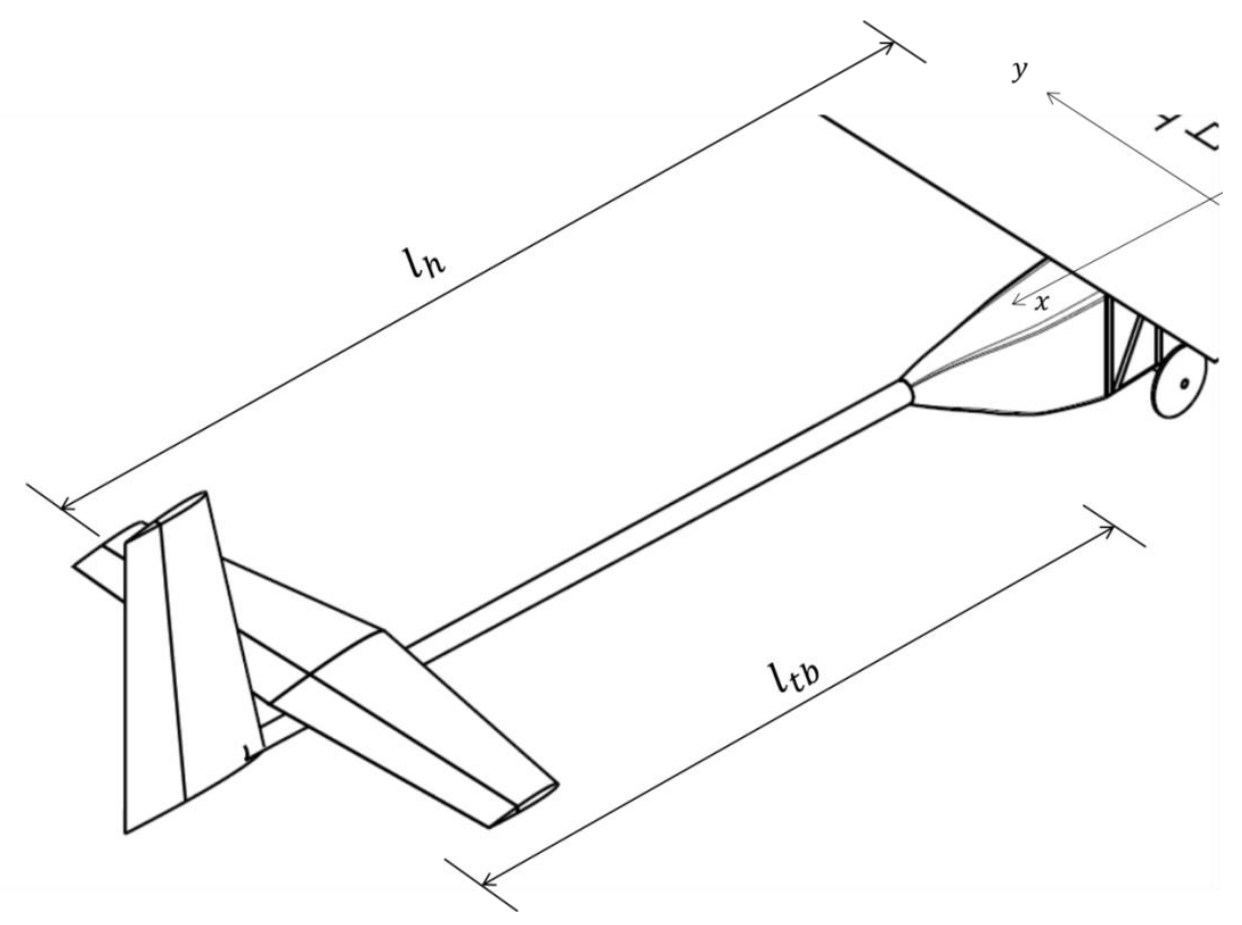

Figure 3.12 - Tail Boom [23].

The determination of the tail boom mass is independent of the wing configuration. For this component it is considered that it is necessary to resist the load applied at the tail and the need to have a limitation on the tail rotation. Based on that, it is necessary to calculate the lift force on the horizontal tail and the resulting bending moment. To do so, the following constants are determined:

$$
\begin{gathered}
K_{h}=\frac{\left(\frac{l_{h}}{b}\right) b}{c} \\
K_{t b}=\frac{\left(\frac{l_{t b}}{b}\right) b}{c}
\end{gathered}
$$


where $l_{h}$ is the arm between the wing and horizontal tail aerodynamic centers and $l_{t b}$ is the tail boom length.

The horizontal tail lift is obtained from known data. That is done based on the need to balance the wing pitching moment with the horizontal tail moment, resulting in the following expressions:

$$
\begin{gathered}
T=l_{h} L_{h} \\
T=\frac{1}{2} \rho V^{2} b c^{2} C_{m} \\
L_{h}=\frac{1}{2} \rho V^{2} S_{h} C_{L_{h}} \\
C_{L_{h}}=\frac{b c C_{m}}{S_{h} K_{h}}
\end{gathered}
$$

where $L_{h}$ is the lift, $S_{h}$ is the area, $C_{L_{h}}$ is the lift coefficient, all related to the horizontal tail.

The resulting bending moment and normal stress are determined once the lift is calculated, from Eq. (3.108). The second moment of area expression, based on the axes represented in Figure 3.12 , considered is the one simplified for thin tubes.

$$
\begin{gathered}
M_{y}=L_{h} l_{t b} \\
I_{y y}=\pi r_{t b}^{3} t_{t b} \\
\sigma_{x}=\frac{M_{y} l_{t b}}{I_{y y}}
\end{gathered}
$$

where $r_{t b}$ is the tail boom radius and $t_{t b}$ is the tail boom tube wall thickness.

The required tail boom thickness, $t_{t b}$, is obtained after the resulting bending moment is determined, substituting Eq. (3.110) and Eq. (3.111) into Eq. (3.112), and based on the tube radius defined:

$$
t_{t b}^{M}=\frac{\rho C_{m} K_{t b}}{2 K_{h} \pi r_{t b}^{2} \sigma_{x_{\max }}} b c^{2} V^{2}
$$

The tail boom tip rotation is given from the following expression: 


$$
\theta=\frac{L_{h} l_{t b}^{2}}{2 E I_{y y}}
$$

Substituting Eq. (3.104) and Eq. (3.109) into Eq. (3.113), the lift in the horizontal tail is:

$$
L_{h}=\frac{\rho V^{2} c b C_{m}}{2 K_{h}}
$$

Substituting Eq. (3.109), Eq. (3.115) and Eq. (3.111) into Eq. (3.114), the rotation is given as:

$$
\theta=\frac{\rho V^{2} c b C_{m} l_{t b}^{2}}{4 K_{h} E \pi r_{t b}^{3} t_{t b}}
$$

The required tail boom thickness is determined from rearranging Eq. (3.116), resulting in the following expression:

$$
t_{t b}^{\theta}=\frac{\rho C_{m} K_{t b}^{2}}{4 \pi E r_{t b}^{3} K_{h} \theta_{\max }} c^{3} b V^{2}
$$

The final tube thickness is maximum value between the ones calculated to withstand the bending moment, Eq. (3.113), and to guarantee the tail rotation, Eq. (3.117), and is given by:

$$
t_{t b}=\max \left(t_{t b}^{M} ; t_{t b}^{\theta}\right)
$$

So that the thickness used to determine the mass adopts a real value and the resulting tube is available in the market, it might be defined by the user.

\subsubsection{Remaining Components}

To determine the total mass of the aircraft it is necessary to know the mass of the remaining components.

Like in previous sections, the airplane is divided into wing, vertical and horizontal tails, fuselage (in this case the fuselage is comprised of the cargo bay and the tail boom), systems, landing gear and payload.

Since the mass of the wing is determined previously, in the horizontal and vertical tails cases, correction factors and the ratio between the tails areas and the wing area are used, to determine their masses. 


$$
\begin{aligned}
& m_{V T}=c f_{V T} \frac{S_{V T}}{S_{w}} m_{\text {wing }} \\
& m_{H T}=c f_{H T} \frac{S_{H T}}{S_{w}} m_{\text {wing }}
\end{aligned}
$$

where $S_{V T}, S_{H T}$ and $S_{w}$ are vertical tail, horizontal tail and wing areas, respectively.

The value of the correction factors, $c f_{H T}$ and $c f_{V T}$, are selected based on existing similar aircraft data, with the objective to approximate the obtained values to the reality.

The cargo bay mass is determined from the surface area, the wall thickness and the material density defined for this component.

$$
m_{C B}=S_{\text {wet }} t_{\text {wall }} \rho_{\text {material }}
$$

where $S_{\text {wet }}$ is the cargo bay surface area, $t_{\text {wall }}$ is the cargo bay wall thickness and $\rho_{\text {material }}$ is the density of the material used in this structure.

As previously referred, the fuselage is comprised of the cargo bay and the tail boom. The fuselage mass, $m_{f u s}$, results from the sum of the tail boom and cargo bay masses determined earlier.

$$
m_{f u s}=m_{C B}+m_{t b}
$$

The landing gear structure depends on the airplane, so its mass is considered to be a function of the empty airplane mass.

$$
m_{L G}=\frac{m_{L G}}{m_{\text {empty }}} m_{\text {empty }}
$$

The ratio between the masses is also adjusted based on the known data to match the reality.

The systems and payload masses are defined directly by the user, based on the experience and/or requirements of the competition.

The empty and total masses are given by:

$$
\begin{gathered}
m_{\text {empty }}=m_{\text {wing }}+m_{H T}+m_{V T}+m_{f u s}+m_{\text {syst }}+m_{L G} \\
m=m_{\text {empty }}+m_{\text {payload }}
\end{gathered}
$$


It is possible to verify that components' mass depend on others, making the determination of the empty and total aircraft masses an iterative process. 


\section{Results and Discussion}

In this chapter, the equations, resulting from the implementation of the described methods in chapter 3 , and the respective graphs, containing the comparison between the calculated and real masses, are presented. Along with that, the results, the error associated to each mass model, the accuracy and the validity are discussed.

\subsection{Statistical Models}

The data used to obtain the required equations was collected from available reports of several participating teams. The payload masses used to develop the models are the ones estimated in the reports, which are elaborated before the competition takes place. It was necessary to analyse the information provided in each one of these reports and the ones considered to this study are presented in Table 4.1.

Table 4.1 - Teams with Reports Considered.

\begin{tabular}{|c|c|c|c|}
\hline Edition & 2007 & 2009 & 2011 \\
\hline Teams & PEGASUS II [24] & $\begin{array}{c}\text { KELAYNAK [25] } \\
\text { LUSOFLY [26] } \\
\text { TUHeavy [27] } \\
\text { INFINIteam [28] } \\
\text { TRENCÀLOS [29] } \\
\text { AKAMOdellO9 [30] } \\
\text { SONICKIDS [31] } \\
\text { COLIBRI [32] }\end{array}$ & Portugal Team [5] \\
\hline Edition & 2013 & 2015 & 2017 \\
\hline Teams & $\begin{array}{c}\text { Anatolian [33] } \\
\text { ATLAS III B [34] } \\
\text { ATLAS IV [35] } \\
\text { LUSITÂNIA [36] } \\
\text { PHOENIX [37] } \\
\text { Rzeszów [38] } \\
\text { Juliett [39] } \\
\text { AKAModell13 [4] } \\
\text { GRAVITY [40] } \\
\text { LIFT [41] }\end{array}$ & AERO@UBI_Team [42] & $\begin{array}{l}\text { AERO@UBI_MARS [23] } \\
\text { AERO@UBI_PVG [43] }\end{array}$ \\
\hline
\end{tabular}

\subsubsection{General Mass Models}

The data collected from the reports and used in this study is summarized in Table 4.2: 
Table 4.2 - Data Collected from the Reports.

\begin{tabular}{|c|c|c|c|c|c|}
\hline Aircraft & $\mathrm{b}[\mathrm{m}]$ & $c[\mathrm{~m}]$ & Empty Mass [kg] & Payload [kg] & Total Mass [kg] \\
\hline AERO@UBI_PVG & 4 & 0.328 & 3.498 & 10 & 13.498 \\
\hline AERO@UBI_MARS & 4.261 & 0.2593 & 4.302 & 10 & 14.302 \\
\hline AERO@UBI_Team & 3.32 & 0.3316 & 1.892 & 10 & 11.892 \\
\hline Anatolian & 2.8 & 0.22 & 1.8568 & 8.9 & 10.7568 \\
\hline ATLAS III B & 3 & 0.3 & 2.700 & 8.5 & 11.200 \\
\hline ATLAS IV & 4.56 & 0.3618 & 3.501 & 10.5 & 14.001 \\
\hline LUSITÂNIA & 4.8 & 0.3125 & 6.000 & 8 & 14.000 \\
\hline PHOENIX & 5.8 & 0.3693 & 3.500 & 12 & 15.500 \\
\hline Rzeszów & 3.954 & 0.3844 & 4.800 & 11 & 15.800 \\
\hline Juliett & 3.9 & 0.3205 & 2.142 & 10 & 12.142 \\
\hline AKAModell13 & 4.5 & .3212 & 2.992 & 12 & 14.992 \\
\hline GRAVITY & 4.74 & 0.3131 & 2.400 & 11 & 13.400 \\
\hline LIFT & 4.74 & 0.3131 & 2.385 & 11 & 13.385 \\
\hline Portugal Team & 4.2 & 0.3236 & 1.793 & 11 & 12.793 \\
\hline PEGASUS II & 1.6 & 0.35 & 2.0295 & 7 & 9.0295 \\
\hline KELAYNAK & 2.13 & 0.2798 & 4.084 & 5.196 & 9.280 \\
\hline LUSOFLY & 2.6 & 0.2115 & 2.915 & 8 & 10.915 \\
\hline TUHeavy & 3.2 & 0.1905 & 2.050 & 9 & 11.050 \\
\hline INFINIteam & 3.1 & 0.1835 & 2.449 & 7 & 9.449 \\
\hline TRENCÀLOS & 3 & 0.2 & 1.900 & 7 & 8.900 \\
\hline AKAModel09 & 2.56 & 0.2257 & 2.200 & 9 & 11.200 \\
\hline SONICKIDS & 1.72 & 0.3052 & 1.950 & 7.84 & 9.790 \\
\hline COLIBRI & 1.68 & 0.3095 & 2.181 & 7 & 9.181 \\
\hline
\end{tabular}

Based on the data collected from the reports, using Eq. (3.4) and fitting the coefficients, the equation obtained is the following:

$$
m=672.8 b^{0.264} c^{0.200} m_{\text {pay }}^{0.307}
$$

The plot obtained, based on Eq. (4.1), comparing the report's estimated masses and real masses is presented in Figure 4.1. 


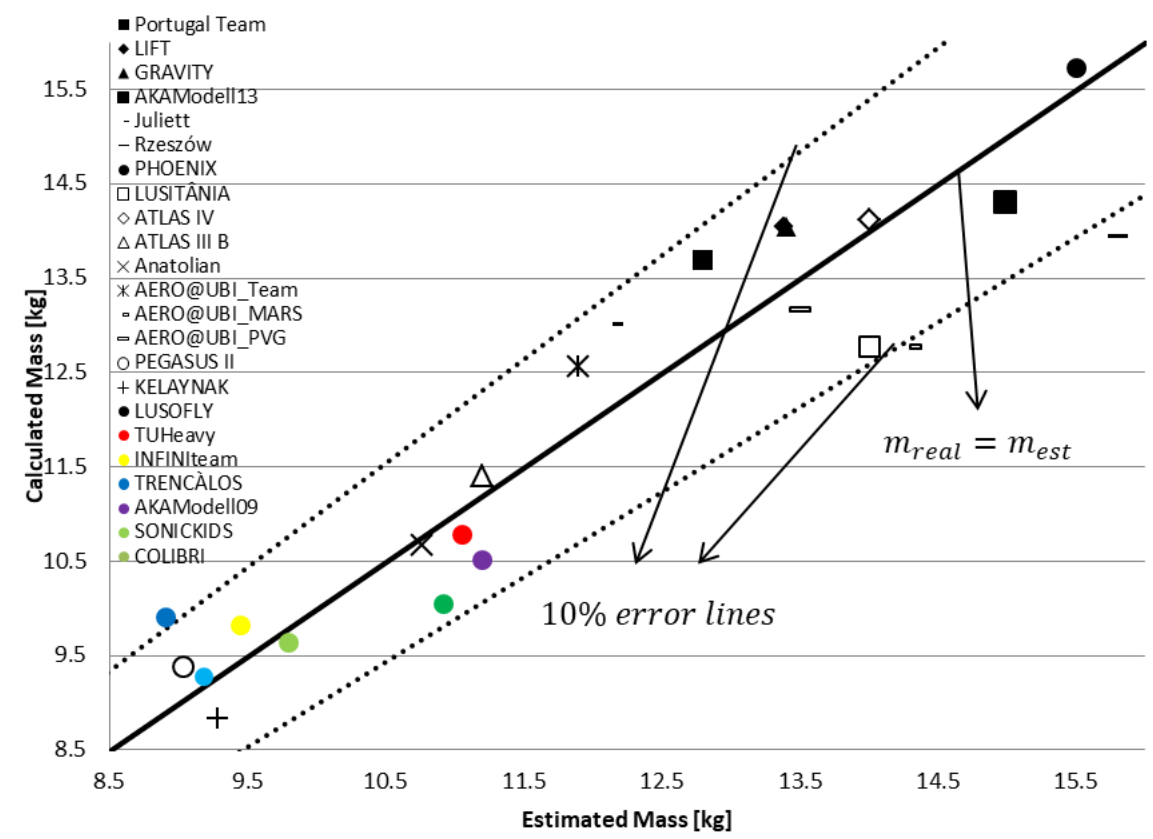

Figure 4.1 - General Mass Model.

For the results obtained, the maximum error is inferior to $12 \%$ and the average is $5 \%$, which can be verified in Figure 4.1. The coefficient of determination for the fitting is 0.871 .

Based on the total mass obtained, the empty mass was calculated, by subtracting the payload, associated to each airplane. The maximum error increases to over $50 \%$ and the average is situated at $22 \%$. This expected increase in the error might be explained by the variation of the size and the type of structure used, in the different airplanes. The fact that the payload masses used are estimations, might also contribute to the errors obtained.

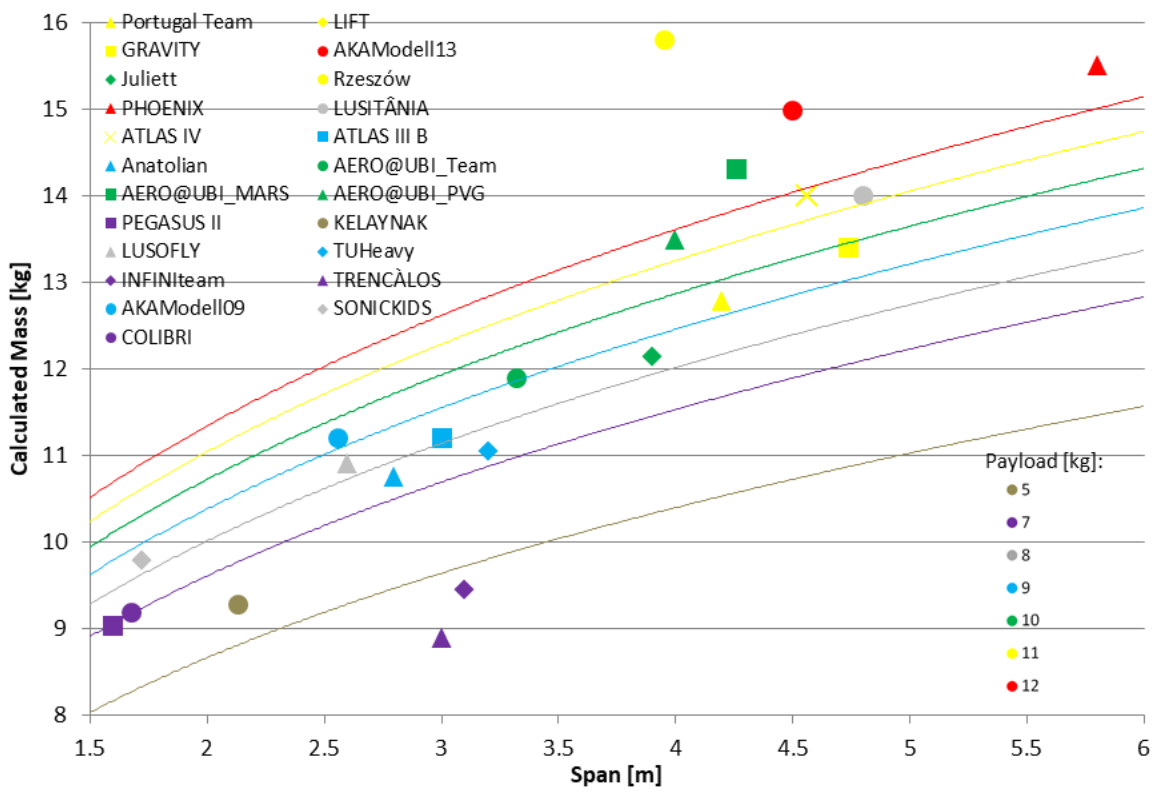

Figure 4.2 - General Mass Model - Fixed Payloads. 
In order to identify the influence of each parameter in the final result, the plots for fixed payloads, chords and spans, are represented in Figure 4.2, Figure 4.3 and Figure 4.4, respectively.

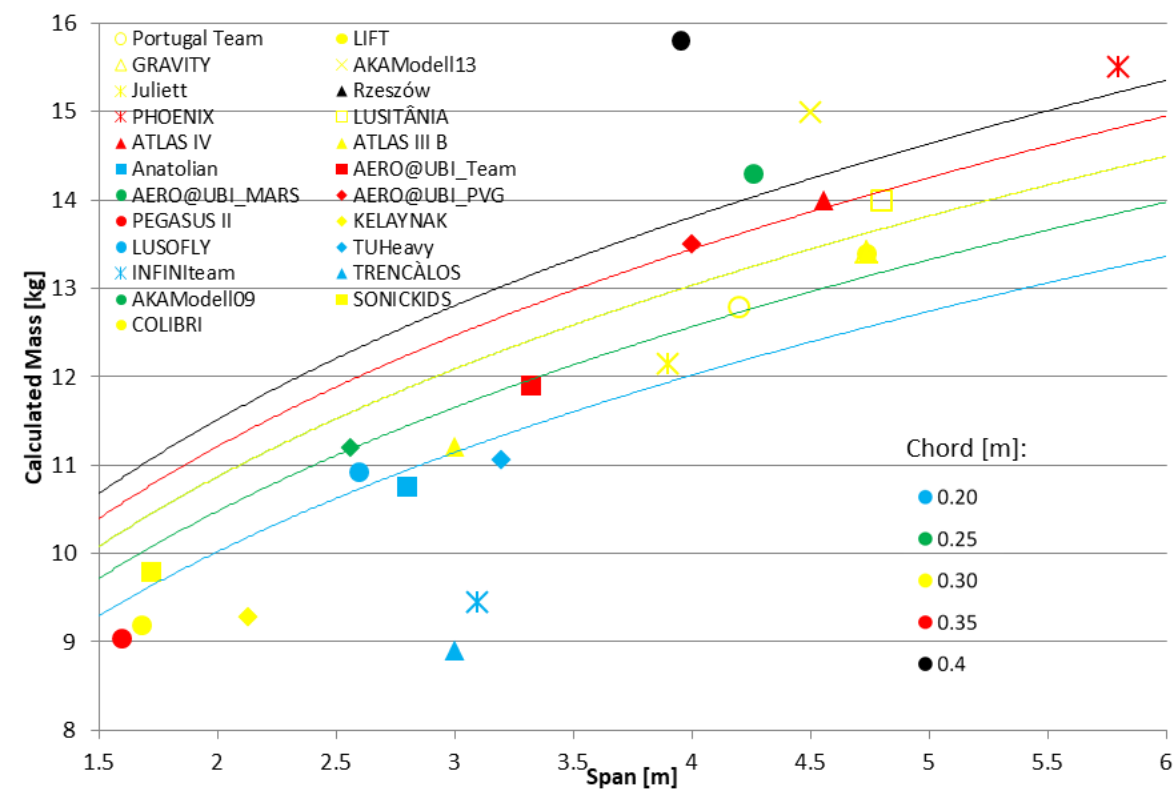

Figure 4.3 - General Mass Model - Fixed Chords.

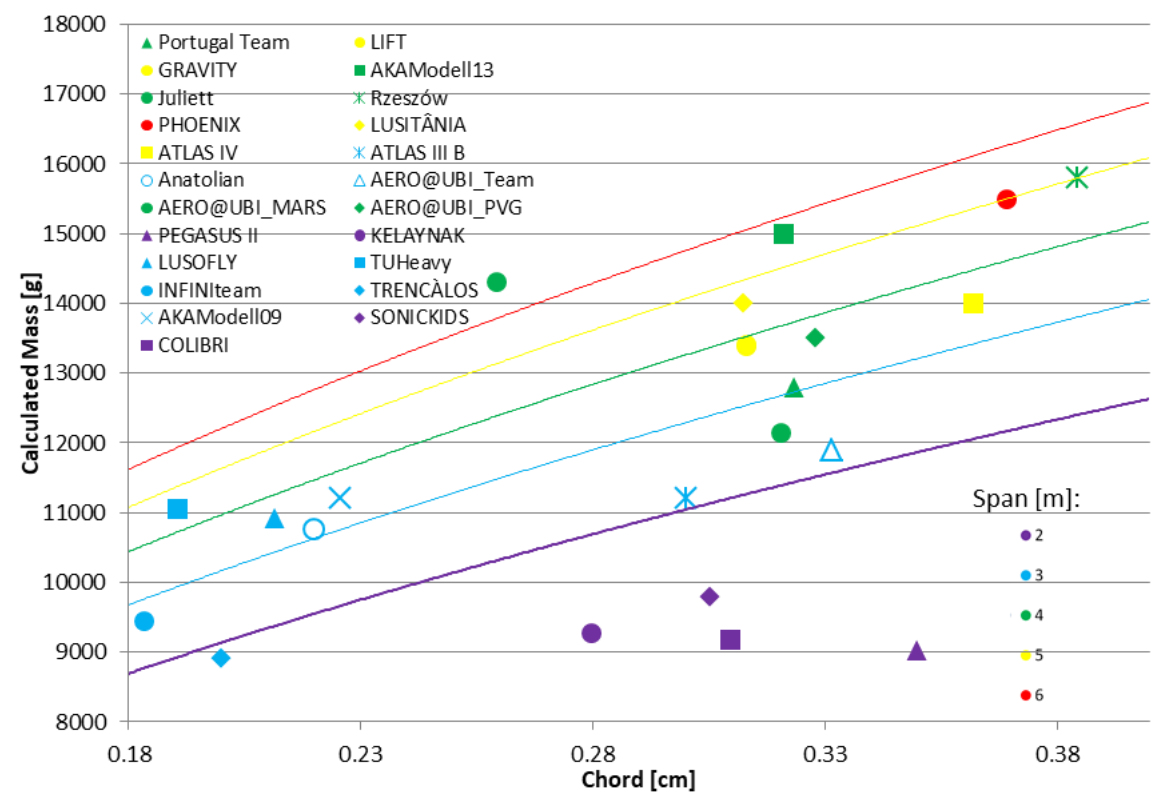

Figure 4.4 - General Mass Model - Fixed Spans.

In these graphs it is possible to verify the proximity of the points to the corresponding line, however, as previously, some estimated airplanes' masses diverge from the equation. Based on the observation of the results, it was considered the hypothesis of dividing the airplanes in two groups. The ones over $13 \mathrm{~kg}$ and with an error over $5 \%$ are allocated to one group, since it 
has been verified that the influence of these airplanes on the final result was quite considerable, and the remaining aircraft in the other. Implementing the same method as before, based on Eq. (3.4), the obtained equations for both groups are:

$$
\begin{gathered}
m=68389 b^{-0.665} c^{0.115} m_{\text {pay }}^{-0.0425} \\
m=1240 b^{0.280} c^{0.152} m_{p a y}^{0.230}
\end{gathered}
$$

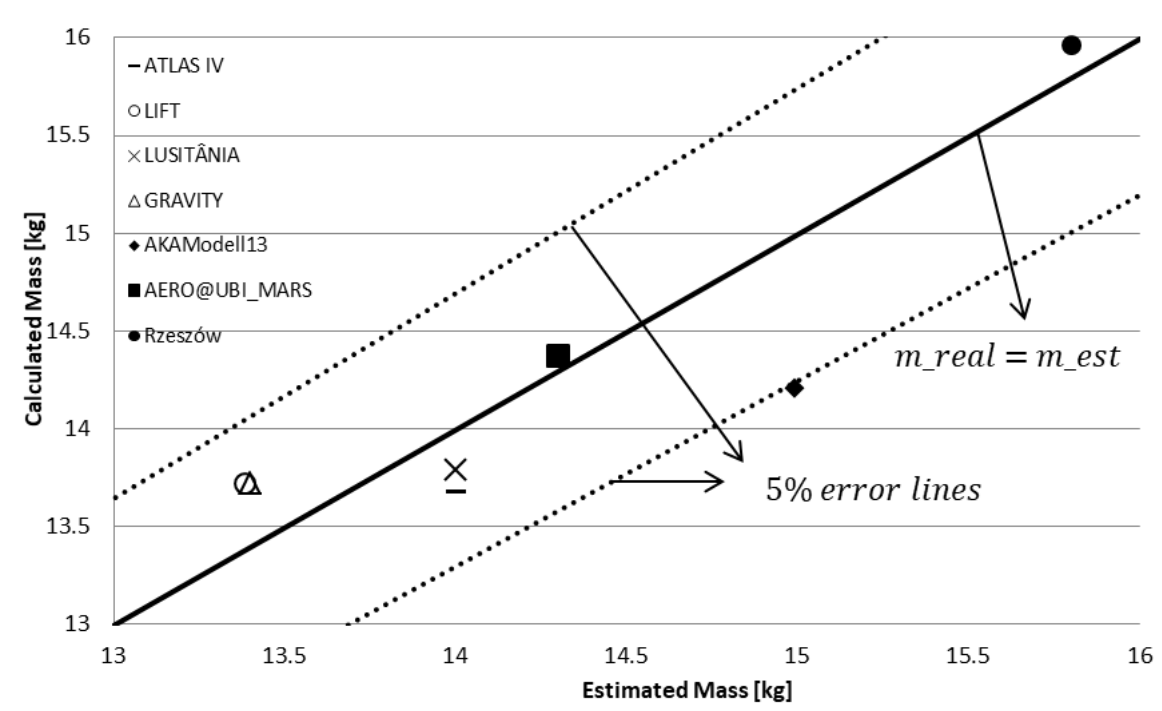

Figure 4.5 - General Mass Model - Group I.

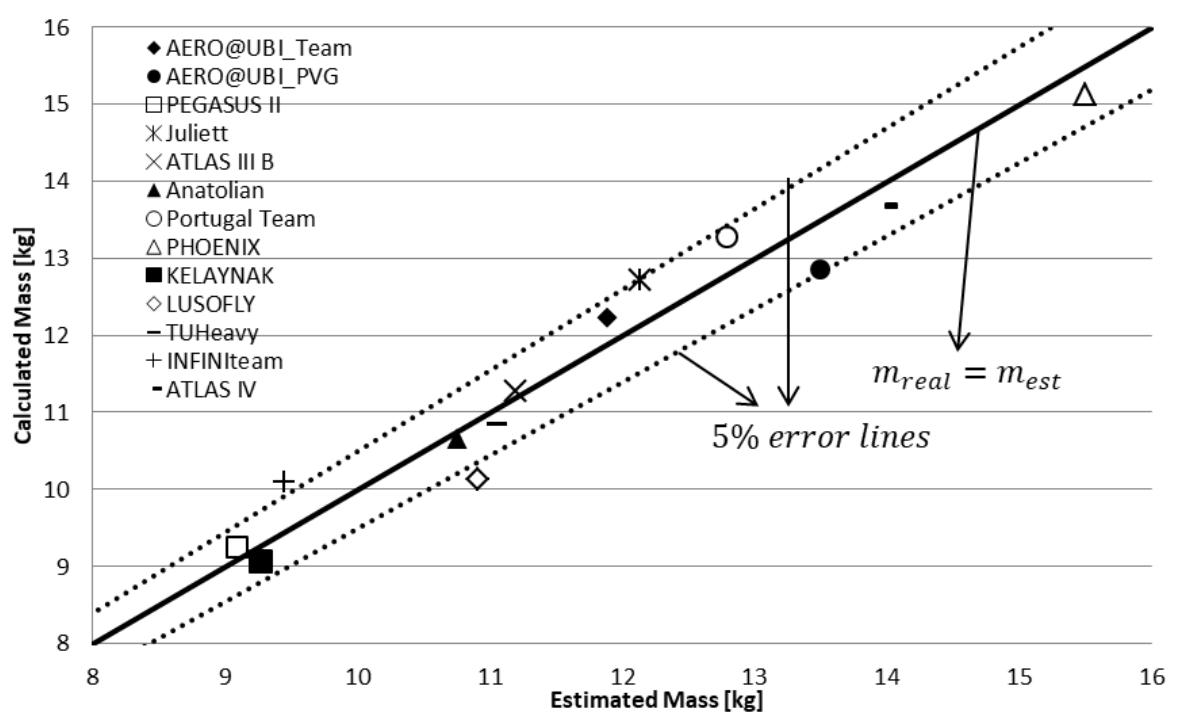

Figure 4.6 - General Model - Group II. 
The coefficients obtained for the equation of the first group have a very different magnitude, as expected. For the other group, the coefficients are quite similar. In Figure 4.5 and Figure 4.6, the plots resulting from Eq. (4.2) and Eq. (4.3), respectively, and the 5\% error lines are represented.

For the total mass of the first group, the maximum error is $5.3 \%$, the average is $2.2 \%$ and the coefficient of determination is 0.996 . Regarding the empty mass, the maximum error is $26 \%$ and the average is $10 \%$.

For the total mass of the second group, the maximum error is $7.3 \%$, the average is $3.3 \%$ and the coefficient of determination is 0.943 . For the empty mass, the maximum error is $27 \%$ and the average is $15 \%$.

In Figure 4.7 and Figure 4.8 the constant payload lines for each group and the airplanes with the corresponding colour associated with that specific payload are presented.

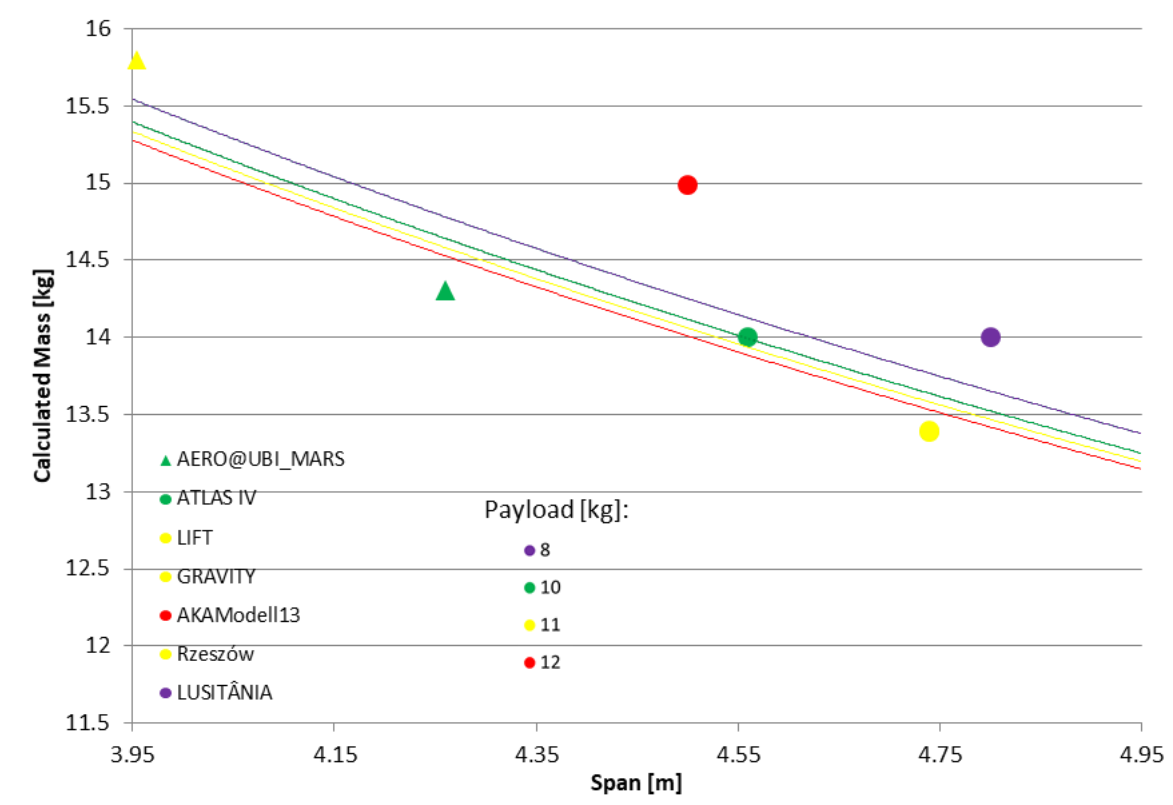

Figure 4.7 - General Mass Model - Fixed Payloads (Group I).

As previously, the points are close to the respective lines. However, it is possible to affirm that the model developed for the group I is not adjusted. That is justified by the analysis of the coefficients of the equation obtained and the respective plots, where the total mass decreases with the increase of the payload mass. In the group II, the decrease of the error associated to each airplane is not only associated to the reduced number of airplanes, but also to the accuracy of the equation obtained, due to the similarity of the aircraft contained 
in this group, unlike what it is verified in the original general mass model. That is proved by the resulting coefficient of determination, which indicate an adequate data fitting.

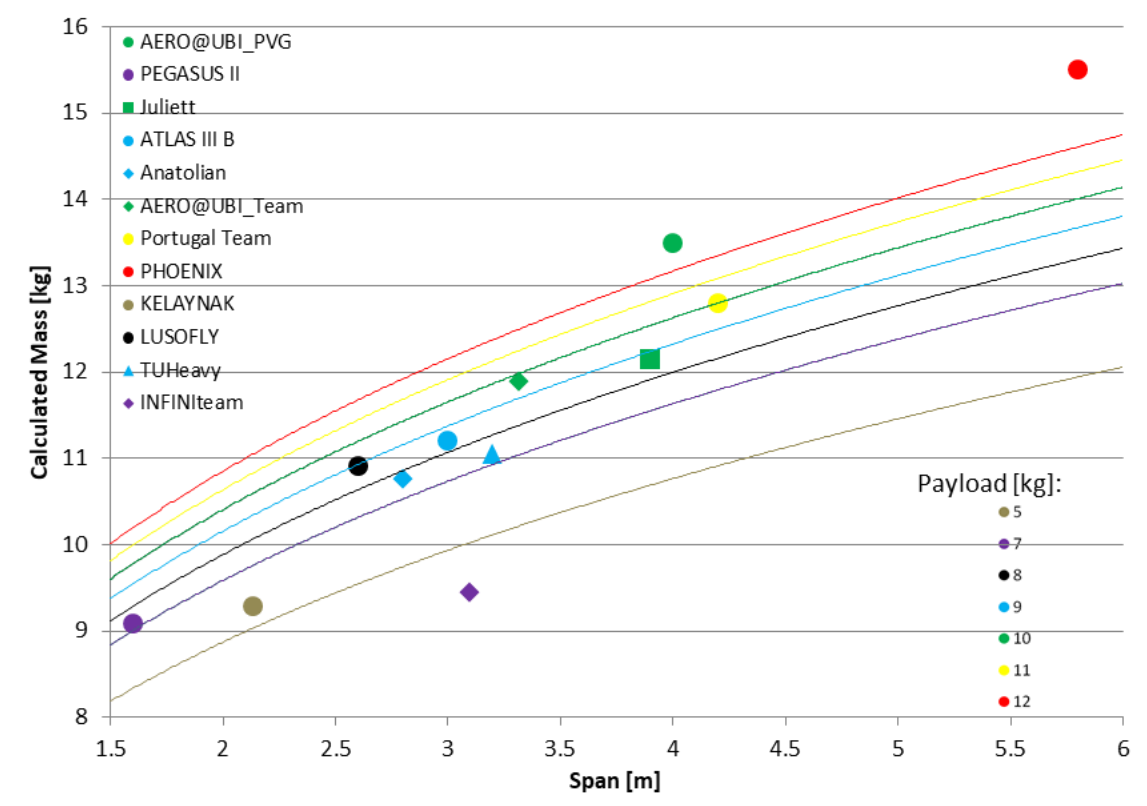

Figure 4.8 - General Mass Model - Fixed Payloads (Group II).

The equations associated to each mass model are summarized in Table 4.3, presented, not only with the same parameters as before, but also with the wing area and aspect ratio instead of the span and chord.

Table 4.3 - General Mass Models Equations.

\begin{tabular}{lcc}
\hline Mass Model & $m=f\left(b, c, m_{\text {pay }}\right)$ & $m=f\left(S, A R, m_{\text {pay }}\right)$ \\
\hline General & $m=672.8 b^{0.264} c^{0.200} m_{\text {pay }}^{0.307}$ & $m=672.8 S^{0.232} A R^{0.0317} m_{\text {pay }}^{0.307}$ \\
Group I & $m=68389 b^{-0.665} c^{0.115} m_{\text {pay }}^{-0.0425}$ & $m=68389 S^{-0.257} A R^{-0.408} m_{\text {pay }}^{-0.0425}$ \\
Group II & $m=1240 b^{0.280} c^{0.152} m_{\text {pay }}^{0.230}$ & $m=1240 S^{0.216} A R^{0.0626} m_{\text {pay }}^{0.230}$ \\
\hline
\end{tabular}

\subsubsection{Component Based Mass Models}

In this case, only the reports with the component's masses discriminated are considered. That said, the considered reports are presented in Table 4.4.

The data collected for this study is summarized in Table 4.5. The remaining information regarding these aircraft was presented in Table 4.2. 
Table 4.4 - Considered Reports (Component Based Mass Models).

\begin{tabular}{c|ccc}
\hline Edition & 2007 & 2009 & 2011 \\
\hline \multirow{2}{*}{ Teams } & PEGASUS II [24] & $\begin{array}{c}\text { KELAYNAK [25] } \\
\text { LUSOFLY [26] } \\
\text { TUHeavy [27] } \\
\text { INFINIteam [28] }\end{array}$ & Portugal Team [5] \\
\hline Edition & 2013 & 2015 & 2017 \\
\hline \multirow{2}{*}{ Teams } & Anatolian [33] & & \\
& ATLAS III B [34] & & \\
& ATLAS IV [35] & & \\
& PHOENIX [37] & AERO@UBI_MARS [23] \\
& Juliett [39] & AEAMOdell13 [4] & AERO@UBI_PVG [43] \\
& GRAVITY [40] & & \\
& LIFT [41] & & \\
\hline
\end{tabular}

Table 4.5 - Data Collected from the Reports.

\begin{tabular}{ccccccccc}
\hline & \multicolumn{2}{c}{ Wing } & \multicolumn{3}{c}{ Horizontal Tail } & \multicolumn{3}{c}{ Vertical Tail } \\
\hline Aircraft & $\lambda$ & $\mathrm{t} / \mathrm{c}$ & $\mathrm{b}[\mathrm{m}]$ & $\mathrm{c}[\mathrm{m}]$ & Mass [kg] & $\mathrm{b}[\mathrm{m}]$ & $\mathrm{c}$ [m] & Mass [kg] \\
\hline AERO@UBI_PVG & 0.4727 & 0.1295 & 0.754 & 0.16 & 0.115 & 0.62 & 0.14 & 0.1 \\
AERO@UBI_MARS & 0.2069 & 0.101 & 0.72 & 0.16 & 0.06 & 0.4 & 0.19 & 0.05 \\
AERO@UBI_Team & 0.6421 & 0.14 & 0.62 & 0.167 & 0.05 & 0.704 & 0.169 & 0.03 \\
Anatolian & 0.4667 & 0.125 & 0.44 & 0.175 & 0.013 & 0.35 & 0.2 & 0.016 \\
ATLAS III B & 0.4 & 0.1429 & 0.72 & 0.139 & 0.105 & 0.31 & 0.16 & 0.055 \\
ATLAS IV & 0.4 & 0.1 & 1.14 & 0.193 & 0.129 & 0.460 & 0.335 & 0.136 \\
PHOENIX & 0.3733 & 0.121 & 0.994 & 0.315 & 0.13 & 0.65 & 0.32 & 0.13 \\
Juliett & 0.5616 & 0.11 & 0.9 & 0.2 & 0.062 & 0.38 & 0.195 & 0.03 \\
AKAMOdell13 & 0.6429 & 0.12 & 0.98 & 0.195 & 0.06 & 0.49 & 0.24 & 0.06 \\
GRAVITY & 0.5 & 0.129 & 0.9 & 0.166 & 0.095 & 0.55 & 0.3 & 0.07 \\
LIFT & 0.5455 & 0.129 & 0.98 & 0.255 & 0.08 & 0.714 & 0.336 & 0.13 \\
Portugal Team & 0.1955 & 0.14 & 0.86 & 0.211 & 0.06 & 0.457 & 0.224 & 0.06 \\
PEGASUS II & 2 & 0.0829 & 0.3 & 0.175 & 0.038 & 0.28 & 0.13 & 0.025 \\
KELAYNAK & 0.7316 & 0.14 & 0.5 & 0.18 & 0.25 & 0.28 & 0.233 & 0.255 \\
LUSOFLY & 0.5 & 0.121 & 0.7 & 0.15 & 0.09 & 0.219 & 0.09 & 0.036 \\
TUHeavy & 0.6 & 0.121 & 0.516 & 0.115 & 0.03 & 0.186 & 0.115 & 0.03 \\
INFINIteam & 0.7 & 0.1 & 0.46 & 0.12 & 0.18 & 0.28 & 0.158 & 0.1 \\
\hline
\end{tabular}

The method described in chapter 3 is implemented and the equations for wing, horizontal tail and vertical tail are determined, based on Eq. (3.5) and Eq. (3.6). The obtained equations are presented in Table 4.6. 
Table 4.6 - Component Based Mass Model Equations.

\begin{tabular}{lc}
\hline Component & Equation \\
\hline Wing & $m_{\text {wing }}=15.141 b^{1.307} c^{-0.0362} \lambda^{0.216}\left(\frac{t}{c}\right)^{-1.238}$ \\
Horizontal Tail & $m_{H T}=25.244 b_{H T}^{2.043} c_{H T}^{-0.794}$ \\
Vertical Tail & $m_{V T}=236.78 b_{V T}^{0.510} c_{V T}^{0.897}$ \\
\hline
\end{tabular}

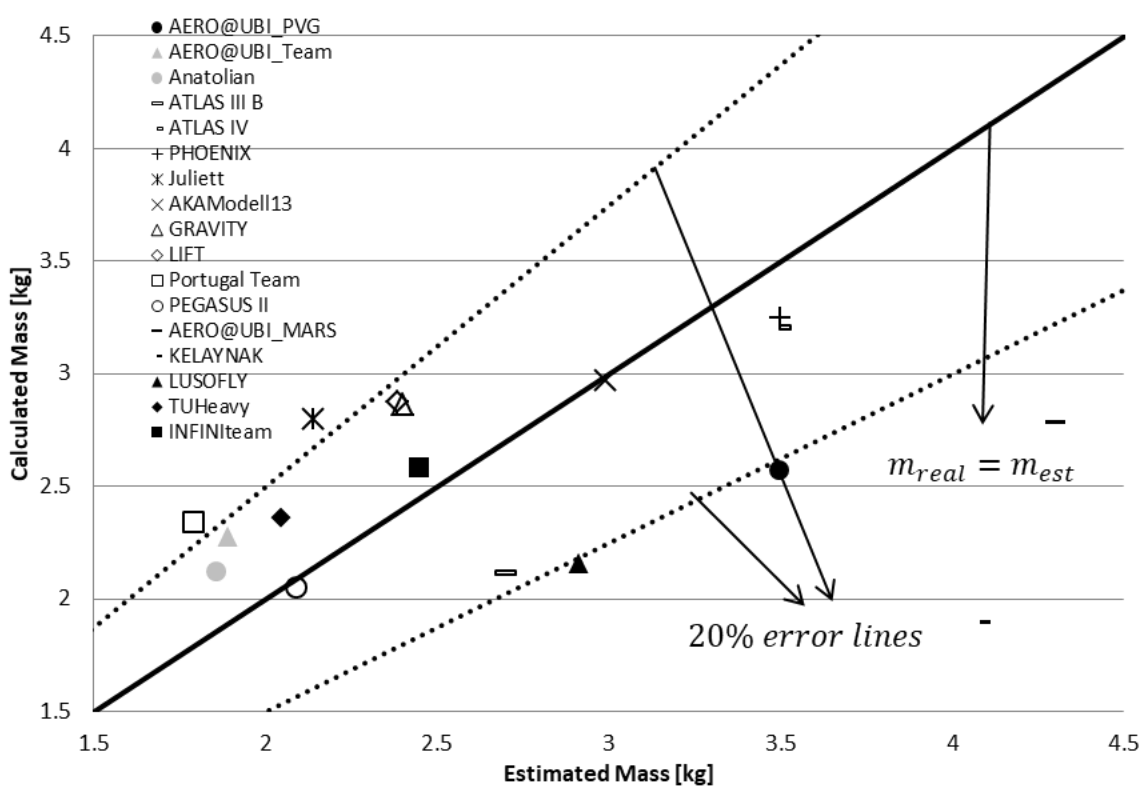

Figure 4.9 - Component Based Mass Model (Empty Mass).

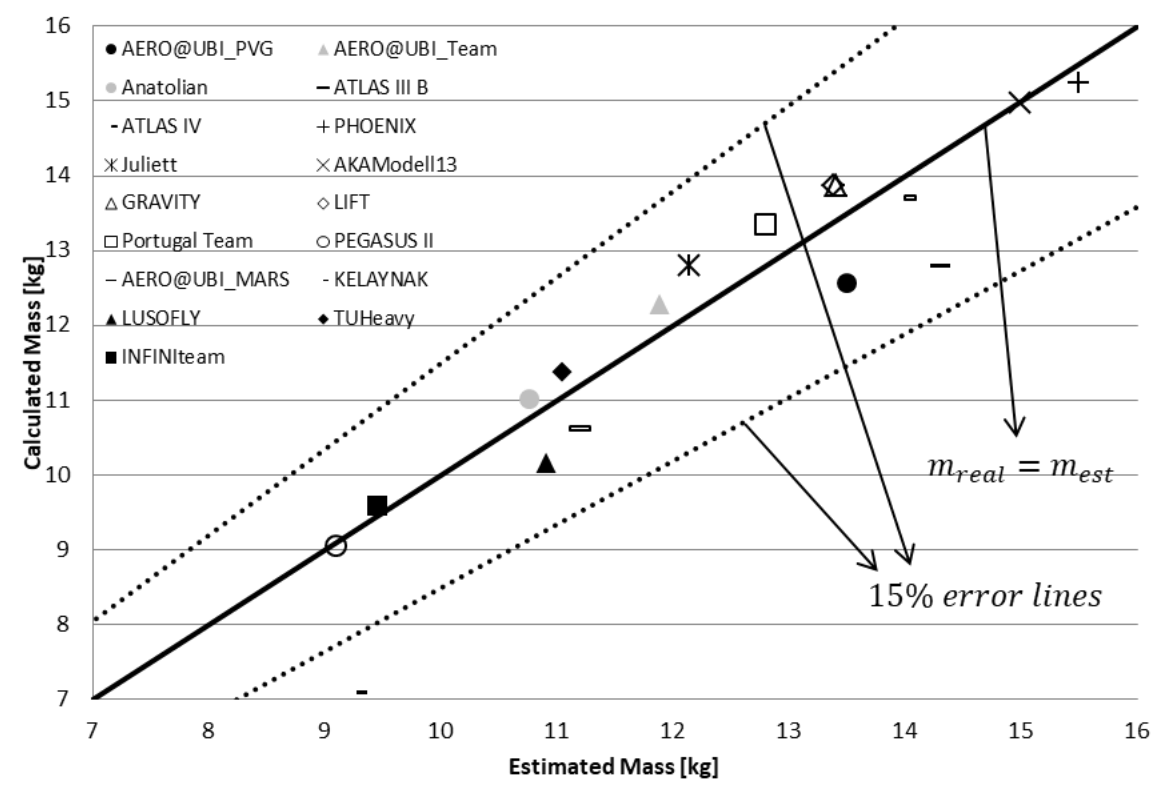

Figure 4.10 - Component Based Mass Model (Total Mass). 
The empty mass is determined using Eq. (3.7) and, in this case, the final mass is given by the sum of the several components of the aircraft, given by Eq. (3.8). Based on that and in Eq. (4.7) to Eq. (4.9), the empty and total masses are computed. The plots that compare the estimated aircraft masses with the calculated masses, for empty and total masses, are represented in Figure 4.9 and Figure 4.10, respectively.

Based on the observation of the results, for the empty mass, it is possible to verify that almost all airplanes are within the error lines. The average error is $20 \%$ and the maximum error is $53 \%$.

In the total mass, as before, almost all aircraft are within the lines considered adequate $15 \%$ error lines), with an associated error with the maximum value of $23 \%$ and average of $5 \%$. The coefficient of determination is 0.843 . Once again, the estimated payload masses, the different types of structures and size of the airplanes, might justify the errors associated to the estimations which results in coefficients that does not make sense, especially in the thickness-to-chord ratio case.

Once identified that some values had an associated error considered impracticable and to compare with the results obtained earlier, the same division, in two groups, is made. Once again, the method based in Eq. (3.5) to Eq. (3.8) is implemented. The equations obtained for wing, horizontal tail and vertical tail, for group I and group II, are summarized in Table 4.7 and Table 4.8, respectively.

Table 4.7 - Component Based Mass Model Equations (Group I).

\begin{tabular}{lc}
\hline Component & Equation \\
\hline Wing & $m_{\text {wing }}=10^{6} b^{-3.509} c^{4.840} \lambda^{-0.819}\left(\frac{t}{c}\right)^{-1.924}$ \\
Horizontal Tail & $m_{H T}=80.851 b_{H T}^{0.354} c_{H T}^{0.0713}$ \\
Vertical Tail & $m_{V T}=88.632 b_{V T}^{2.916} c_{V T}^{-1.235}$ \\
\hline
\end{tabular}

In the wing mass equation (Eq. (4.10)), in group I, it was verified that the constant, resulting from the implementation of the resolution method, assumed an extremely high value, when compared with other constants. This constant was limited to the value indicated, being proved that the influence in the final result is almost inexistent, and the coefficients were determined using the same resolution method. 
Table 4.8 - Component Based Mass Model Equations (Group II).

\begin{tabular}{lc}
\hline Component & Equation \\
\hline Wing & $m_{\text {win }}=62.403 b^{1.163} c^{0.0603} \lambda^{0.344}\left(\frac{t}{c}\right)^{-0.739}$ \\
Horizontal Tail & $m_{H T}=26.881 b_{H T}^{2.250} c_{H T}^{-0.832}$ \\
Vertical Tail & $m_{V T}=17.858 b_{V T}^{03797} c_{V T}^{-0.480}$ \\
\hline
\end{tabular}

Figure 4.11 and Figure 4.12 represent the empty and total calculated masses, for group I, obtained based on Eq. (3.7) and Eq. (3.8), respectively, compared to the estimated values.

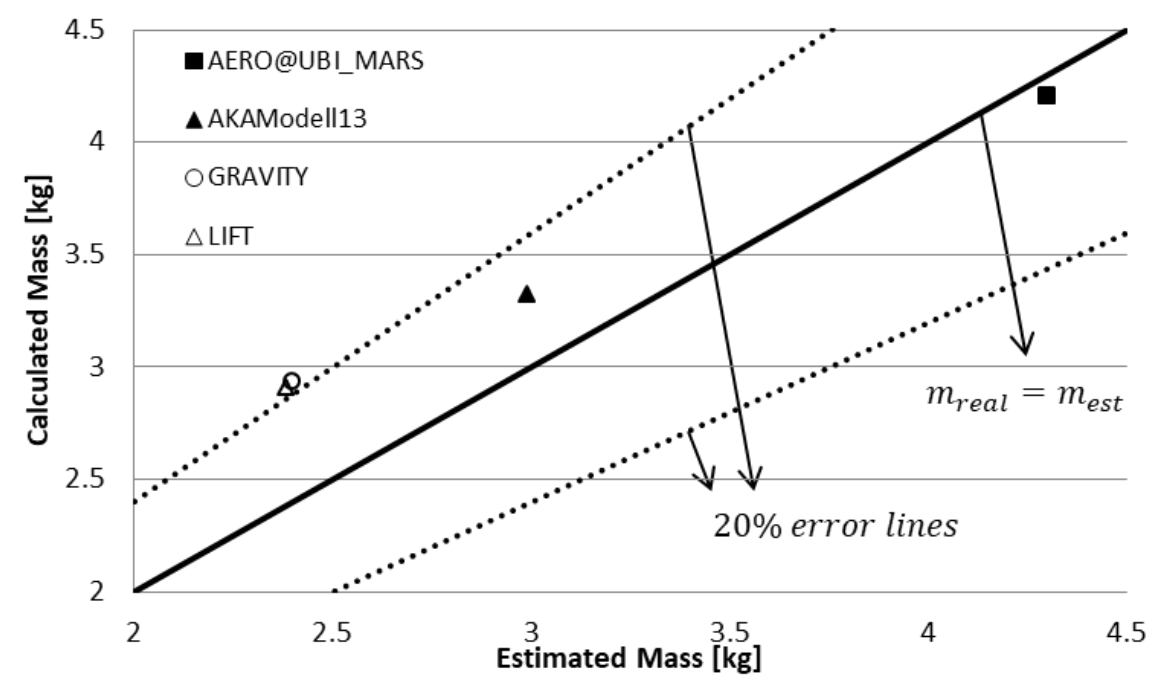

Figure 4.11 - Component Based Mass Model - Group I (Empty Mass).

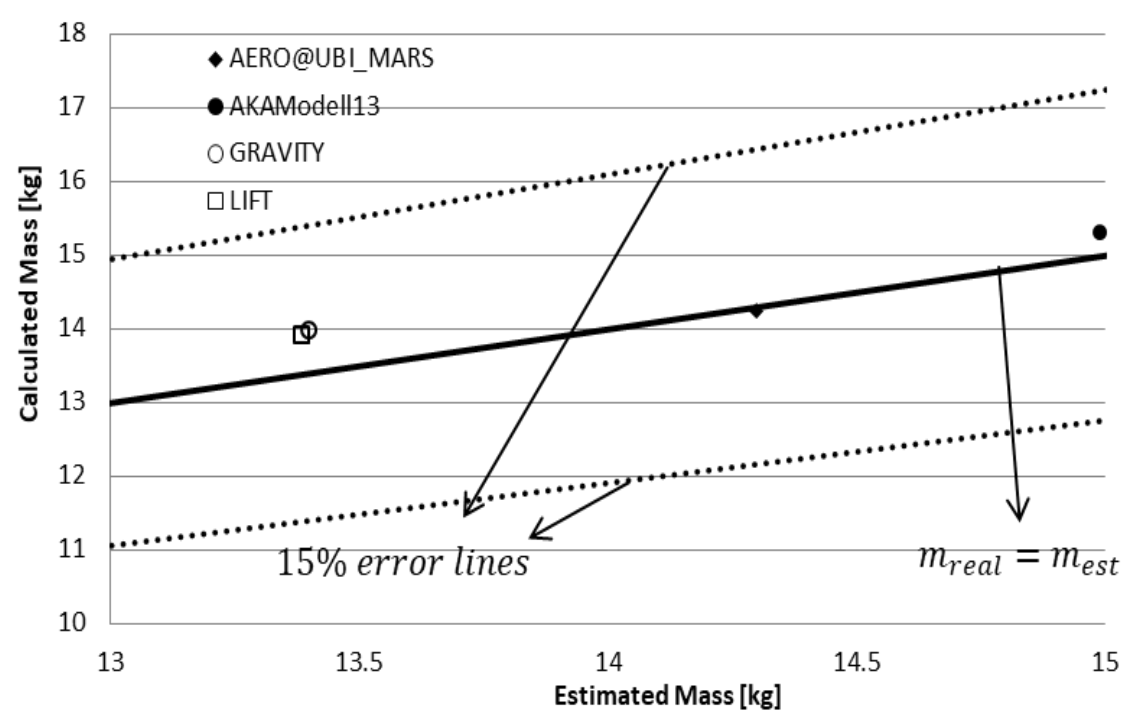

Figure 4.12 - Component Based Mass Model - Group I (Total Mass). 
Figure 4.13 and Figure 4.14 represent empty and total calculated masses for group II, compared to the estimated values.

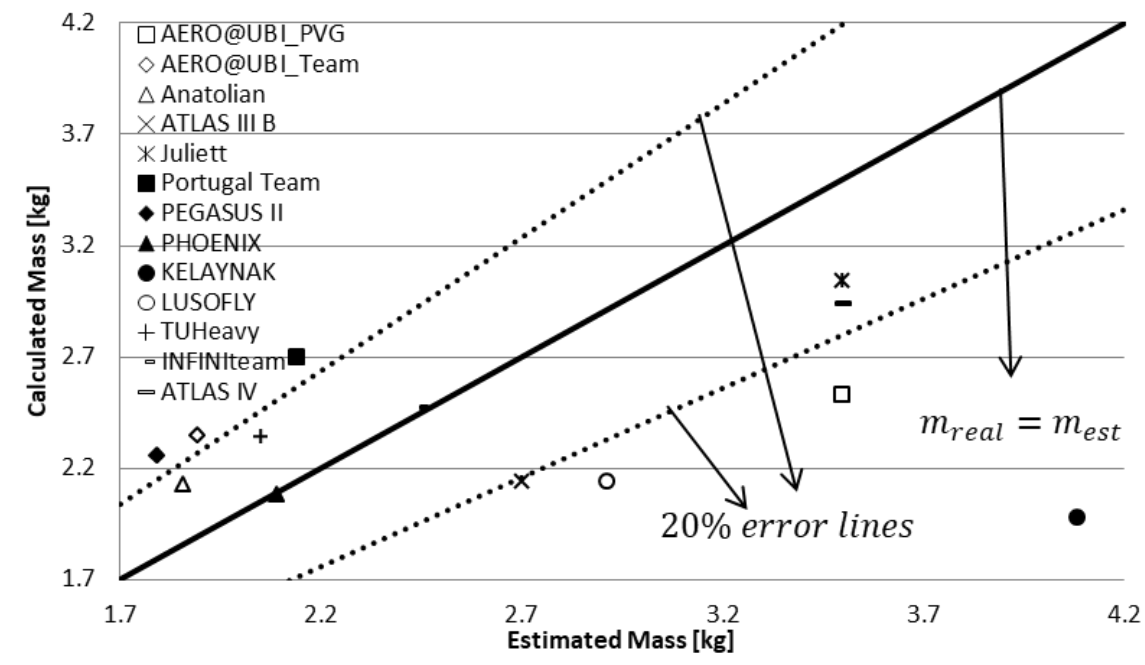

Figure 4.13 - Component Based Mass Model - Group II (Empty Mass).

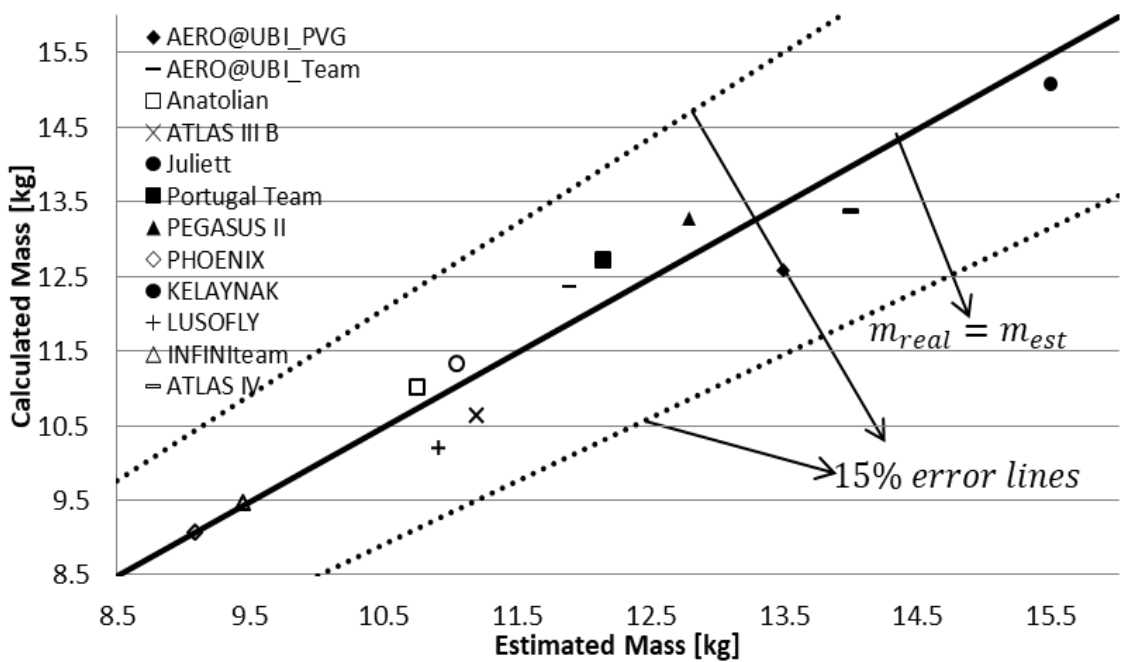

Figure 4.14 - Component Based Mass Model - Group II (Total Mass).

The same error lines, for the empty mass and total mass plots (20\% and $15 \%$, respectively), were used. Based on that, it is possible to verify, for both cases, the increase of the number of aircraft inside those boundaries.

For the first group, the errors decrease, taking maximum values of $22 \%$ and $4 \%$ and average values of $14 \%$ and $2.7 \%$ for empty and total masses, respectively. The coefficient of determination associated to the total mass fit is 0.632 . 
However, in the other group, the errors are similar to the original model. The maximum errors are $52 \%$ and $23 \%$ and the average are $20 \%$ and $5.1 \%$, for empty and total masses, respectively. The coefficient of determination for the total mass fit is 0.828 .

Due to the fact that each group has a smaller number of airplanes, even with smaller associated errors, the obtained equations cannot be considered accurate. That is sustained by the fact that the coefficients obtained for the equations does not make sense, once again, which obviously results in coefficients of determination, associated to these models, that indicate that the fittings do not describe the data properly.

\subsubsection{Comparison between General and Component Based Mass Models}

In order to establish the differences between the general and the component based mass models, the associated errors with each model are presented in Table 4.9 and Table 4.10.

Table 4.9 - Error Comparison.

\begin{tabular}{ccccc}
\hline Mass Model & \multicolumn{2}{c}{ General } & \multicolumn{2}{c}{ Component Based } \\
& Empty & Total & Empty & Total \\
\hline Maximum & $52.7 \%$ & $11.7 \%$ & $53.2 \%$ & $23.4 \%$ \\
Average & $22.3 \%$ & $5.04 \%$ & $19.9 \%$ & $4.98 \%$ \\
\hline
\end{tabular}

Table 4.10 - Error Comparison for Groups Division.

\begin{tabular}{cccccc}
\hline & Mass Model & \multicolumn{2}{c}{ General } & \multicolumn{2}{c}{ Component Based } \\
& & Empty & Total & Empty & Total \\
\hline \multirow{2}{*}{ Group I } & Maximum & $26.4 \%$ & $5.27 \%$ & $22.3 \%$ & $3.99 \%$ \\
& Average & $10.4 \%$ & $2.19 \%$ & $14.2 \%$ & $2.67 \%$ \\
\multirow{2}{*}{ Group II } & Maximum & $27.4 \%$ & $7.28 \%$ & $51.5 \%$ & $22.7 \%$ \\
& Average & $14.9 \%$ & $3.26 \%$ & $20.4 \%$ & $5.11 \%$ \\
\hline
\end{tabular}

Analysing these results, it is possible to realize that, unlike the expected, the models developed directly for the total mass of the airplane present inferior errors, when compared to the ones developed for the aircraft divided by components. The main reason for this might be the fact that, even with small errors associated for the wing equation, the remaining components have big associated errors, resulting in a less accurate fit.

To evaluate the validity of each mass model, it was also considered important to compare the coefficients of determination obtained. The respective coefficients of determination for each mass model are presented in Table 4.11. 
Associated to higher errors, in the component based models, are lower coefficients of determination. The only case where this situation is not verified is in the model developed for group I of the component based model. In this case, however the errors are small, the inferior number of airplanes results in a value, for this coefficient, smaller than the others, which indicates the imprecision of the fitting and inaccuracy in the model.

Table 4.11 - Coefficient of Determination Comparison.

\begin{tabular}{ccc}
\hline Mass Model & & Coefficient of Determination, $R^{2}$ \\
\hline \multirow{2}{*}{ General } & All & 0.871 \\
& Group I & 0.943 \\
& Group II & 0.996 \\
& All & 0.843 \\
Component Based & Group I & 0.632 \\
& Group II & 0.828 \\
\hline
\end{tabular}

\subsection{Structure Type Based Mass Models}

To define the necessary coefficients, the reference aircraft used are the ones developed at UBI, due to the fact that the data and the airplanes themselves are available, offering the possibility to collect more accurate information and obtain better results. The teams indicated in tables with MARS, AKA, PVG, UBI15, UBI11 and Beihang correspond to AERO@UBI_MARS, AKAModell13, AERO@UBI_PVG, AERO@UBI_Team, Portugal_Team and GRAVITY, respectively.

The inputs required to all configurations, divided by component, where geometric characteristics, design parameters and limitations are included, are presented in Table 4.12.

The parameters regarding the wing and tails were collected from the respective reports of each aircraft (see Table 4.1). The tail boom and cargo bay characteristics were assumed based on the observation of the drawings in the reports. The limitations, concerning the displacements and rotations, the load factor and the design speed were assumed based on the respective regulation and respective requirements, in force for the edition in which the respective airplane participated. Although the maximum deflection and twist at the wing tip were not taken into account in the UBI's aircraft's projects and the considerations for the other ones are not known, it was considered interesting to impose these parameters and verify the results obtained. In the AERO@UBI_PVG case, the maximum deflection and twist at the wing tip are indicated with N. A., due to the fact that, in the design of this particular airplane, the remaining considerations of this specific project are known. 
The remaining inputs are specific to each configuration, such as area and perimeter ratios and materials properties, being presented in the respective sections. In the materials properties case, the provided values are the ultimate stresses. In the determination of the mass, the admissible stresses are used and are obtained using the safety factor equation (Eq. (3.9)).

Table 4.12 - Generic Inputs.

\begin{tabular}{|c|c|c|c|c|c|c|c|}
\hline Component & Inputs & MARS & AKA & PVG & UBI15 & UBI11 & Beihan§ \\
\hline \multirow{5}{*}{ Wing } & Span [m] & 4.18 & 4.5 & 4 & 3.32 & 4.16 & 4.74 \\
\hline & M. A. C. $[\mathrm{m}]$ & 0.248 & 0.323 & 0.327 & 0.332 & 0.322 & 0.296 \\
\hline & Airfoil thickness & 0.1 & 0.12 & 0.13 & 0.14 & 0.14 & 0.12 \\
\hline & Maximum Tip deflection/span ratio & 0.1 & 0.1 & N. A. & 0.1 & 0.2 & 0.2 \\
\hline & Maximum Tip twist angle [degree] & 2 & 2 & N. A. & 3 & 5 & 4 \\
\hline \multirow{4}{*}{ Tail boom } & Tail arm/span ratio & 0.35 & 0.35 & 0.35 & 0.45 & 0.45 & 0.35 \\
\hline & Length/span ratio & 0.3 & 0.3 & 0.3 & 0.4 & 0.4 & 0.3 \\
\hline & Diameter $[\mathrm{m}]$ & 0.030 & 0.03 & 0.030 & 0.018 & 0.018 & 0.018 \\
\hline & Maximum Tail Rotation [degree] & 0.5 & 0.5 & 1 & 1 & 1 & 1 \\
\hline $\begin{array}{l}\text { Horizontal } \\
\text { tail }\end{array}$ & Area $\left[\mathrm{m}^{\wedge} 2\right]$ & 0.1152 & 0.1911 & 0.1206 & 0.1035 & 0.1815 & 0.1490 \\
\hline Vertical tail & Area $\left[\mathrm{m}^{\wedge} 2\right]$ & 0.076 & 0.1176 & 0.1206 & 0.1190 & 0.1024 & 0.1650 \\
\hline \multirow{2}{*}{ Cargo bay } & Surface area $\left[\mathrm{m}^{\wedge} 2\right]$ & 0.3 & 0.3 & 0.5 & 0.3 & 0.3 & 0.3 \\
\hline & Thickness [m] & 0.005 & 0.005 & 0.005 & 0.005 & 0.005 & 0.005 \\
\hline \multirow{6}{*}{ Others } & Coefficient of moment & 0.15 & 0.15 & 0.15 & 0.15 & 0.15 & 0.15 \\
\hline & Air density $\left[\mathrm{kg} / \mathrm{m}^{\wedge} 3\right]$ & \multicolumn{6}{|c|}{1.225} \\
\hline & Safety factor & \multicolumn{6}{|c|}{1.5} \\
\hline & Gravity acceleration $\left[\mathrm{m} / \mathrm{s}^{\wedge} 2\right]$ & \multicolumn{6}{|c|}{9.80655} \\
\hline & Load factor & \multicolumn{6}{|c|}{2} \\
\hline & Design speed $[\mathrm{m} / \mathrm{s}]$ & 18 & 14 & 25 & 9 & 7 & 8 \\
\hline
\end{tabular}

\subsubsection{Load Bearing Skin Wing Configuration}

The airplane considered to develop and adjust the coefficients is the AERO@UBI_MARS, participant of the ACC 2017 edition.

The specific inputs assumed and material properties required to determine the mass of the aircraft are presented in Table 4.13 and Table 4.14, respectively. The area and perimeter ratios were assumed, for the AERO@UBI_MARS, based on the observation of the actual airplane. The airfoil ratios used were calculated from the coordinates of the real airfoil, 
available at the university. For the AKAModell13, the same ratios were used, being considered that the airplanes are similar, in terms of the wing structure. It was assumed the Selig s1223 airfoil to determine the airfoil ratios.

Table 4.13 - Specific Inputs for Carbon Fiber Configuration.

\begin{tabular}{|c|c|c|c|}
\hline Component & Inputs & MARS & AKA \\
\hline \multirow{8}{*}{ Wing } & Cell I area/Airfoil area ratio & 0.3 & 0.3 \\
\hline & Cell II area/Airfoil area ratio & 0.7 & 0.7 \\
\hline & Cell I perimeter/Airfoil perimeter ratio & 0.35 & 0.35 \\
\hline & Cell I perimeter/Airfoil perimeter ratio & 0.75 & 0.75 \\
\hline & Airfoil perimeter/chord ratio & 2.039 & 2.095 \\
\hline & Airfoil area/chord ratio squared & 0.0664 & 0.0649 \\
\hline & Number of Interfaces & 5 & 4 \\
\hline & Core thickness [m] & 0.002 & 0.002 \\
\hline
\end{tabular}

Table 4.14 - Material Properties for Carbon Fiber Configuration.

\begin{tabular}{cccc}
\hline Material & \multicolumn{2}{c}{ Property } & Value \\
\hline \multirow{2}{*}{$\begin{array}{c}\text { Uni-directional CFRP } \\
\text { (Spar/Tube) }\end{array}$} & Normal stress & $\sigma[\mathrm{MPa}]$ & 720 \\
& Young's Modulus & $\mathrm{E}[\mathrm{GPa}]$ & 84 \\
\hline \multirow{2}{*}{$\begin{array}{c}\text { Bi-directional CFRP } \\
\text { (Skin) }\end{array}$} & Density & $\rho\left[\mathrm{kg} / \mathrm{m}^{\wedge} 3\right]$ & 1600 \\
& Shear Stress & $\tau[\mathrm{MPa}]$ & 54 \\
\hline Foam (Core) & Density & $\mathrm{G}[\mathrm{GPa}]$ & 5 \\
\hline
\end{tabular}

Initially, it is required to define the inputs and the wing sections. Then, based on the equations obtained for the required material, the masses for the wing, tail boom and cargo bay are computed.

To adjust the wing mass, the penalty factors related to the interfaces and extra material are defined, taking values of $0.025 \mathrm{~kg} /$ interface and $0.1 m_{\text {wing }}$, respectively. Recalculating the wing mass and based on the obtained result, the correction factors for the horizontal and vertical tails are defined, taking a value of 0.3 for both cases. The same is done for the landing gear, where the coefficient defined is 0.03 . 
The final results for the AERO@UBI_MARS aircraft are presented in Table 4.15. The components masses considered, in this case, are the real values due to the fact that the airplane is available in the university.

Table 4.15 - AERO@UBI_MARS Calculated and Real Masses.

\begin{tabular}{cccc}
\hline Component & Calculated Mass $[\mathrm{kg}]$ & Real Mass $[\mathrm{kg}]$ & Error $[\%]$ \\
\hline Wing & 2.806 & 2.692 & 4.22 \\
Tail Boom & 0.189 & N. A. & N. A. \\
Horizontal Tail & 0.094 & 0.060 & 56.0 \\
Vertical Tail & 0.062 & 0.050 & 23.5 \\
Cargo Bay & 0.300 & N. A. & N. A. \\
Cargo Bay + Tail Boom & 0.489 & 0.670 & -27.0 \\
Systems & 0.700 & 0.700 & - \\
Payload & 10.000 & 10.000 & - \\
Landing Gear & 0.128 & 0.130 & -1.27 \\
Empty & 4.278 & 4.302 & -0.55 \\
Total & 14.278 & 14.302 & -0.17 \\
\hline
\end{tabular}

The masses for the tail boom and cargo bay were not available separately, so only the fuselage mass is indicated. Considering that the AERO@UBI_MARS is the airplane used to define the adjustment factors, it was expected that the errors associated were small. The magnitude of the components' masses with higher errors (tails, cargo bay and tail boom) is small in the final mass. For that reason, the errors associated these components do not prevent the obtaining of high accuracy results for the empty and total masses.

Table 4.16 - AKAModell13 Calculated and Estimated Masses.

\begin{tabular}{cccc}
\hline Component & Calculated Mass [kg] & Estimated Mass [kg] & Error [\%] \\
\hline Wing & 1.801 & 1.777 & 1.33 \\
Tail Boom & 0.203 & 0.120 & 25 \\
Horizontal Tail & 0.071 & 0.060 & 18.5 \\
Vertical Tail & 0.044 & 0.060 & -27.1 \\
Cargo Bay & 0.300 & 0.240 & 69.6 \\
Cargo Bay + Tail Boom & 0.503 & 0.360 & 39.9 \\
Systems & 0.600 & 0.600 & - \\
Payload & 12.000 & 12.000 & - \\
Landing Gear & 0.091 & 0.110 & -15.1 \\
Empty & 3.112 & 2.992 & 4.02 \\
Total & 15.112 & 14.992 & 0.80 \\
\hline
\end{tabular}


Once the penalty factors and the correction factors are defined, the same equations are applied in the AKAModell13, with the results being presented in Table 4.16. The components masses considered were obtained from the respective report and are the estimations presented in it.

As expected, the errors associated to the empty and total masses are larger in the AKAModell13 than in the AERO@UBI_MARS. However, the $4 \%$ and $0.8 \%$ errors associated to the empty and total masses, respectively, are considered adequate, allowing to affirm that the mass model developed is valid.

\subsubsection{D-box Wing Configuration}

In this case, the airplane considered to develop the model is the AERO@UBI_PVG, participant of the ACC 2017 edition.

The specific inputs and material properties required to determine the mass of the aircraft are presented in Table 4.17 and Table 4.18. Once again, the area and perimeter ratios were assumed, based on the observation of the actual airplane. Once the airfoil was developed in the university, its coordinates are available, guarantying real values for the airfoil ratios.

Table 4.17 - Specific Inputs for D-box Configuration.

\begin{tabular}{ccc}
\hline Component & Geometric inputs & PVG \\
\hline D-box area/Airfoil area ratio & 0.4 \\
& D-box perimeter/Airfoil perimeter ratio & 0.365 \\
TE area/Airfoil area ratio & 0.05 \\
Rib area/Airfoil area ratio & 0.55 \\
Wing & Rib length/chord ratio & 0.6 \\
& Airfoil perimeter/chord ratio & 2.065 \\
& Airfoil area/chord ratio squared & 0.0765 \\
& Number of Interfaces & 5 \\
& Core thickness [m] & 0.002 \\
\hline
\end{tabular}

The same process described earlier, for the carbon fiber configuration, is implemented. The inputs and the wing sections are defined and then, based on the equations obtained for the required material, the masses for the wing, tail boom and cargo bay are computed.

Once again, the penalty factors related to the interfaces and extra material are defined, taking values of $0.025 \mathrm{~kg} /$ interface and $0.1 \mathrm{~m}_{\text {wing }}$, respectively. The correction factors for the horizontal and vertical tails and landing gear are defined, taking values of 0.6 , for the first two, and 0.05 , for the third. 
Table 4.18 - Material Properties for D-box Configuration.

\begin{tabular}{|c|c|c|c|}
\hline Material & \multicolumn{2}{|c|}{ Property } & Value \\
\hline \multirow{3}{*}{$\begin{array}{l}\text { Uni-directional CFRP } \\
\text { (Spar/Tube) }\end{array}$} & Normal stress & $\sigma[\mathrm{MPa}]$ & 720 \\
\hline & Young's Modulus & $\mathrm{E}[\mathrm{GPa}]$ & 84 \\
\hline & Density & $\rho\left[\mathrm{kg} / \mathrm{m}^{\wedge} 3\right]$ & 1600 \\
\hline \multirow{3}{*}{$\begin{array}{l}\text { Bi-directional CFRP } \\
\text { (Skin) }\end{array}$} & Shear Stress & $\tau[\mathrm{MPa}]$ & 54 \\
\hline & Shear Modulus & $\mathrm{G}[\mathrm{GPa}]$ & 5 \\
\hline & Density & $\rho\left[\mathrm{kg} / \mathrm{m}^{\wedge} 3\right]$ & 1600 \\
\hline \multirow{2}{*}{ Balsa (Ribs/TE) } & Shear Stress & $\tau[\mathrm{MPa}]$ & 1.4 \\
\hline & Density & $\rho\left[\mathrm{kg} / \mathrm{m}^{\wedge} 3\right]$ & 200 \\
\hline Foam (Core) & Density & $\rho\left[\mathrm{kg} / \mathrm{m}^{\wedge} 3\right]$ & 40 \\
\hline
\end{tabular}

The final results for the AERO@UBI_PVG aircraft are presented in Table 4.19. The components masses considered, in this case, are the real values due to the fact that the airplane is available in the university.

Table 4.19 - AERO@UBI_PVG Calculated and Real Masses.

\begin{tabular}{cccc}
\hline Component & Calculated Mass [kg] & Real Mass [kg] & Error [\%] \\
\hline Wing & 1.616 & 1.675 & -3.5 \\
Tail Boom & 0.181 & 0.390 & -53.6 \\
Horizontal Tail & 0.089 & 0.115 & -22.2 \\
Vertical Tail & 0.089 & 0.100 & -10.6 \\
Cargo Bay & 0.500 & 0.285 & 75.4 \\
Cargo Bay + Tail Boom & 0.681 & 0.675 & 0.88 \\
Systems & 0.700 & 0.700 & - \\
Payload & 10.000 & 10.000 & - \\
Landing Gear & 0.167 & 0.140 & 19.4 \\
Empty & 3.343 & 3.498 & -4.44 \\
Total & 13.343 & 13.498 & -1.12 \\
\hline
\end{tabular}

The wing configuration used in AERO@UBI_PVG is not identical to the one considered in the developed model. However, the error associated to the mass of this component is small. Regarding the empty and total masses, it is possible to verify errors within the considered reasonable, with values inferior of $5 \%$ for the empty mass and around $1 \%$ for the total mass.

\subsubsection{Tube Spar Wing Configuration}

In this case, the airplane considered to develop the method is the AERO@UBI_Team, participant of the ACC 2015. 
The specific inputs and material properties required to determine the mass of the aircraft are presented in Table 4.20 and Table 4.21. The ratios, regarding the reinforcements in the leading and trailing edges, were assumed based on the observation of the real airplanes, in the AERO@UBI_Team and Portugal Team cases, and in the viability of the manufacturing these components. The same values were assumed for the GRAVITY airplane, because of the structure similarity. The airfoil ratios assumed for the GRAVITY are equal to the ones used in the UBI's airplanes.

Table 4.20 - Specific Inputs for Tube Configuration.

\begin{tabular}{ccccc}
\hline Component & Geometric inputs & UBI15 & UBI11 & Beihang \\
\hline \multirow{2}{*}{ Wing } & TE area/Airfoil area ratio & 0.05 & 0.05 & 0.05 \\
& LE area/Airfoil area ratio & 0.05 & 0.05 & 0.05 \\
& Airfoil perimeter/chord ratio & 2.095 & 2.095 & 2.095 \\
& Airfoil area/chord ratio squared & 0.0649 & 0.0649 & 0.0649 \\
\hline
\end{tabular}

Table 4.21 - Material Properties for Tube Configuration.

\begin{tabular}{cccc}
\hline Material & \multicolumn{2}{c}{ Property } & Value \\
\hline \multirow{2}{*}{$\begin{array}{c}\text { Uni-directional CFRP } \\
\text { (Tube) }\end{array}$} & Normal stress & $\sigma[\mathrm{MPa}]$ & 720 \\
& Young's Modulus & $\mathrm{E}[\mathrm{GPa}]$ & 84 \\
& Density & $\rho\left[\mathrm{kg} / \mathrm{m}^{\wedge} 3\right]$ & 1600 \\
\hline \multirow{2}{*}{ Balsa (Ribs/LE/TE) } & Shear Stress & $\tau[\mathrm{MPa}]$ & 1.4 \\
& Density & $\rho\left[\mathrm{kg} / \mathrm{m}^{\wedge} 3\right]$ & 200 \\
\hline
\end{tabular}

Table 4.22 - AERO@UBI_Team Calculated and Real Masses.

\begin{tabular}{cccc}
\hline Component & Calculated Mass [kg] & Real Mass [kg] & Error [\%] \\
\hline Wing & 0.751 & 0.680 & 10.5 \\
Tail Boom & 0.120 & 0.175 & -31.3 \\
Horizontal Tail & 0.035 & 0.050 & -29.5 \\
Vertical Tail & 0.041 & 0.030 & 35.1 \\
Cargo Bay & 0.300 & 0.155 & 93.6 \\
Cargo Bay + Tail Boom & 0.420 & 0.330 & 27.3 \\
Systems & 0.650 & 0.650 & - \\
Payload & 10.000 & 10.000 & - \\
Landing Gear & 0.077 & 0.150 & -48.3 \\
Empty & 1.937 & 1.892 & 2.39 \\
Total & 11.937 & 11.892 & 0.38 \\
\hline
\end{tabular}


Once again, the same process is implemented and the inputs and wing sections are defined. From the equations developed for the required material to withstand the loads, the masses for the wing, tail boom and cargo bay are computed.

The penalty factor related to the extra material is defined, taking a value of $0.1 m_{\text {wing }}$. The correction factors for the horizontal and vertical tails are 0.5 , for both cases. For the landing gear, the coefficient defined is 0.04 . The final results for the AERO@UBI_Team aircraft are presented in Table 4.22. The components masses considered, in this case, are the real values due to the fact that the airplane is available in the university.

For the AERO@UBI_Team airplane, the mass obtained for the wing is, about, $10 \%$ superior than the real value. However, this difference in this estimation of the wing' mass, does not prevent an adequate estimation for the empty and total masses.

Once established the coefficients to adjust the final result, the same equations are applied in the Portugal_Team and GRAVITY. The results are presented in Table 4.23 and Table 4.24, respectively. The components masses considered, in the Portugal_Team case, are the real values due to the fact that the airplane is available in the university. In the Gravity case, the masses are the estimations available in the respective report.

Table 4.23 - Portugal Team Calculated and Real Masses.

\begin{tabular}{cccc}
\hline Component & Calculated Mass $[\mathrm{kg}]$ & Real Mass $[\mathrm{kg}]$ & Error $[\%]$ \\
\hline Wing & 0.716 & 0.670 & 6.87 \\
Tail Boom & 0.151 & 0.076 & 98.1 \\
Horizontal Tail & 0.049 & 0.060 & -19.1 \\
Vertical Tail & 0.027 & 0.060 & -54.3 \\
Cargo Bay & 0.300 & 0.260 & 15.4 \\
Cargo Bay + Tail Boom & 0.451 & 0.336 & 34.1 \\
Systems & 0.500 & 0.500 & - \\
Payload & 11.000 & 11.000 & - \\
Landing Gear & 0.071 & 0.050 & 42.6 \\
Empty & 1.783 & 1.794 & -0.58 \\
Total & 12.783 & 12.793 & -0.08 \\
\hline
\end{tabular}

In the Portugal Team case, the error associated to the wing mass is inferior than the one obtained for the AERO@UBI_Team. For the empty mass, the values for the real and calculated masses are almost the same, with the same situation being verified for the total mass.

The GRAVITY airplane is significantly larger than the AERO@UBI_Team and Portugal Team aircraft. That has an influence in the results, especially in the fuselage (cargo bay and tail boom) and the landing gear estimations. In this case, however the error associated to the 
wing mass is smaller than in the two previous cases, the errors associated to the remaining components lead to an error in the empty mass of almost $9 \%$. This is the maximum value obtained for the structure based mass models and the same reality is verified for the total mass, as expected.

Table 4.24 - GRAVITY Calculated and Estimated Masses.

\begin{tabular}{cccc}
\hline Component & Calculated Mass [kg] & Estimated Mass [kg] & Error [\%] \\
\hline Wing & 1.340 & 1.400 & -4.3 \\
Tail Boom & 0.129 & 0.200 & -35.7 \\
Horizontal Tail & 0.071 & 0.095 & -25.1 \\
Vertical Tail & 0.079 & 0.070 & 12.6 \\
Cargo Bay & 0.300 & 0.060 & 400 \\
Cargo Bay + Tail Boom & 0.429 & 0.260 & 64.9 \\
Systems & 0.650 & 0.650 & - \\
Payload & 11.000 & 11.000 & - \\
Landing Gear & 0.104 & 0.045 & 132 \\
Empty & 2.609 & 2.400 & 8.69 \\
Total & 13.609 & 13.400 & 1.56 \\
\hline
\end{tabular}

\subsubsection{Comparison between Results for the Different Configurations}

Based on the results obtained it is necessary to verify its accuracy. The comparisons between the real and estimated empty and total masses are presented in Figure 4.15 and Figure 4.16, respectively.

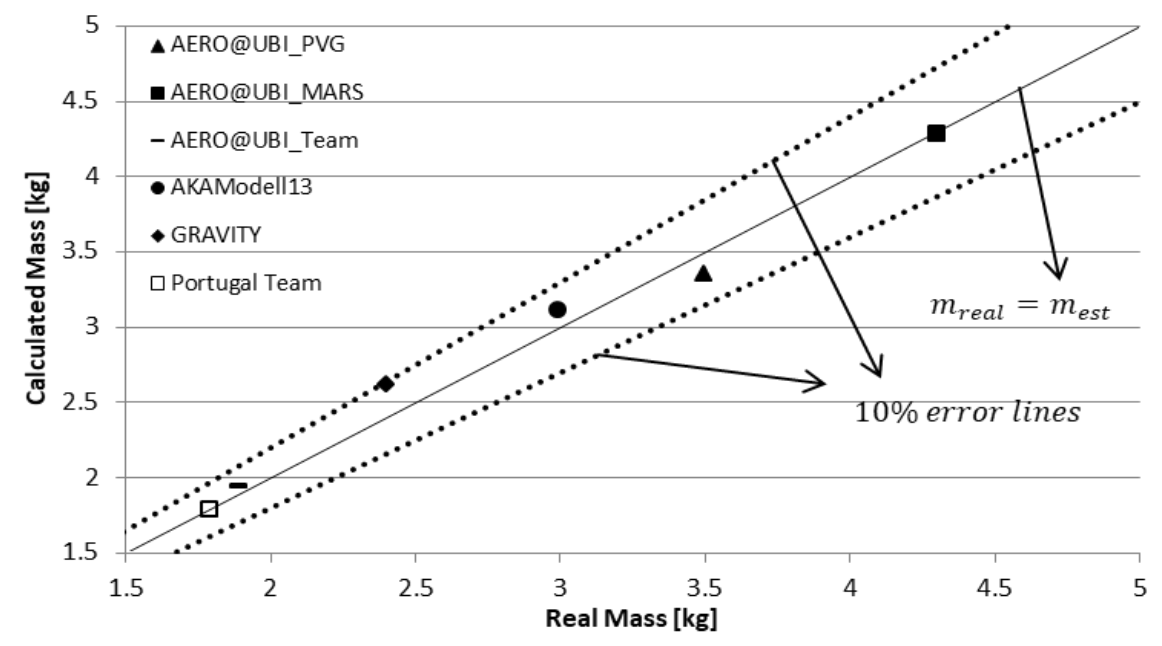

Figure 4.15 - Structure Based Mass Model - Empty Mass. 
From the observation of the graphs, it is possible to observe the high accuracy of these models. The maximum error in the empty mass is $8.7 \%$ and the average is $3.5 \%$. In the total mass, the maximum is $1.6 \%$ and the average is $0.7 \%$.

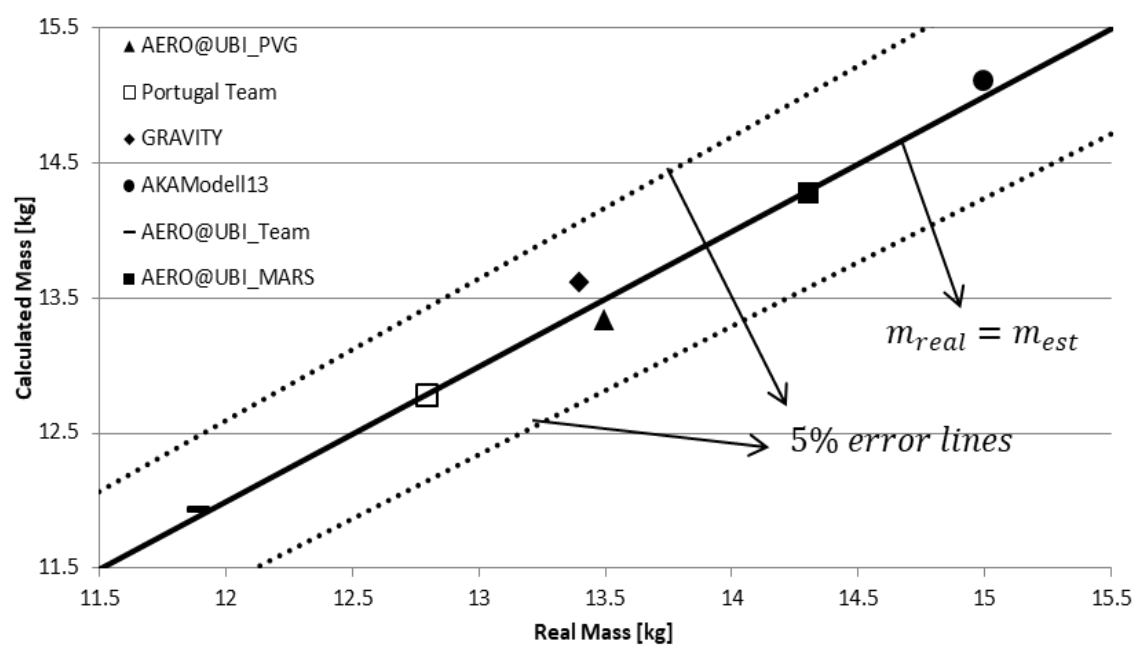

Figure 4.16 - Structure Based Mass Model - Total Mass.

As expected, the accuracy of these models is higher than the ones developed based on statistical data. However, to implement the general mass models, it is necessary only three input data, span, chord and payload mass. In the component based mass models, the number of inputs increase to ten, specifically, wing and tails geometric characteristics and estimations for remaining components masses. In these cases, for the structure based type mass models, the number of inputs is about thirty, for example, wing, tails and fuselage characteristics, structural limitations, type of structure and geometrical characteristics of the wing section. Because of this increase in the number of inputs, it is considered that these structure based mass models are adjusted for preliminary design, unlike the statistical mass models, that are more indicated to conceptual design. 


\section{Conclusions and Future Work}

\subsection{Conclusions}

The development of mass prediction models for the Air Cargo Challenge competition is presented in this dissertation. These models are divided in two types: statistical and created from structure equations.

For the first type, the data is collected from reports of participants of past editions and statistical methods are applied to fit the coefficients of the mass prediction equations. These models are divided in general and component based mass models, being developed directly for the total mass of the airplane and for each component of the airplane, respectively. For the second type, three wing configurations are considered, namely, mainly made of carbon fiber composite, D-box made of carbon fiber composite and tube spar made of carbon fiber composite with balsa wood ribs. The equations are obtained to determine the quantity of material required to withstand the loads the structure is subjected to.

The accuracy of the statistical models is, mainly, dependent on the amount of data available. For the general models, the coefficients of determination are close to one, which indicates that the equations obtained for the general mass models describe the data properly, with low associated errors. However, in the group I, the obtained coefficients for the equation indicates imprecision in the model. As for the component based mass models, the errors are higher and the coefficients of determination are lower, when compared with the general mass models. This is explained by the fact that the number of aircraft is smaller and the errors associated to the individual components are significantly larger.

For the structure based mass models, with only a few detailed reports, containing the components mass and mission requirements, and the aircraft available in the university, it is possible to get high accuracy results. The maximum error obtained for the application of these models in case studies is inferior to $2 \%$.

Based on the results obtained for the statistical mass models, it is possible to conclude that the utilization of the general mass models is valid, due to the fact that the errors are small and the required input data is small, compatible with conceptual design. As for the component based mass models, the lack of accuracy of the equations obtained, prevents its utilization.

The applicability of the structure equations mass models is conditioned by the required number of inputs. That said, in preliminary design, the number of parameters available is higher than in the conceptual design and the application of these models provides extremely accurate values for the estimation of the airplane mass. 


\subsection{Future Work}

The accuracy of the statistical mass models is dependent on the amount of data available. In this particular situation, the collection of more information regarding the participants of past editions is considered interesting. This might be more reliable information about geometric characteristics and type of structures used in the different components. The actual performance of the aircraft in the competitions is also a factor to be considered, instead of the predicted payload presented in the reports, used in this study. With more information available, the equations can be updated and it is possible to obtain more robust mass models, more accurate in terms of division in components, leading to estimations closer to the reality.

It is also considered interesting the integration of the models in Multidisciplinary Design Optimization (MDO) software, allowing the automatization of future ACC projects. Depending on the design stage, where the amount of data available varies, the different models might be integrated in such software, allowing a better control of the final mass of the aircraft.

In terms of mass estimation models, in general, this kind of approach, in terms of development methods, might be extended for other types of aircraft. Despite the simplicity of the mathematical methods used, the obtained results demonstrate that this approach is valid. Thereof, in the design of similar aircraft, such as sailplanes and solar planes, the same methods might be used, simplifying the development, without compromising the accuracy of the results. 


\section{Bibliography}

[1] D. P. Raymer et al., Aircraft Design : A Conceptual Approach, Second edi. Washington, DC: American Institute of Aeronautics and Astronautics, Inc., 1992.

[2] "About Air Cargo Challenge." [Online]. Available: http://www.acc2017.com/page/about-air-cargo-challenge. [Accessed: 02-Mar-2018].

[3] “AIAA's Design/Build/Fly." [Online]. Available: https://www.aiaadbf.org/. [Accessed: 11-May-2018].

[4] R. Bühler, C. Molter, J. Illg, M. Abel, B. Armbrumster, and C. Hille, "Air Cargo Challenge 2013 - AKAModell Stuttgart," Design Report, AKAModell Stuttgart, Stuttgart, 2013.

[5] P. Alves et al., "Air Cargo Challenge 2011 - UBI," Design Report, University of Beira Interior, Covilhã, 2011.

[6] O. Dababneh and T. Kipouros, "A review of aircraft wing mass estimation methods," Aerosp. Sci. Technol., vol. 72, pp. 256-266, 2018.

[7] A. Elham, G. La Rocca, and M. J. L. Van Tooren, "Development and implementation of an advanced, design-sensitive method for wing weight estimation," Aerosp. Sci. Technol., vol. 29, no. 1, pp. 100-113, 2013.

[8] J. Roskam, Airplane design. DARcorporation, 1985.

[9] L. R. Jenkinson, P. Simpkin, and D. Rhodes, Civil Jet Aircraft Design. London: Arnold Publishers, 1999.

[10] E. Torenbeek, Synthesis of subsonic airplane design. Rotterdam: Delft University Press, 1979.

[11] C. R. Glatt, "WAATS - A COMPUTER PROGRAM FOR WEIGHTS ANALYSIS OF ADVANCED TRANSPORTATION SYSTEMS," 1974.

[12] M. C.-Y. Niu, "Airframe Structural Design: Practical Design Information and Data on Aircraft Structures," GTRI Proj. A-5636 Tech. Rep. Final Rep. ..., 1988.

[13] D. Howe, Aircraft Conceptual Design Synthesis. Professional Engineering Publishing, 2000.

[14] G. Bindolino, G. Ghiringhelli, S. Ricci, and M. Terraneo, "Multilevel structural optimization for preliminary wing-box weight estimation," J. Aircr., vol. 47, no. 2, pp. 475-489, 2010.

[15] M. D. Ardema, M. C. Chambers, A. P. Patron, A. S. Hahn, H. Miura, and M. D. Moore, "Estimation of Transport Aircraft Analytical Fuselage and Wing Weight," Nasa Tech. Memo. 110392, no. May, 1996.

[16] M. E. Burt, "Weight prediction for wings of box construction," Ministry of Supply, Royal Aircraft Establishment, RAE Farnborough, 1955.

[17] E. Torenbeek, "Development and Application of a Comprehensive, Design-sensitive Weight Predicition Method for Wing Structures of Transport Category Aircraft," Lr-693. 
1992.

[18] A. van der Velden, R. Kelm, and J. Mertens, "Application of MDO to Large Subsonic Transport Aircraft," no. c, 2000.

[19] G. Dijk, "Development of a wing weight prediction method," Haarlem Haarlem Inst. Technol., 1987.

[20] L. S. Lasdon, R. L. Fox, and M. W. Ratner, "Nonlinear optimization using the generalized reduced gradient method," Rev. Fr. d'Automatique, Inform. Rech. Opérationnelle, vol. 3, pp. 73-104, 1974.

[21] A. Colin Cameron and F. A. G. Windmeijer, "An R-squared measure of goodness of fit for some common nonlinear regression models," J. Econom., vol. 77, no. 2, pp. 329342, 1997.

[22] A. Noth, R. Siegwart, and W. Engel, "Design of Solar Powered Airplanes for Continuous Flight," Environ. Res., no. 18010, p. 18, 2007.

[23] A. Andrade, A. Brum, A. Gomes, B. Silvestre, F. Fraqueiro, and H. Almeida, "Air Cargo Challenge 2017 - AERO@UBI_MARS,” Design Report, University of Beira Interior, Covilhã, 2017.

[24] Anonymus, “Air Cargo Challenge 2007 - UBI Pegasus II," Design Report, University of Beira Interior ,Covilhã, 2007.

[25] N. Alemdaroğlu, Ö. Turgut, I. Kayabaşi, A. E. Çetiner, B. Korkut, and U. Karban, “Air Cargo Challenge '09 - KELAYNAK," Design Report, Middle East Technical University, Ankara, 2009.

[26] Anonymus, "Air Cargo Challenge '09 - LUSOFLY," Design Report, Air Force Academy, Lisboa, 2009.

[27] F. Holzapfel et al., "Air Cargo Challenge '09 - TUHeavy," Design Report, Technische Universität München, München, 2009.

[28] Anonymus, "Air Cargo Challenge '09 - INFINIteam," Design Report, Polytechnic University of Bucharest, Bucuresti, 2009.

[29] J. C. Becerra et al., "Air Cargo Challenge '09 - TRENCÀLOS," Design Report, Universitat Politécnica de Catalunya, Terrassa, 2009.

[30] A. Rautenberg et al., "Air Cargo Challenge '09 - AKAModell09," Design Report, AKAModell Stuttgart, Stuttgart, 2009.

[31] Anonymus, "Air Cargo Challenge '09 - SONICKIDS," Design Report, Universitatea "POLITEHNiCA" Bucuresti, Bucuresti, 2009.

[32] Anonymus, “Air Cargo Challenge '09 - COLIBRI," Design Report, University of Minho, Braga, 2009.

[33] I. Yüecl et al., "Air Cargo Challenge '13 - Anatolian Craft," Design Report, Middle East Technical University, Ankara, 2013.

[34] Anonymus, "Air Cargo Challenge '13 - ATLAS III B," Design Report, University of Patras, Patras, 2013.

[35] Anonymus, “Air Cargo Challenge '13 - ATLAS IV," Design Report, University of Patras, 
Patras, 2013.

[36] F. Albuquerque, D. Vicente, D. Melo, H. D. Lopes, A. Eleutério, and P. Precioso, "Air Cargo Challenge '13 - LUSITÂNIA Team,” Design Report, Instituto Superior Técnico, Lisboa, 2013.

[37] Anonymus, “Air Cargo Challenge '13 - PHOENIX," Design Report, Universitatea "POLITEHNiCA" Bucuresti, Bucuresti, 2013.

[38] J. Rogóż et al., “Air Cargo Challenge '13 - Rzeszów," Design Report, Rzeszów University of Technology, Rzeszów, 2013.

[39] Anonymus, “Air Cargo Challenge '13 - EESC-USP Juliett," Design Report, Esola de Engenharia de São Carlos, São Paulo, 2012.

[40] G. Guangyao et al., "Air Cargo Challenge '13 - Gravity," Design Report, Beihang University, Beihang, 2013.

[41] G. Jing et al., "Air Cargo Challenge '13 - LIFT," Design Report, Beihang University, Beihang, 2013.

[42] M. A. R. Silvestre et al., “Air Cargo Challenge 2015 - AERO@UBI_Team,” Design Report, University of Beira Interior, Covilhã, 2015.

[43] A. Franco, B. Martins, F. Ventura, F. Leal, I. Morão, and N. Licova, "Air Cargo Challenge 2017 - AERO@UBI_PVG," Design Report, University of Beira Interior, Covilhã, 2017. 